\title{
Improving shared decision-making in breast cancer radiotherapy
}

Citation for published version (APA):

Raphael, D. B. (2021). Improving shared decision-making in breast cancer radiotherapy: development and implementation of a patient decision aid. [Doctoral Thesis, Maastricht University]. Maastricht University. https://doi.org/10.26481/dis.20210603dr

Document status and date:

Published: 01/01/2021

DOI:

10.26481/dis.20210603dr

Document Version:

Publisher's PDF, also known as Version of record

\section{Please check the document version of this publication:}

- A submitted manuscript is the version of the article upon submission and before peer-review. There can be important differences between the submitted version and the official published version of record.

People interested in the research are advised to contact the author for the final version of the publication, or visit the DOI to the publisher's website.

- The final author version and the galley proof are versions of the publication after peer review.

- The final published version features the final layout of the paper including the volume, issue and page numbers.

Link to publication

\footnotetext{
General rights rights.

- You may freely distribute the URL identifying the publication in the public portal. please follow below link for the End User Agreement:

www.umlib.nl/taverne-license

Take down policy

If you believe that this document breaches copyright please contact us at:

repository@maastrichtuniversity.nl

providing details and we will investigate your claim.
}

Copyright and moral rights for the publications made accessible in the public portal are retained by the authors and/or other copyright owners and it is a condition of accessing publications that users recognise and abide by the legal requirements associated with these

- Users may download and print one copy of any publication from the public portal for the purpose of private study or research.

- You may not further distribute the material or use it for any profit-making activity or commercial gain

If the publication is distributed under the terms of Article $25 \mathrm{fa}$ of the Dutch Copyright Act, indicated by the "Taverne" license above, 
Improving shared decision-making in breast cancer radiotherapy: development and implementation of a patient decision aid 
The research presented in this thesis was conducted at CAPHRI Care and Public Health Research Institute, department of Family Practice at Maastricht University, the Netherlands, GROW School for Oncology and Developmental Biology at Maastricht University, the Netherlands, and at the Netherlands Cancer Institute - Antoni van Leeuwenhoek, Amsterdam, the Netherlands. CAPHRI participates in the Netherlands School of Public Health and Care Research (CaRe). The study in this thesis was supported by a grant from Alpe d'Huzes KWF, grant number MAC 2014-7024: “The challenge of implementation shared decision-making to personalized choices for loco regional treatment and its followup of breast cancer patients".

Proefschrift

Ter verkrijging van de graad van doctor aan de Universiteit Maastricht, op gezag van Rector Magnificus, prof. dr. Rianne M. Letschert, volgens het besluit van het College van Decanen, in het openbaar te verdedigen op donderdag 3 juni 2021, om 16 uur.

Door

COLOFON

Cover design : Suzanne Bernhardt

lay out: Daniela Raphael, Suzanne Bernhardt

Daniela Beatriz Raphae

Printing: proefschrift-aio.n

C Copyright: Daniela Raphael, Amsterdam 2021

ISBN: 978-94-93184-92-3 


\section{Promotores}

Prof. dr. L.J. Boersma

Prof. dr. T. van der Weijden

\section{Co-promotor}

Dr. N.S. Russell (NKI-AVL Amsterdam)

\section{Beoordelingscommissie}

Prof. dr. M.L. Smidt (voorzitter)

Prof. dr. V.C.G. Tjan-Heijnen

Prof. dr. D.T. Ubbink (Amsterdam UMC)

Dr. K.M.P.J. Verhoeven

Dr. H. Meijer (Radboud UMC)
Table of contents

page

Chapter $1 \quad$ General introduction

Chapter 2 What do patients and health care professionals view as important attributes in radiotherapy decisions? Input for a breast cancer patient decision aid

The Breast 2020; 49:149-156.
Chapter 3

$$
\begin{aligned}
& \text { Risk communication in a patient decision aid for } \\
& \text { radiotherapy in breast cancer: how to deal with } \\
& \text { uncertainty? }
\end{aligned}
$$

The Breast 2020; 51:105-13

Chapter 4

Implementing a patient decision aid, a process evaluation of a large-scale pre and post-implementation trial

Breast Cancer Research and Treatment 2020, Online ahead of publiation.

Chapter 5 A patient decision aid for breast cancer patients deciding on their radiation treatment: no change in decisional conflict but better-informed choices

\section{Submitted}

General discussion

Annex

Summary
Nederlandse samenvatting

Impact section

Curriculum Vitae

Dankwoord 


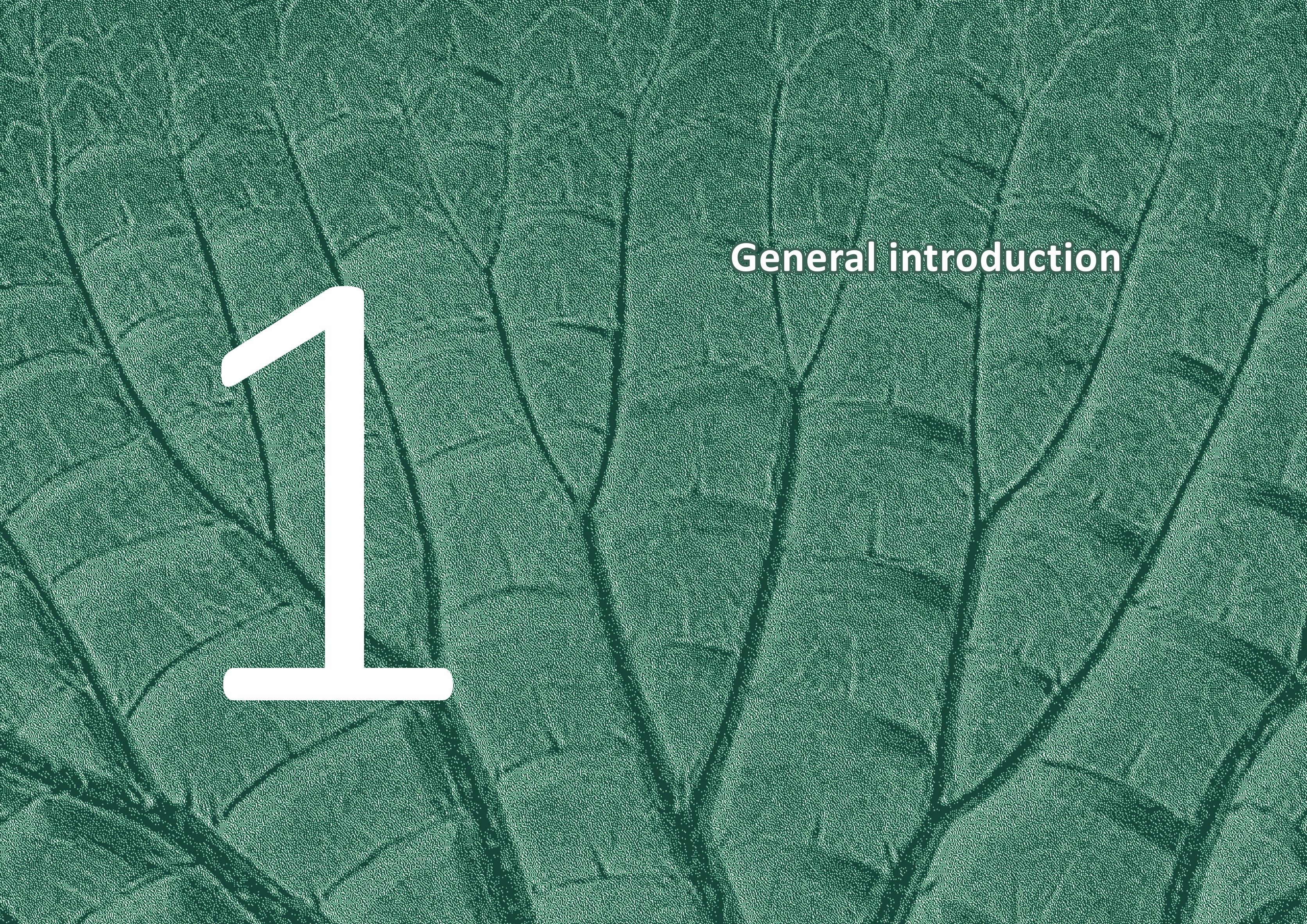




\section{Breast cancer}

Breast cancer is the most prevalent cancer diagnosis in women in the world, and in the Netherlands (1).

Per year, worldwide around 2.1 million women receive a diagnosis of breast cancer, of which 1,500 women in the Netherlands (2). The incidence of breast cancer in the Netherlands is rising and has doubled since 1989. The lifetime risk for Dutch women to suffer from breast cancer is 1 in 7 , and 1 in 27 women die from breast cancer in the Netherlands. In addition, around 2300 Ductal Carcinoma In Situ (DCIS) cases are diagnosed per year in the Netherlands. A large proportion of cases is diagnosed through the national breast cancer screening program while still in a low stadium (3).

\section{Breast cancer treatment}

Breast cancer is a heterogeneous disease, resulting in different treatments for individual patients (4). Most patients are treated with a multi-modality treatment, meaning that more than one treatment is given. $90 \%$ of patients are treated with surgery, being either breast-conserving surgery or a mastectomy; $68 \%$ receive radiotherapy (RT), $45 \%$ receive hormonal therapy, $32 \%$ chemotherapy, and $10 \%$ targeted therapy (5). The 10 -year local recurrence risk for the entire breast cancer population in the Netherlands is $4.7 \%$. This is $3.0 \%$ for regional recurrence and $15 \%$ for distant metastasis. The individual recurrence risk for patients varies widely, depending on the patient's personal situation, the treatment and tumor characteristics (4)

\section{Breast cancer radiotherapy}

As stated before, $68 \%$ of Dutch breast cancer patients are treated with RT. This high rate is related to the high rate of patients treated with breast-conserving surgery in the Netherlands. Most patients treated with breast-conserving surgery are also offered (whole) breast RT (6). Post-operative RT for breast cancer patients has proven to reduce the risk of a local recurrence significantly (7). In general, post-operative RT reduces the loca recurrence risk with a factor three to four, independent of the absolute recurrence risk. This results in a larger effect of RT when the absolute recurrence risk is high. For example, when patients have a $30 \%$ recurrence risk after surgery, the absolute effect of RT is large, reducing the recurrence risk to approximately $5-10 \%$. However, when the recurrence risk after surgery is low, the absolute additional effect or RT is also small $(8,9)$. Therefore, when the recurrence risk after surgery is high (usually $>15-20 \%$ ), RT is stated to be offered as the standard treatment by (inter)national guidelines. When the absolute recurrence risk after surgery is considered to be low $(<5 \%)$, RT is usually omitted (10). There is, however, a gray area between these two groups $(11,12)$. From an overview of older clinical trials, it is estimated that one patient will have a survival benefit for every four patients where a local recurrence is prevented by radiotherapy (13). This results in a large benefit in survival, in case of a large local recurrence risk reduction. This effect however does not always hold in more recent clinical trials, where in specific patient categories no or only limited survival benefit is found, also in cases where there is a relatively large reduction in local recurrence risk (14). Simultaneously, RT of the breast or chest wall can cause short and long-term side effects. The most important short-term side effects are fatigue, skin redness and sensitivity, pain, and edema of the breast and chest wall. The most important long-term side effects are fibrosis, edema and skin discoloration of the breast and chest wall, and rib, heart and lung problems. Although the probability and severity of the side effects is related to the radiation dose and the irradiated volume (15), it is difficult to predict the extent to which patients will suffer from side effects, since individual radiosensitivity varies widely (16-18). The choice for more or less intensive RT is therefore considered a preference-sensitive decision in the cases mentioned above. Since breast cancer treatments are improving and (local) recurrence rates are decreasing, new debates emerge on gray areas, with a focus on de-escalation of treatment (19). Patients who fall within this gray area either have little or no survival benefit from the adjuvant RT (20-24).

\section{Gray areas in radiotherapy addressed in this thesis}

1. Whole-breast or partial-breast RT for patients with low-risk DCIS treated with breastconserving surgery. There is a wide range of literature showing that RT for this group significantly lowers the local recurrence risk. The absolute local recurrence risk in DCIS patients varies widely, depending on disease and patient characteristics, such as tumo grade and size, and age at diagnosis. In DCIS patients, RT halves the local recurrence risk. Of the patients who suffer from a local recurrence, in general half the patients will develop a new DCIS lesion, while the other half will develop invasive breast cance $(20,25)$. Therefore, DCIS is treated the same way as invasive breast cancer. National and international guidelines recommend offering RT to all DCIS patients treated with breast-conserving treatment. Although the effect of RT on local recurrence is apparent, especially in patients with an absolute high risk of a local recurrence, no survival benefit has been found in large cohort studies for RT after breast-conserving surgery, not even for patients with a high local recurrence risk $(12,20)$. Therefore, a lot of effort has been put in investigating which patients might have a benefit in survival from post-operative RT. Sagara et al. found that a modified score proposed by Smith et al. (26), based on tumor grade, tumor size, and age of the patient at diagnosis, was related to overall survival (24). However, this study was based on data from retrospective studies, and other important treatment characteristics of the included patients were unknown, such as surgical margins, adjuvant hormonal treatment, and the reason for receiving or omitting RT. There is stil a lot of ongoing research to identify which DCIS patients benefit from post-operative RT $(27,28)$ and to identify the role of surgical margins $(29)$. Furthermore, studies have been and are investigating the additional value of a boost dose to the tumor bed (30) and/or hormonal treatment (31). However, no firm conclusions can be drawn yet. Fortunately, the breast cancer specific survival for all DCIS patients is very high, in the order of over $90 \%$ (20). Patients with a DCIS and a relatively low recurrence risk, consequently, also have a low risk of developing invasive breast cancer, and an extremely low risk of dying of the disease. Therefore, choosing for post-operative RT or not in this low-risk DCIS group is a preference-sensitive decision. The decision is a trade-off between a relatively small reduction in local recurrence risk-and therefore a small reduction in the risk of developing invasive breast cancer without an expected survival benefit-and with the risk of developing side effects of RT. 
2. Whole-breast or partial-breast RT for patients with very low-risk invasive ductal carcinoma treated with breast-conserving surgery. Breast-conserving therapy in combination with post-operative RT versus mastectomy without postoperative RT are considered equally effective treatments in early breast cancer and have thus been the standard treatment already for a long time (32). Therefore, all patients treated with breast-conserving treatment are offered post-operative RT. Recent literature, though, shows that for elderly patients, with a very low absolute post-operative local recurrence risk without RT, RT can safely be omitted. In this group of elderly patients, RT does lower the recurrence risk but does not result in survival benefit $(21,33)$. For example, in the PRIME II trial, 1326 women of 65 years or older, with low-risk breast cancer and adjuvant endocrine therapy, were randomized to receive post-operative RT or not. The 10-year local recurrence in these patients was $1.3 \%$ for patients treated with post-operative RT versus $4.1 \%$ for patients treated without post-operative RT respectively. Overall survival did not differ between both groups (21). Also in a review on patients of $>70$ years treated with breast-conservative treatment, a 5-year local recurrence was found of $2.2 \%$ for women treated with post-operative RT versus $6.5 \%$ for women treated without post-operative RT, without any survival benefit (32). Nevertheless, up till recently, post-operative RT for these women was considered the standard treatment. There are different trials ongoing that investigate whether this could be changed. In the Netherlands, the TOP-1 study is open for inclusion: in this prospective cohort study, patients $>70$ years, with a very low risk of breast cancer and without an indication for adjuvant endocrine treatment, are offered the option to leave out post-operative RT (TOP-1 study, NL58117.058.16). The role of postoperative partial-breast RT (PBI) has been studied in numerous trials (e.g. RAPID trial, NSABP trial, IMPORT LOW); in addition, studies have been done and are ongoing on the role of pre-operative PBI (e.g. PAPBI-II study NL53862.031.15, ABLATIVE-2). While awaiting the results of these studies, post-operative RT in this group can be considered a preference-sensitive treatment decision.

3. Chest wall RT for patients with intermediate-risk breast cancer treated with a mastectomy. Literature is inconclusive on the exact benefit of RT in this group. In patients treated with a mastectomy, with a low risk of local recurrence (i.e. patients with small indolent tumors and no regional disease), there is consensus on not offering post-operative RT. Fo patients with a high local recurrence risk after mastectomy, patients with advanced local disease (usually with four or more positive regional lymph nodes), there is consensus on offering post-operative RT. In this high-risk group, research has shown that post-operative RT results in a significant survival benefit (23). For the intermediate-risk breast cance group (patients with 1-3 positive lymph nodes, or patients with more aggressive tumors but without involved lymph nodes), literature is inconclusive on the exact benefit of postoperative RT. There is evidence that post-operative RT does lower the local recurrence risk in this category, as shown in a meta-analysis of 22 trials on post-mastectomy RT (23) with an associated reduction in mortality. However, in the trials included in this metaanalysis, patients were not treated with optimal adjuvant systemic therapy according to current standards. The survival of contemporary patients with intermediate risk is currently much higher than in the overview trials. Therefore, the survival benefit of postmastectomy RT in this intermediate group remains unclear (34). To determine the role of radiotherapy in the era of contemporary systemic therapy, between 2006-2013 patient in this intermediate group were included in the SUPREMO trial (ISRCTN61145589) and randomized between post-operative RT or no post-operative RT $(35,36)$. Since follow-up of this trial for the primary endpoint is overall survival at 10 years, no clear answers are expected before 2023. In addition, breast cancer treatments have changed in the last decade. More patients are being treated with (novel) neo-adjuvant systemic treatments, lowering long-term local recurrence risks. This results in more uncertainty on the effect of post-operative chest wall RT. Some guidelines therefore recommend discussing postoperative RT with the patient (11).

4. Whole-breast RT with or without an extra boost dose to the tumor bed for patients with intermediate-risk breast cancer treated with breast-conserving surgery. Also, in this group, there is a clear benefit to the extra boost dose on local recurrence risk. However, in randomized clinical trials, no survival benefit has been found of the extra boost dose. Between 1989 and 1996, 5,318 patients were included in the EORTC boost/no-boost trial and randomized between post-operative whole-breast RT with $50 \mathrm{~Gy}$; patients were randomized to receive either and post-operative whole breast RT with 50 Gy with an additional dose of $16 \mathrm{~Gy}$ at the original tumor bed. This trial showed that the extra boost dose halved the local recurrence risk independent of the absolute recurrence risk. Therefore, a larger effect on local recurrence risk is seen in patients with a higher absolute recurrence risk. However, no effect on survival was found for the boost dose $(14,37)$. On top of that, due to improved breast cancer treatments, the absolute local recurrence rate for most breast cancer patients has decreased over the last decade. These lower absolute local recurrence risks, therefore, also result in a lower absolute effect of the extra boost dose (38). On the other hand, the boost dose does result in potentially more severe side effects such as severe breast fibrosis and poor cosmetic outcome (39). Most guidelines therefore recommend offering a boost dose to patients with a higher absolute recurrence risk, but not to patients with a low absolute recurrence risk. There is a gray area between these groups. Since it is also hard to predict which patients will develop more severe side effects and no survival benefit has been found for the extra boost dose, this may also be considered a preference-sensitive treatment decision.

In all these gray areas, there is not one best (medical) treatment option for the individua patient, and decisions in these situations are therefore so-called preference-sensitive decisions (40). Which treatment is best for the individual patient depends on what attributes are the most important for the individual patient. In other words, it should be taken into account which "price" patients are willing to pay; in this case, the chances of which side effects or other treatment burdens for which gain in recurrence risk or survival benefit (41). There is increasing awareness that, especially in this type of decisions, better decisions are being made, i.e. decisions that fit best to their own perspectives and preferences, if taken together with their clinician. This process, in which clinicians and patients decide together, taking into account the patient's preferences, is called shared decision-making (SDM) $(42,43)$. To support and stimulate SDM, patient decision aids (PtDAs) have been developed, and many studies have been performed to evaluate these patient decision aids. Stacey et al. performed a systematic review, and evaluated 115 randomized clinical trials (44). They found that patients who receive a PtDA are better informed and have a more accurate risk perception. These patients made choices that 
were more congruent with their own preferences and had a lower decisional conflict. PtDAs should provide neutral evidence-based information, make clear that there is a decision to be made, and facilitate the elicitation of patients' preferences on treatment options (45). PtDAs have been shown to cause no harm with respect to psychosocial outcomes, such as anxiety (44). Nevertheless, SDM is not yet widely implemented in the field of RT for breast cancer patients (46). Consequently, patients are dependent on thei clinician, if and how they are informed about their different treatment options. This leads to wide, unwanted, practice variation (47). To improve SDM for decisions in the gray areas described above, we aimed to develop a PtDA for breast cancer patients deciding on their $\mathrm{RT}$ and to evaluate this tool in clinical practice.

\section{Development of a patient decision aid}

The International Patient Decision Aid Standards (IPDAS) Collaboration has set a standard for PtDA development (45). According to the IPDAS criteria, guidelines have been made for PtDA development (48). Important steps in the development process are exploring patients' and clinicians' needs on the subject of the PtDA, the making of a prototype, and alpha and beta testing of the tool (48) (Figure 1). The development of a PtDA is an elaborate process, and it is important to include all stakeholders in this process (49). Not much research has been done on the important attributes for patients and clinician deciding on RT for breast cancer (50). What information patients receive from thei radiation oncologist on the effect and side effects of radiation treatment differs widely among clinicians. Kunneman et al. audiotaped consultations of patients with their radiation oncologists prior to their RT for rectal cancer. There was a wide range in number of attributes mentioned by the clinician (range of 2-13 different attributes), and in total 30 different attributes were mentioned by the different clinicians (51). We are not aware of any study exploring the information provision of radiation oncologists to breast cancer patients. Literature on important attributes for breast cancer patients deciding on RT is scarce (50). Therefore, it is unknown which attributes are important for patients and clinicians when deciding on RT for breast cancer patients.

When the important attributes are known, another problem arises. The benefit of choosing for RT is a reduction in local recurrence risk. From clinical trials, there is knowledge on recurrence risks in large group of patients/ the trial population, but the exact benefit for individual patient is usually unknown, especially since patient characteristics of tria populations often do not match with all patients in general clinical practice (52). Estimated local recurrence risks are therefore surrounded by uncertainty margins. Although there have been some attempts to develop prediction models for breast cancer patients deciding on RT, no prediction model has been widely accepted and implemented in clinica practice (53-55). Subsequently, the effect of RT on tumor control, should be balanced against the risk and severity of developing side effects. Since long-term side effects of RT occur months to years after treatment, these side effects are not well documented and there is a lack of data on prevalence and severity of side effects after post-operative RT. Therefore, there is even more uncertainty around the exact risk and expected severity of side effects for individual patients (10). In addition to the lack of data and exact estimates, communicating risks to patients in a comprehensive way is challenging as well. Although a lot of research has focused on this topic, no clear guidelines exist on the best way to communicate risks (56). Communicating uncertainty around risks in a comprehensive way is even a bigger challenge (57). While little is known on the best way to communicate risks in a PtDA, even less is known on the best way to communicate uncertainty around these risks in a PtDA $(58,59)$.

Figure 1. Patient decision aid development process (Coulter 2013).

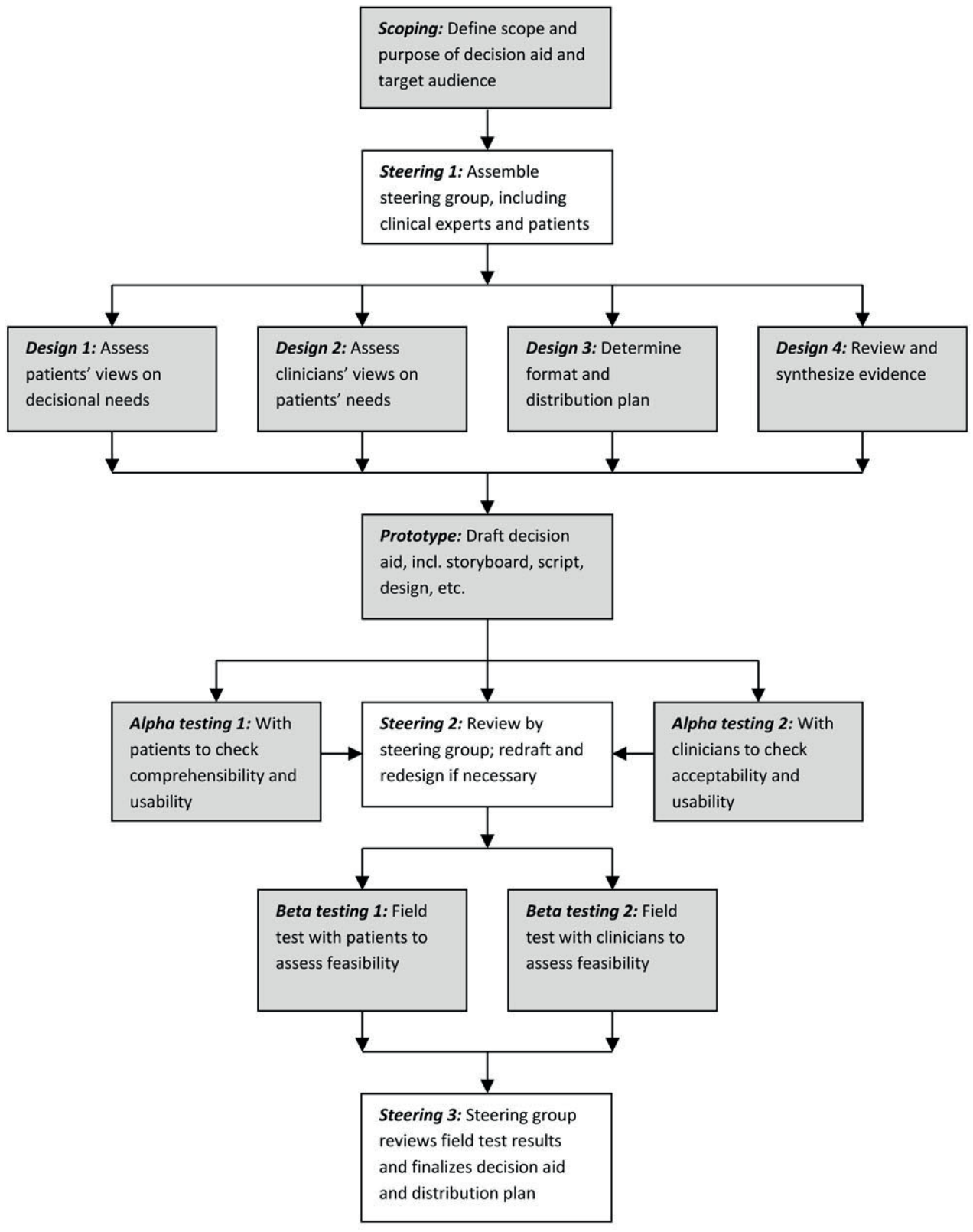




\section{Testing and implementation of a patient decision aid}

Despite the positive results found in PtDA studies, as mentioned earlier, PtDAs have not been widely implemented in daily clinical practice $(60,61)$. One important barrier for implementation might be that physicians doubt the effect of PtDAs. Since evidence-based medicine is the heart of our clinical practice (62), scientific evidence is asked for before implementing new treatments and interventions in guidelines and daily clinical practice. The quality of the SDM process can be measured from different points of view: observedbased (OPTION scale (63)), clinicians' view (SDM-Q-DOC (64). There is consensus on distinguishing different types of effect of a PtDA, and consequently several outcome measures have been used to measure the effect of PtDAs (65).The quality of the SDM process can be measured from different points of view: observed-based (OPTION scale (63)), clinicians' view (SDM-Q-DOC (64)), and patient-reported (collaboRATE and the SDM-Q9 $(64,66))$. Observer-based measures, however, are very time-consuming. Another way of measuring the effect of a PtDA is to measure the effect on quality of the decision made. Therefore, different measures have been developed (67). Frequently used outcome measures are the Decisional Conflict Scale and informed decision/ knowledge on the treatment options (44).

Apart from the scientific evidence, theories have also been conceived on other barriers and facilitators in implementation of PtDAs. Important facilitators are considered: clinicians supporting the content of the PtDA, mentioning patients' eligibility for the PtDA in multidisciplinary team meetings, and the PtDA not interfering too much with the logistics of the clinical center. Important barriers are the belief that a PtDA is too time-consuming and a lack of leadership in implementation $(68,69)$. It has been stated, however, that the exact reason for this implementation problem has not totally been solved yet. An even bigger knowledge gap exists with regards to the implementation of PtDAs in oncology care (68). Therefore, much is unknown about important factors that influence implementation of a PtDA in oncology care. In the field of RT for breast cancer patients there is a need from the clinic to develop and implement a PtDA to support the SDM process in the gray areas (bottom-up). There is great readiness from radiation oncologists from different RT centers in the Netherlands to co-operate in the development and implementation of the tool. This creates an opportunity to gain insight in patient, clinician, and organizational factors that influence implementation of a PtDA in breast cancer patients choosing for RT.

\section{Aim and research questions}

In summary, there are several gray areas for breast cancer patients choosing for postoperative RT. In these patient groups, post-operative RT lowers the (local) recurrence risk without a clear survival benefit, whilst simultaneously it does cause side effects. The best treatment for the individual patient therefore depends on the ideas and preferences of the individual patient. Therefore, these decisions should be made by the patient and the clinician together, shared decision-making. How these gray areas are discussed with the patient differs per clinician and per medical center, resulting in wide, unwarranted practice variation. The process of SDM is a difficult process and patient decision aids can help to support this process.

The main aims of this thesis are to develop and evaluate the effect of a patient decision aid for breast cancer patients who have a preference-sensitive treatment decision on RT in the realistic situation of daily clinical practice, and to investigate barriers and facilitators for implementation of the PtDA. We defined four research questions:

1. What are the experiences, decisional attributes and needs of patients and health care professionals experiences, decisional attributes and needs as input for the development of a patient decision aid for breast cancer patients deciding on radiation treatment, to facilitate shared decision-making?

2. How can we incorporate uncertainties in a patient decision aid for breast cancer patients to support their decision on radiation treatment?

3. What are important patient, clinician, and organizational success factors for implementing a patient decision aid, designed for breast cancer patients, facing a decision on their radiation treatment?

4. What is the effect of a patient decision aid for breast cancer patients deciding on radiation treatment on decisional conflict, perceived shared decision-making, and knowledge on treatment options?

\section{Outline of this thesis}

Chapter 2 describes the results of a qualitative study. This is the first step in PtDA development, eliciting the patients' and clinicians' views. Interviews were held with breast cancer patients who had faced a decision in their RT treatment and with (breast cancer) clinicians. The scope of this chapter was to explore the patients' and clinicians view on important attributes when making a decision on RT after breast cancer surgery.

The results of the interviews were used to develop a prototype of the PtDA. Chapter 3 describes the development process of the final version of the PtDA. In this chapter, additional attention is given to risk communication and communication of uncertainty in the PtDA.

The final version of the PtDA was tested in a multi-center pre- and post-intervention study, the BRASA-study. First breast cancer patients who faced a preference sensitive decision of RT after breast surgery where included in the study and asked to fill in a questionnair on the decision making process without the support of a PtDA. The subsequent patients who were included in the study, did receive the PtDA when deciding on their RT and were asked to fill in the same questionnaire on the decision-making process. 
Chapter 4 describes the process evaluation of the implementation of the PtDA in the group of patients that did receive the PtDA. It explores the patient, clinician, and organizational factors that influence the uptake of the PtDA.

The effect evaluation of the BRASA-study is described in chapter 5 . This chapter describes the effect of the PtDA on decisional conflict, the decision-making process, and patien knowledge on the different treatment options, duration of consultation, and the actual choice for more or less intensive treatment.

Chapter 6 is the general discussion summarizing and discussing the main results. This chapter reflects on the present study and discusses perspectives on research in the future.

\section{References}

1. Ghoncheh M, Pournamdar Z, Salehiniya H. Incidence and Mortality and Epidemiology of Breast Cancer in the World. Asian Pac J Cancer Prev. 2016;17(S3):43-6.

2. [Available from: https://www.who.int/cancer/prevention/diagnosis-screening/breast-cancer/ en/.

3. [Available from: https://www.iknl.nl/kankersoorten/borstkanker/registratie/incidentie.

4. van Maaren MC, de Munck L, Strobbe LJA, Sonke GS, Westenend PJ, Smidt ML, et al. Ten-year recurrence rates for breast cancer subtypes in the Netherlands: A large population-based study. Int J Cancer. 2019;144(2):263-72.

5. [Available from: https://www.iknl.nl/kankersoorten/borstkanker/registratie/behandeling.

6. van Maaren MC, de Munck L, de Bock GH, Jobsen JJ, van Dalen T, Linn SC, et al. 10 year survival after breast-conserving surgery plus radiotherapy compared with mastectomy in early breas cancer in the Netherlands: a population-based study. Lancet Oncol. 2016;17(8):1158-70

7. Castaneda SA, Strasser J. Updates in the Treatment of Breast Cancer with Radiotherapy. Surs Oncol Clin N Am. 2017;26(3):371-82.

8. Clarke M, Collins R, Darby S, Davies C, Elphinstone P, Evans V, et al. Effects of radiotherapy and of differences in the extent of surgery for early breast cancer on local recurrence and 15-year survival: an overview of the randomised trials. Lancet. 2005;366(9503):2087-106.

9. Favourable and unfavourable effects on long-term survival of radiotherapy for early breast cancer: an overview of the randomised trials. Early Breast Cancer Trialists' Collaborative Group. Lancet. 2000;355(9217):1757-70.

10. Bartelink H. The changing landscape in radiotherapy for breast cancer: Lessons from long term follow-up in some European breast cancer trials. Radiother Oncol. 2016;121(3):348-56.

11. Recht A, Comen EA, Fine RE, Fleming GF, Hardenbergh PH, Ho AY, et al. Postmastectomy Radiotherapy: An American Society of Clinical Oncology, American Society for Radiation Oncology, and Society of Surgical Oncology Focused Guideline Update. Pract Radiat Oncol. 2016;6(6):e219-e34.

12. Krug D, Baumann R, Budach W, Dunst J, Feyer P, Fietkau R, et al. Current controversies in radiotherapy for breast cancer. Radiat Oncol. 2017;12(1):25.

13. Darby S, McGale P, Correa C, Taylor C, Arriagada R, Clarke M, et al. Effect of radiotherapy after breast-conserving surgery on 10-year recurrence and 15-year breast cancer death: meta-analysis of individual patient data for 10,801 women in 17 randomised trials. Lancet. 2011;378(9804):1707-16.

14. Bartelink H, Maingon P, Poortmans P, Weltens C, Fourquet A, Jager J, et al. Whole-breast irradiation with or without a boost for patients treated with breast-conserving surgery for early breast cancer: 20-year follow-up of a randomised phase 3 trial. Lancet Oncol. 2015;16(1):47-56.

15. Ratosa I, Jenko A, Oblak I. Breast size impact on adjuvant radiotherapy adverse effects and dose parameters in treatment planning. Radiol Oncol. 2018;52(3):233-44.

16. McDonald MW, Godette KD, Butker EK, Davis LW, Johnstone PA. Long-term outcomes of IMRT for breast cancer: a single-institution cohort analysis. Int J Radiat Oncol Biol Phys. 2008;72(4):103140.

17. Freedman GM, Anderson PR, Li J, Eisenberg DF, Hanlon AL, Wang L, et al. Intensity modulated radiation therapy (IMRT) decreases acute skin toxicity for women receiving radiation for breast cancer. Am J Clin Oncol. 2006;29(1):66-70. 
18. Barnett GC, Wilkinson JS, Moody AM, Wilson CB, Twyman N, Wishart GC, et al. The Cambridge Breast Intensity-modulated Radiotherapy Trial: patient- and treatment-related factors that influence late toxicity. Clin Oncol (R Coll Radiol). 2011;23(10):662-73.

19. Boersma LJ, Sonke GS, Verkooijen HM. [Cancer treatment; there are options]. Ned Tijdschr Geneeskd. 2019;163.

20. Donker M, Litière S, Werutsky G, Julien JP, Fentiman IS, Agresti R, et al. Breast-conserving treatment with or without radiotherapy in ductal carcinoma In Situ: 15-year recurrence rates and outcome after a recurrence, from the EORTC 10853 randomized phase III trial. J Clin Oncol. 2013;31(32):4054-9.

21. Kunkler IH, Williams LJ, Jack WJ, Cameron DA, Dixon JM. Breast-conserving surgery with or without irradiation in women aged 65 years or older with early breast cancer (PRIME II): a randomised controlled trial. Lancet Oncol. 2015;16(3):266-73.

22. Kantor O, Pesce C, Singh P, Miller M, Tseng J, Wang CH, et al. Post-mastectomy radiation therapy and overall survival after neoadjuvant chemotherapy. J Surg Oncol. 2017;115(6):668-76.

23. McGale P, Taylor C, Correa C, Cutter D, Duane F, Ewertz M, et al. Effect of radiotherapy after mastectomy and axillary surgery on 10-year recurrence and 20-year breast cancer mortality: meta-analysis of individual patient data for 8135 women in 22 randomised trials. Lancet. 2014;383(9935):2127-35.

24. Sagara Y, Freedman RA, Vaz-Luis I, Mallory MA, Wong SM, Aydogan F, et al. Patient Prognostic Score and Associations With Survival Improvement Offered by Radiotherapy After BreastConserving Surgery for Ductal Carcinoma In Situ: A Population-Based Longitudinal Cohort Study. J Clin Oncol. 2016;34(11):1190-6.

25. Wärnberg F, Garmo H, Emdin S, Hedberg V, Adwall L, Sandelin K, et al. Effect of radiotherapy after breast-conserving surgery for ductal carcinoma in situ: 20 years follow-up in the randomized SweDCIS Trial. J Clin Oncol. 2014;32(32):3613-8.

26. Smith GL, Smith BD, Haffty BG. Rationalization and regionalization of treatment for ductal carcinoma in situ of the breast. Int J Radiat Oncol Biol Phys. 2006;65(5):1397-403.

27. Sagara Y, Julia W, Golshan M, Toi M. Paradigm Shift toward Reducing Overtreatment of Ductal Carcinoma In Situ of Breast. Front Oncol. 2017:7:192.

28. Stuart KE, Houssami N, Taylor R, Hayen A, Boyages J. Long-term outcomes of ductal carcinoma in situ of the breast: a systematic review, meta-analysis and meta-regression analysis. BMC Cancer. 2015;15:890.

29. Marinovich ML, Azizi L, Macaskill P, Irwig L, Morrow M, Solin LJ, et al. The Association of Surgica Margins and Local Recurrence in Women with Ductal Carcinoma In Situ Treated with BreastConserving Therapy: A Meta-Analysis. Ann Surg Oncol. 2016;23(12):3811-21.

30. Moran MS, Zhao Y, Ma S, Kirova Y, Fourquet A, Chen P, et al. Association of Radiotherapy Boost for Ductal Carcinoma In Situ With Local Control After Whole-Breast Radiotherapy. JAMA Oncol. 2017;3(8):1060-8

31. Forbes JF, Sestak I, Howell A, Bonanni B, Bundred N, Levy C, et al. Anastrozole versus tamoxifen for the prevention of locoregional and contralateral breast cancer in postmenopausal women with locally excised ductal carcinoma in situ (IBIS-II DCIS): a double-blind, randomised controlled trial. Lancet. 2016;387(10021):866-73.

32. van de Water W, Bastiaannet E, Scholten AN, Kiderlen M, de Craen AJ, Westendorp RG, et al. Breast-conserving surgery with or without radiotherapy in older breast patients with early stage breast cancer: a systematic review and meta-analysis. Ann Surg Oncol. 2014;21(3):78694.
33. de Boer AZ, Bastiaannet E, de Glas NA, Marang-van de Mheen PJ, Dekkers OM, Siesling S, et al. Effectiveness of radiotherapy after breast-conserving surgery in older patients with T1-2NO breast cancer. Breast Cancer Res Treat. 2019;178(3):637-45.

34. Kunkler I. Adjuvant chest wall radiotherapy for breast cancer: black, white and shades of grey. Eur J Surg Oncol. 2010;36(4):331-4

35. Kunkler IH, Canney P, van Tienhoven G, Russell NS. Elucidating the role of chest wall irradiation in 'intermediate-risk' breast cancer: the MRC/EORTC SUPREMO trial. Clin Oncol (R Coll Radiol). 2008;20(1):31-4.

36. Thomas IS, Hanby AM, Russell N, van Tienhoven G, Riddle K, Anderson N, et al. The BIG 2.04 MRC/EORTC SUPREMO Trial: pathology quality assurance of a large phase 3 randomised international clinical trial of postmastectomy radiotherapy in intermediate-risk breast cancer. Breast Cancer Res Treat. 2017;163(1):63-9.

37. Bartelink H, Horiot JC, Poortmans PM, Struikmans H, Van den Bogaert W, Fourquet A, et al. Impact of a higher radiation dose on local control and survival in breast-conserving therapy of early breast cancer: 10-year results of the randomized boost versus no boost EORTC 22881 10882 trial. J Clin Oncol. 2007:25(22):3259-65.

38. Bosma SC, van der Leij F, van Werkhoven E, Bartelink H, Wesseling J, Linn S, et al. Very low loca recurrence rates after breast-conserving therapy: analysis of 8485 patients treated over a 28 year period. Breast Cancer Res Treat. 2016;156(2):391-400.

39. Vrieling C, Collette L, Fourquet A, Hoogenraad WJ, Horiot JC, Jager JJ, et al. The influence of the boost in breast-conserving therapy on cosmetic outcome in the EORTC "boost versus no boost" trial. EORTC Radiotherapy and Breast Cancer Cooperative Groups. European Organization for Research and Treatment of Cancer. Int J Radiat Oncol Biol Phys. 1999;45(3):677-85.

40. Ostermann J, Brown DS, van Til JA, Bansback N, Légaré F, Marshall DA, et al. Support Tools for Preference-Sensitive Decisions in Healthcare: Where Are We? Where Do We Go? How Do We Get There? Patient. 2019;12(5):439-43.

41. Mulley AG, Trimble C, Elwyn G. Stop the silent misdiagnosis: patients' preferences matter. Bmj. 2012;345:e6572.

42. Coulter A, Collins A. Making shared decision-making a reality: no decision about me, without me: King's Fund; 2011.

43. Elwyn G, Durand MA, Song J, Aarts J, Barr PJ, Berger Z, et al. A three-talk model for shared decision making: multistage consultation process. Bmj. 2017;359:j4891.

44. Stacey D, Legare F, Col NF, Bennett CL, Barry MJ, Eden KB, et al. Decision aids for people facing health treatment or screening decisions. Cochrane Database Syst Rev. 2014(1):Cd001431.

45. Elwyn G, O'Connor A, Stacey D, Volk R, Edwards A, Coulter A, et al. Developing a quality criteria framework for patient decision aids: online international Delphi consensus process. Bmj. 2006;333(7565):417

46. Wong J, Szumacher E. Patients' decision-making in radiation oncology. Expert Rev Pharmacoecon Outcomes Res. 2012;12(1):95-104

47. Schreuder K, Maduro JH, Spronk PER, Bijker N, Poortmans PMP, van Dalen T, et al. Variation in the Use of Boost Irradiation in Breast-Conserving Therapy in the Netherlands: The Effect of a National Guideline and Cofounding Factors. Clin Oncol (R Coll Radiol). 2019;31(4):250-9.

48. Coulter A, Stilwell D, Kryworuchko J, Mullen PD, Ng CJ, van der Weijden T. A systematic development process for patient decision aids. BMC Med Inform Decis Mak. 2013;13 Suppl 2:S2. 
49. Savelberg W, van der Weijden T, Boersma L, Smidt M, Willekens C, Moser A. Developing a patient decision aid for the treatment of women with early stage breast cancer: the struggle between simplicity and complexity. BMC Med Inform Decis Mak. 2017;17(1):112.

50. Hendry JA. A qualitative focus group study to explore the information, support and communication needs of women receiving adjuvant radiotherapy for primary breast cancer. Journal of Radiotherapy in Practice. 2011;10(2):103-15.

51. Kunneman M, Marijnen CA, Rozema T, Ceha HM, Grootenboers DA, Neelis KJ, et al. Decision consultations on preoperative radiotherapy for rectal cancer: large variation in benefits and harms that are addressed. Br J Cancer. 2015;112(1):39-43.

52. Poortmans PMP, Arenas M, Livi L. Over-irradiation. Breast. 2017;31:295-302.

53. Boland GP, Chan KC, Knox WF, Roberts SA, Bundred NJ. Value of the Van Nuys Prognostic Index in prediction of recurrence of ductal carcinoma in situ after breast-conserving surgery. Br I Surg. 2003;90(4):426-32.

54. van Werkhoven E, Hart G, Tinteren H, Elkhuizen P, Collette L, Poortmans P, et al. Nomogram to predict ipsilateral breast relapse based on pathology review from the EORTC 22881-10882 boost versus no boost trial. Radiother Oncol. 2011;100(1):101-7.

55. Witteveen A, Vliegen IM, Sonke GS, Klaase JM, MJ IJ, Siesling S. Personalisation of breast cancer follow-up: a time-dependent prognostic nomogram for the estimation of annual risk of locoregional recurrence in early breast cancer patients. Breast Cancer Res Treat. 2015;152(3):627-36.

56. Harrison M, Rigby D, Vass C, Flynn T, Louviere J, Payne K. Risk as an attribute in discrete choice experiments: a systematic review of the literature. Patient. 2014;7(2):151-70.

57. Engelhardt EG, Pieterse AH, Han PK, van Duijn-Bakker N, Cluitmans F, Maartense E, et al. Disclosing the Uncertainty Associated with Prognostic Estimates in Breast Cancer. Med Decis Making. 2017;37(3):179-92.

58. Klein KA, Watson L, Ash JS, Eden KB. Evaluation of risk communication in a mammography patient decision aid. Patient Educ Couns. 2016;99(7):1240-8.

59. Lipkus IM, Klein WM, Rimer BK. Communicating breast cancer risks to women using different formats. Cancer Epidemiol Biomarkers Prev. 2001:10(8):895-8.

60. Elwyn G, Scholl I, Tietbohl C, Mann M, Edwards AG, Clay C, et al. "Many miles to go ...": a systematic review of the implementation of patient decision support interventions into routine clinical practice. BMC Med Inform Decis Mak. 2013;13 Suppl 2(Suppl 2):S14.

61. Agoritsas T, Heen AF, Brandt L, Alonso-Coello P, Kristiansen A, Akl EA, et al. Decision aids that really promote shared decision making: the pace quickens. Bmj. 2015;350:g7624.

62. Bolt TC, Huisman FG. [David Sackett and 25 years of evidence-based medicine: person and the context]. Ned Tijdschr Geneeskd. 2015;159:A9297.

63. Nicolai J, Moshagen M, Eich W, Bieber C. The OPTION scale for the assessment of shared decision making (SDM): methodological issues. Z Evid Fortbild Qual Gesundhwes. 2012;106(4):264-71.

64. Rodenburg-Vandenbussche S, Pieterse AH, Kroonenberg PM, Scholl I, van der Weijden T, Luyten GP, et al. Dutch Translation and Psychometric Testing of the 9-Item Shared Decision Making Questionnaire (SDM-Q-9) and Shared Decision Making Questionnaire-Physician Version (SDMQ-Doc) in Primary and Secondary Care. PLoS One. 2015;10(7):e0132158.

65. Sepucha KR, Borkhoff CM, Lally J, Levin CA, Matlock DD, Ng CJ, et al. Establishing the effectivenes of patient decision aids: key constructs and measurement instruments. BMC Med Inform Decis Mak. 2013;13 Suppl 2(Suppl 2):S12
66. Barr PJ, Thompson R, Walsh T, Grande SW, Ozanne EM, Elwyn G. The psychometric properties of CollaboRATE: a fast and frugal patient-reported measure of the shared decision-making process. J Med Internet Res. 2014;16(1):e2.

67. Scholl I, Koelewijn-van Loon M, Sepucha K, Elwyn G, Legare F, Harter M, et al. Measurement of shared decision making - a review of instruments. Z Evid Fortbild Qual Gesundhwes. 2011;105(4):313-24.

68. Herrmann A, Mansfield E, Hall AE, Sanson-Fisher R, Zdenkowski N. Wilfully out of sight? A literature review on the effectiveness of cancer-related decision aids and implementation strategies. BMC Med Inform Decis Mak. 2016;16:36.

69. Feibelmann S, Yang TS, Uzogara EE, Sepucha K. What does it take to have sustained use of decision aids? A programme evaluation for the Breast Cancer Initiative. Health Expect. 2011:14 Suppl 1(Suppl 1):85-95. 


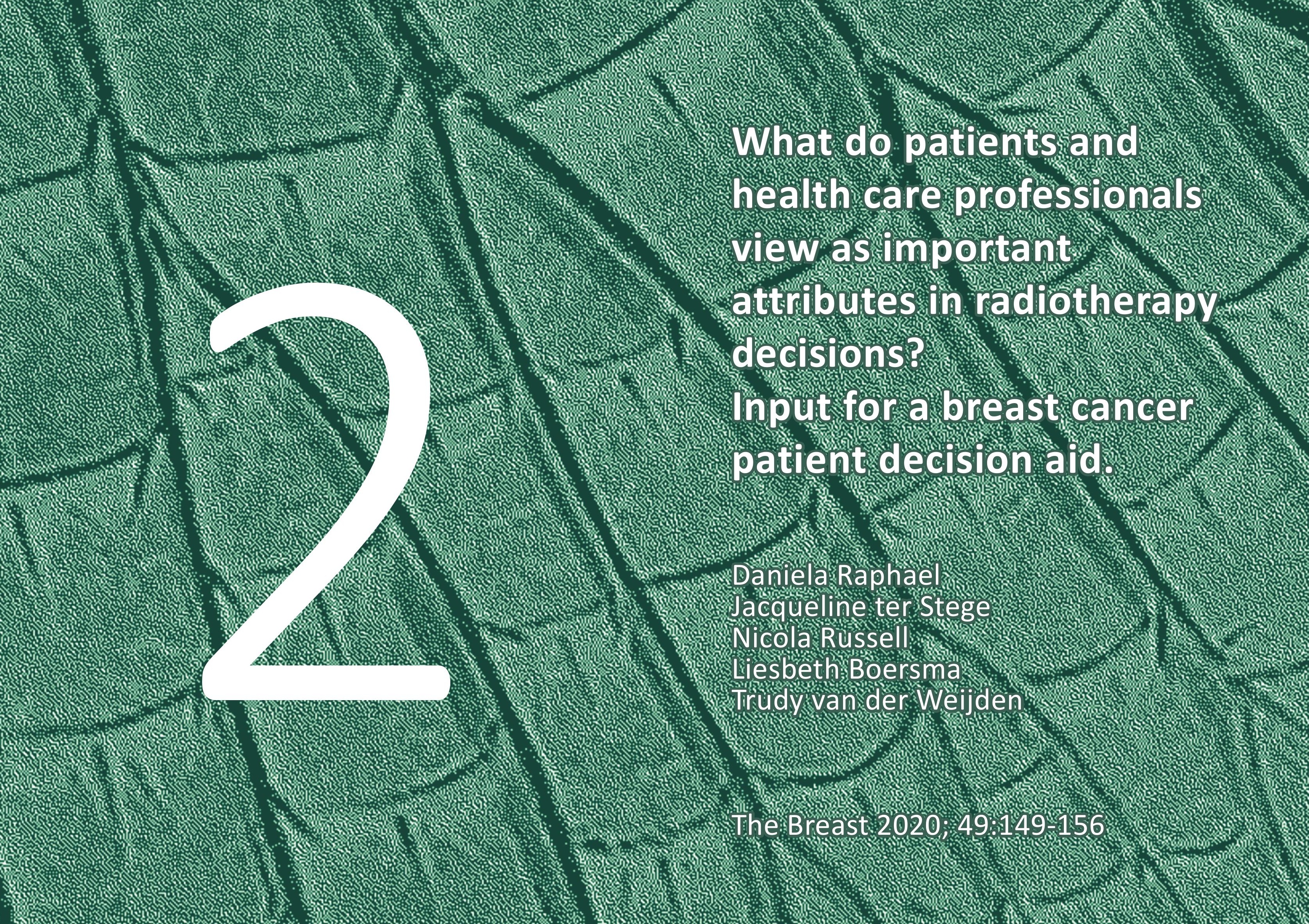




\section{Abstract}

Background and aim: There is increased attention for shared decision-making (SDM) when deciding on radiotherapy for selected patients with Stage 0-2 breast cancer. This study aimed to explore patients' and health care professionals' experiences, decisiona attributes, and needs, as input for the development of a patient decision aid to facilitate SDM.

Methods: Qualitative semi-structured interviews were held with fifteen breast cance patients, being confronted with a radiotherapy decision one month to eight years earlier. Another fifteen interviews were held with professionals specialized in breast cancer care. Interviews were transcribed verbatim and independently coded by two researchers, who agreed upon relevant issues.

Results: Most patients made their decision by weighing the advantages of radiotherapy, i.e., comparing the decrease in recurrence risk with and without radiotherapy, and disadvantages, i.e., possible side effects. Patients and professionals agreed that recurrence risks should be communicated but not on how to deal with uncertainty. There was wide variation in which, and how, side effects were explained by professionals. The most common side effects mentioned by both patients and professionals were skin toxicity, fatigue, and breast deformity.

Conclusion: Patients and professionals appeared to agree on what type of attributes should be communicated during SDM on radiotherapy, but how this should be done is up for discussion. To ensure the patient's voice, these attributes and needs be incorporated in the risk communication and value elicitation sections of the patient decision aid. The format in which the attributes are communicated should be critically evaluated.

\section{Introduction}

Currently, there is a growing trend to de-escalate treatment for selected patients with Stage 0-2 breast cancer. Clinical trials, such as the PRIME II trial (1), the BASO II trial (2), and the EUROPA trial (NCT04134598), evaluate the omission and / or replacement of endocrine therapy with breast radiotherapy (RT) for these patients. In the Netherlands, where endocrine therapy is not offered for these very low risk invasive breast cancer, the TOP-1 trial is being conducted in which also the local breast RT is omitted after breastconserving surgery in patients above 70 years of age (NL5983) $(1,3)$.

In such cases, de-escalating treatment from the current adjuvant standard is justified on the grounds that a small absolute benefit in terms of tumour control will not necessarily translate into a survival advantage (4). Consequently, the decision on which treatment option to apply is therefore a so-called a "preference-sensitive decision", meaning that the outcome of the decision depends on the individual situation and values of the patient. For example, the trade-off between the level of recurrence risk and side effects with possible consequences for their health-related quality of life (HRQoL) at which patients will accept omission of RT is an individualized decision.

Shared decision-making (SDM) is a process in which a clinician and patient work together to choose the best available treatment for the individual patient $(5,6)$, and is the preferred model for preference-sensitive decisions (7-10). Patient decision aids (PtDAs) can support doctors as well as patients in implementing SDM. PtDAs lower decisional conflict among patients and increase patients' knowledge of different treatment options and feeling of being involved in the decision-making process (11-14). The use of PtDAs might also reduce regional practice variation (13)

To our knowledge, two PtDAs have been described for breast cancer patients, exclusively for decision making on RT. Both decision aids have been developed in Canada and are only suitable for small groups of patients (one for older women, and the other for node-negative woman after lumpectomy); they have not been implemented in the Netherlands (15-18).

According to international guidelines, a first step in the development of a PtDA is exploration of patients' and HPs' informational needs based on the results of qualitative interview studies (19-21). There is quite some literature on informational needs of breast cancer patients deciding on other aspects of their treatment $(22,23)$. However, only two studies have investigated the informational needs of patients deciding on RT. One study focused on older patients (24); another study included five patients only. Both studies were not designed in the light of the development of a PtDA (25). We found no studies exploring HPs' perspectives.

Therefore, the aim of this qualitative study was to explore patients' and HPs' perspectives with regard to the most relevant attributes in decision-making on RT for breast cancer. The results have since been used to develop a PtDA to support the SDM process. The development of the format of the PtDA (an online tool) and its effects will be reported at a later date in separate manuscripts. 


\section{Methods}

We performed a qualitative study with semi-structured interviews in breast cancer patients and HPs. All interviews were held by DR, a research clinician, who received basic training in qualitative research and interview techniques from experts in the field. There was no prior relationship between the researcher and the patients. We have used the Coreq checklist for the reporting of this study (26).

\section{Study population and recruitment}

Patients: We asked female breast cancer patients to participate, who had explicitly been given the option to receive or to omit radiotherapy after surgery in the past. We aimed to develop a PtDA for four groups of patients deciding on RT:

1. Patients with low-risk ductal carcinoma in situ (DCIS) after breast-conserving surgery deciding on whole/partial breast RT or no RT.

2. Patients with low-risk invasive ductal carcinoma after breast-conserving surgery deciding on whole/partial breast RT or no RT.

3. Patients with intermediate risk breast cancer after mastectomy deciding on thoracic wall RT or no RT.

4. Patients with intermediate risk breast cancer after breast-conserving surgery deciding on whole breast RT with or without an extra boost dose to the tumor bed.

Therefore, to obtain an as heterogeneous a group as possible, a purposive sample was taken of patients from each of these four groups. Patients with varying educational levels and of different ages were selected. Patients were recruited from hospitals in Amsterdam and Maastricht.

We invited patients 1 to 3 months after their decision and a group five years after treatment. The first group was selected to ensure that they had passed the stage of highes emotional arousal but still remembered sufficient details of their decisional process. The second group had participated in the SUPREMO trial (ISRCTN61145589), a clinical trial in which breast cancer patients with an intermediate risk were randomized between chest wall irradiation or not, following mastectomy (27). All patients in our study group had been allocated to receive RT, so that they could reflect on the impact of the late side effects of RT and their impact on HRQoL.

Patients were informed about the current study by their physician and were asked for consent to be contacted by the researcher. The information letter was sent to them by mail and questions were answered by phone. A face-to-face interview was planned at the time and place of their preference. w Health care professionals: A purposive sample was taken by recruiting different HPs (physician assistants, nurse practitioners, breast cancer surgeons, and radiation oncologists) from eight different peripheral and academic centers in The Netherlands. They were selected to generate a heterogeneous sample with regard to working experience and past experience in the development or use of PtDAs.

We contacted HPs by e-mail via personal contacts. A face-to face interview was planned in their working hospitals.

Semi structured interviews/data collection

Patients: Before the start of the interview, patients were asked to complete a short questionnaire, consisting of ten questions, such as on their marital status, number of children, educational level, and computer and internet skills.

The interview guide (Table 1a) was constructed based on literature $(15,17,25)$ and on questions raised by the study protocol and the research team. The interview guide contained questions on patients' experience with and their opinion about the information provision, and on how they had experienced the decision-making process and what specific attributes had been important in that process. Finally, questions were asked about specific requirements for a PtDA.

Healthcare professionals: The interview guide was aligned to the content of the patient interview guide (table 1b). The interview contained questions on the information provision on RT, their experience on SDM and their experiences with and ideas for a PtDA. 
As I mentioned earlier, we are currently developing a patient decision aid for patients who have

Word of welcome: Thank you for coming, let me introduce myself.

Explanation about the study: Maastro and the Netherlands Cancer Institute are currently conducting a study to improve support for future patients who have the choice between whether or not to undergo radiotherapy. To do this, we want to develop a patient decision aid to facilitate the process of "shared decision-making" The first step in the process is to talk with patients who have already experienced making a choice, to learn about how they experienced the process, to explore their ideas are about "shared decision-making"; wh a patient decision aid and its contents. I'll come back to this later. This conversation will take about 60 minutes, and with your permission I will record the whole conversation so that I can use it for scientific research. After analyzing the information, I will delete the recording and the information will remain anonymous. Do you give consent for this?

Could you introduce yourself? What sort of schooling or training have you followed/ What is your work?

What sort of information did you receive about the radiation treatment?

Who provided the information and when?

Did you look for information on the internet, from friends or acquaintances, or from patien organizations?

What did you think of the information?

Amount, content, difficulty, timing?

What information did you miss/ what had you rather not known beforehand, and what did you consider the most valuable information?

Did your ideas about this change during the treatment period?

What information was the most important for you in making the treatment choice?

If you were to advise another patient about whether to undergo radiotherapy or not, what

in your opinion should she be aware of before making the decision? And what would you advise her?

How do you look back on your decision?

Did you feel that there was a choice to be made?

How was the decision made? What was your role? Was the choice made after discussing it with someone?

- In your opinion, who should make the medical decisions, and to what extent do want to be involved in your own treatment?

Have you previously used an existing patient decision aid?

What do you expect from a patient decision aid and what is your experience with one?

Would you use one, if available?

-When do you think it would have helped you the most?

What do you think should be definitely covered in a patient decision aid?

-Which numbers or percentages should be given?

Would you like to see pictures or videos in the patient decision aid, and if so, which?

What do you think about an online patient decision aid?

These were all my questions. I would like to thank you for this interview. Do you have any questions now? Should you have any questions later, then please contact me at any time.

Table 1b. Interview protocol healthcare professionals (HPs)

Word of welcome: Thank you for coming, let me introduce myself.

Explanation about the study: Maastro and the Netherlands Cancer Institute are currently developing a patient decision aid to support "shared decision-making" for patients who have a choice between whether or not to undergo radiotherapy. As part of the development, we would like the input form clinicians: doctors, physician assistants, and nurse specialists.

This conversation will take about 35 minutes, and with your permission, I will record

the whole conversation so that I can use it for scientific research. After analyzing the information, I will delete the recording and the information will remain anonymous. Do you give consent for this?

Could you introduce yourself?

What information is given to patients in your hospital concerning radiotherapy?

- From whom do patients get this information, at what time-point?

- Do you refer patients to websites or other sources of information?

How much information do you give to patients?

What information is the most relevant? And what information can you burden a patient with?

- Do you adapt the information to the patient sitting in front of you, and if so, how? 
Do you always discuss the possible options with the patient?

- To what extent do you think that patients can participate in deciding on their own treatment?

- How do you apply shared decision-making in your own practice?

- What is needed to facilitate the application of SDM?

As I mentioned earlier, we are currently developing a patient decision aid for patients who have a choice whether or not to undergo radiotherapy. In the patient decision aid, we want to provide information about the radiation treatment, including the benefits as well as the side effects.

Do you already have experience with use of a patient decision aid?

- What is your experience with a patient decision aid, and do you already use one in your practice? What are the reasons for using/ not using one?

- Would you use one if it was available?

- At what point in the treatment would you want to use one, and how?

What do you think should be definitely covered in a patient decision aid for these breast cancer patients?

- Which numbers or percentages should be given?

- Would you like to see pictures or videos in the patient decision aid, and if so, which?

- What do you think about an online patient decision aid?

These were all my questions. I would like to thank you for this interview. Do you have any other questions? Should you have any questions later, then please contact me.

Data analysis

Interviews were recorded and transcribed verbatim. The transcripts were analyzed through a thematic analysis. All interviews were independently coded by two researchers (DR and JTS), who sought consensus by discussion upon relevant issues in case of discrepancies. All findings and codes were shared with the entire project team in numerous project meetings. NVIVO 11 (QSR International Pty Ltd, Victoria, Australia) was used to store the coded interviews, ordered by different themes. After the first round of coding, we selected the codes which answered our research question.

\section{Results}

Patients' and HPs' characteristics

Fifteen patients were included; mean age was 59 years. Half of these patients had received RT. Most patients were married, and half had a high educational status (Table 2a). The interviews lasted between 30 and 90 minutes.

All fifteen HPs who were approached agreed to participate; eight radiation oncologists, three breast cancer surgeons, two physician assistants, and two nurse practitioners.
Their working experience varied between 1.5 and 30 years (Table 2b). Interviews lasted between 20 and 40 minutes.

After the fifteen interviews, saturation was reached in both patients' and HPs' interviews, meaning that no new attributes were identified, and that further inclusion of patients would not yield new insights.

Table 2A. Patient characteristics ( $N=15)$

\begin{tabular}{|c|c|}
\hline \multirow[t]{2}{*}{ Mean age at time of interview in years (range) } & $59(38-79)$ \\
\hline & N \\
\hline \multicolumn{2}{|l|}{ Time since diagnosis } \\
\hline 1-6 months & 11 \\
\hline$>5$ years & 4 \\
\hline \multicolumn{2}{|l|}{ Underwent RT: } \\
\hline Yes & 8 \\
\hline No & 7 \\
\hline \multicolumn{2}{|l|}{ Marital state: } \\
\hline Married & 13 \\
\hline Not married & 2 \\
\hline \multicolumn{2}{|l|}{ Educational level: } \\
\hline University & 2 \\
\hline Higher vocational education & 5 \\
\hline Intermediate vocational education & 5 \\
\hline Secondary education & 3 \\
\hline \multicolumn{2}{|l|}{ Reason for facing radiotherapy decision: } \\
\hline Whole breast irradiation after lumpectomy for DCIS & 6 \\
\hline $\begin{array}{l}\text { Whole breast irradiation after lumpectomy for low-risk invasive } \\
\text { breast cancer }\end{array}$ & 1 \\
\hline Thoracic wall irradiation after mastectomy & 7 \\
\hline Axillary RT yes or no instead of an axillary lymph node dissection & 1 \\
\hline & $\mathrm{N}$ \\
\hline \multicolumn{2}{|l|}{ Specialisation } \\
\hline Radiation oncologist & 7 \\
\hline Physician assistant & 2 \\
\hline Surgeon & 4 \\
\hline Nurse practitioner & 2 \\
\hline \multicolumn{2}{|l|}{ Years of working experience } \\
\hline$<5$ years & 3 \\
\hline $5-15$ years & 7 \\
\hline$>15$ years & 5 \\
\hline
\end{tabular}


Main findings from the interviews

Patients and HPs mentioned the same sort of attributes that should be reflected on during SDM on the decision for RT, i.e., information about recurrence risks with and without RT and the side effects of RT. In the next paragraph we describe the main findings from the interviews. Quotes from the patients and HPs are cited in the appendix.

\section{Informational needs and important attributes}

Information on recurrence risk

The majority of the patients remembered that an explanation was given about their recurrence risk with and without RT, without remembering the exact risk estimates. Most patients experienced this as a useful attribute. One patient felt that these estimates could not help her making the decision since, in her view, her odds were fifty-fifty (the tumor will recur or not). While some patients weighed the recurrence risk in relation to the possible side effects to decide on RT yes or no, other patients chose for RT independent of the actual recurrence.

While most HPs thought it is important to mention the recurrence risk, there was no consensus on how this should be done. Some HPs thought that numbers are difficult to understand for patients and therefore used narrative descriptions (small, large, etc.) only. Uncertainty, based on outdated trial data with non-representative patient populations, was seen as an important barrier to communicate exact numbers. Therefore, most HPs thought that the uncertainty range around the risk estimates should be communicated, although most HPs acknowledged that this might be even more difficult to understand for patients. HPs agreed that if numbers are given, this should be communicated to patients in a visual way.

Information on side effects

Quite some variation was observed in the need to be informed or to inform about side effects and their impact on HRQoL, both regarding which side effects and how side effects were framed.

Patients remembered having been told about only a few possible side effects, not making a distinction between short-term and long-term side effects. The most frequently mentioned side effect was skin reaction, which was characterized most frequently as a burn lesion. Pain and tiredness were also commonly remembered. The fibrosis/change in breast shape was framed as a deformation. Patients differed in their experience of received information about side effects on heart and lungs. Some patients mentioned to remember that RT had a negative effect on the heart and lungs, while others were told that there is no negative effect, since the heart is not affected (Table 3).

There was variation in the number of side effects communicated by the HPs, between only one up to fourteen possible side effects. Most HPs differentiated between short-term and long-term side effects. The most frequently mentioned short-time side effects were skin reaction and fatigue. Edema and pain were mentioned both as short-term and as long- term side effects. Most attention was given to the long-term side effects of fibrosis and subsequent change of the breast shape. There was a difference in which and how the side effects of the lungs and the heart were explained. While some HPs mentioned that RT may cause heart and lung damage, other HPs only mentioned that this is rare with the modern radiation techniques. Only a minority of the HPs mentioned the risk of secondary tumors.

Table 3. Side effects and their effects on Health-Related Quality of Life mentioned by HPs and patients.

\begin{tabular}{|c|c|c|}
\hline & Health care professionals & Patients \\
\hline \multicolumn{3}{|c|}{ Short-term side effects } \\
\hline Skin toxicity & $\begin{array}{l}\text { Skin reaction (redness, } \\
\text { light burning, itching, and } \\
\text { sometimes open) } \\
\text { (Dark) skin discoloration } \\
\text { Small blood vessels } \\
\text { Radiation dermatitis } \\
\text { Erythema } \\
\text { Epidermolysis }\end{array}$ & $\begin{array}{l}\text { Skin open } \\
\text { Skin burns } \\
\text { Redness }\end{array}$ \\
\hline Fatigue & Tiredness & Tiredness \\
\hline \multicolumn{3}{|c|}{ Short- and long-term side effects } \\
\hline Edema & $\begin{array}{l}\text { (Lymph) edema } \\
\text { Only mentioned in the case } \\
\text { of regional radiation }\end{array}$ & Edema \\
\hline Pain & $\begin{array}{l}\text { Pain } \\
\text { Painful stabbing feeling } \\
\text { Feeling of tightness } \\
\text { Painful muscle }\end{array}$ & $\begin{array}{l}\text { Pain } \\
\text { Sensitivity of the breast } \\
\text { Permanent burning } \\
\text { sensation }\end{array}$ \\
\hline \multicolumn{3}{|c|}{ Long-term effects } \\
\hline $\begin{array}{l}\text { Fibrosis or change in breast } \\
\text { shape }\end{array}$ & $\begin{array}{l}\text { Fibrosis of chest wall } \\
\text { Scarring, scar tissue } \\
\text { formation leading to nipple } \\
\text { transposition } \\
\text { Connective tissue formation } \\
\text { Fibrosis with pain and } \\
\text { changes in shape and } \\
\text { contour } \\
\text { Shrinking } \\
\text { Asymmetry } \\
\text { Change in texture }\end{array}$ & $\begin{array}{l}\text { Malformation } \\
\text { Deformation } \\
\text { Scarring }\end{array}$ \\
\hline $\begin{array}{l}\text { Consequences for breast } \\
\text { reconstruction }\end{array}$ & $\begin{array}{l}\text { Consequences for } \\
\text { reconstruction }\end{array}$ & $\begin{array}{l}\text { Consequences for } \\
\text { reconstruction }\end{array}$ \\
\hline $\begin{array}{l}\text { Problems for ribs / chest } \\
\text { wall }\end{array}$ & $\begin{array}{l}\text { Painful ribs } \\
\text { Rib complaints } \\
\text { Rib fractures }\end{array}$ & Side effects affecting the ribs \\
\hline
\end{tabular}


Radiation pneumonitis

Lung fibrosis

Secondary lung tumor (if

$$
\text { smoker) }
$$

\begin{tabular}{lll}
\hline Second cancer & Second tumors (minority) & \\
\hline Mobility limitations & $\begin{array}{l}\text { Reduced mobility of } \\
\text { shoulder } \\
\text { Reduced mobility due to } \\
\text { regional radiation }\end{array}$ \\
\hline $\begin{array}{l}\text { Swallowing complaints after } \\
\text { esophagus regional RT }\end{array}$ & $\begin{array}{l}\text { Swallowing complaints in } \\
\text { case of regional RT }\end{array}$ \\
\hline Other & $\begin{array}{l}\text { Changes in the effects if also } \\
\text { chemotherapy given }\end{array}$ \\
\hline
\end{tabular}

\section{Information on treatment burden}

Most patients were aware of the treatment burden of the RT. The treatment burden was framed as the number of times patients have to come to the hospital (normally three-four weeks on a daily basis, in addition to a separate preparatory session), how much time the RT takes (15-30 minutes a day) and travel time. Only one patient mentioned this as an important attribute. Some HPs mentioned the treatment burden as an important attribute when deciding on RT. In some centers all the practical information about RT was given after the decision on RT has been made.

\section{Other attributes}

The majority of patients were satisfied with the (amount of) information received. Only a few patients mentioned they had missed certain information, although this did not influence their feeling about their decision. One patient did not realize that RT was given on the naked upper body. Although everybody was respectful to her, she felt her breast became a "public property". Another patient missed information on the consequences for the post-treatment check-ups when choosing for RT or not. Another attribute mentioned by several patients, was what they considered consequences of their choice for future therapy options. Some patients mentioned that an advantage of omitting RT left open the option for breast-conserving therapy in case of a recurrence, whereas immediate RT would render breast-conserving therapy impossible due to the earlier RT.

\section{Discussion and conclusion}

We found that patients and HPs mentioned the same type of attributes as relevant for SDM on RT, i.e. information about recurrence risks with and without RT and the side effects of RT impacting HRQoL. However, in what way and how detailed the information should be communicated varied between all interviewed persons. Although in some countries endocrine therapy is offered to patients with a very low risk of recurrence, affecting the balance on advantages and disadvantages of choosing for RT and/or endocrine therapy this is not clinical practice in the Netherlands (3); and was therefore, not included in this study.

\section{Information on recurrence risk}

The majority of patients and HPs agreed that patients should be informed about the risk reduction caused by RT. To find the best way of communicating risks in a way that is understandable for patients is, however, a challenge. It might seem attractive to use narratives to avoid this problem, but patients interpret these labels in different ways (28). Another issue is that while patients are aware that there is a risk of recurrence, they feel that there is an uncertainty as to whether the given risk will apply in their individual case. For example, if there is a $10 \%$ recurrence risk, will I fall into the $10 \%$ group? This is called an aleatory uncertainty. HPs also worried about how to communicate the uncertainty and reliability of the given risk estimates or their range (known as epistemic uncertainty) Communicating epistemic uncertainty seems to be even more challenging than communicating risk. A recently published paper showed wide variation in how uncertainty is being communicated in PtDAs $(29,30)$; this is due to a lack of evidence on how this should be done (31). Van der Bles et al. (32) recently reviewed interdisciplinary literature on communicating epistemic uncertainty. They advise to adapt the given information on the available evidence to separate the magnitude of the effect of the treatment and the magnitude of the uncertainty around the effect, and they point out that communicating epistemic uncertainty does not undermine trust (32). The use of natural frequencies in combination with visual pictographs with textual explanation might support risk communication $(33,34)$.

Information on side effects

In our study, there was large variation in how much and how detailed HPs communicate about side effects. This has also been found in a study by Kunneman et al. (35). In that study, consultations with radiation oncologists giving information on RT for rectal cance were audiotaped. A range of two to thirteen side effects were mentioned. Which and how much information patients received depended on their HP. A difference was the framing of the side effects by patients compared to HPs. While the majority of HPs referred to skin toxicity as redness, patients phrased this as burn lesions. The same applied to fibrosis or change in breast shape, which patients phrased as breast deformation. This may indicate that side effects should be communicated in terms of symptoms and their impact on $H R Q$ oL instead of biologic etiology. The variation in the information patients received may be a cause of the wide practice variation observed (36). A decision aid may reduce this practice variation, since it supports the standardization of the information given. 
Information on treatment burden

Whereas other studies describe distance to radiotherapy centers as a barrier for choosing for RT (37-40), this does not seem to be a problem in our study, since in our study only one patient took the treatment burden into account when deciding on RT. An explanation might be that in small countries such as the Netherlands there is easy and wide access to RT centers for all inhabitants $(40,41)$.

\section{Other attributes}

Apart from local recurrence risks and side effects, two patients also mentioned anothe reason to refrain from RT. They believed that avoiding RT in the initial treatment would increase the possibility to keep their breast in case of a recurrence, since re-irradiation is often not advised. However, literature in DCIS shows that patients who do not undergo RT after lumpectomy have an $11 \%$ higher risk of ultimately undergoing a mastectomy, compared to those immediately irradiated post-operatively (42).

\section{Strengths and limitations}

A limitation of this study may be a selection bias among the patients. Participating patients may have been more actively involved in the decision-making process or may have had a more positive attitude towards SDM. We have no insight into how many patients refused, since clinicians only told us when patients gave permission. No patients were included from more remote areas, such as the Dutch islands. It is impossible to avoid all recall bias in such a study. However, we tried to reduce this by interviewing patients who had been faced RT decision within weeks after the decision. A strength of this study is that we addressed information exchanged from the perspectives of both patients and HPs.

\section{Conclusions and future plans}

These interviews yielded valuable attributes for decision-making, which will be incorporated into a PtDA, standardizing information on side effects and treatment burden, to assist SDM in breast cancer radiotherapy. Although a PtDA can give a good visual representation of recurrence risks with and without RT, the best way to communicate epistemic uncertainty in a decision aid is still unclear (29). This will be further explored whilst developing the decision aid.

\section{References}

1. Kunkler IH, Williams $L$, Jack WJ, Cameron DA, Dixon JM. Breast-conserving surgery with or without irradiation in women aged 65 years or older with early breast cancer (PRIME II): randomised controlled trial. The Lancet Oncology. 2015;16(3):266-73.

2. Blamey RW, Bates T, Chetty U, Duffy SW, Ellis IO, George D, et al. Radiotherapy or tamoxifen after conserving surgery for breast cancers of excellent prognosis: British Association of Surgical Oncology (BASO) II trial. European journal of cancer (Oxford, England : 1990). 2013;49(10):2294302.

3. de Boer AZ, Bastiaannet E, de Glas NA, Marang-van de Mheen PJ, Dekkers OM, Siesling S, et al. Effectiveness of radiotherapy after breast-conserving surgery in older patients with T1-2NO breast cancer. Breast cancer research and treatment. 2019.

4. Taylor C, Correa C, Duane FK, Aznar MC, Anderson SJ, Bergh J, et al. Estimating the Risks of Breast Cancer Radiotherapy: Evidence From Modern Radiation Doses to the Lungs and Heart and From Previous Randomized Trials. Journal of clinical oncology : official journal of the American Society of Clinical Oncology. 2017:35(15):1641-9.

5. Légaré $F$, Thompson-Leduc PJPe, counseling. Twelve myths about shared decision making 2014;96(3):281-6.

6. [cited 2019 01-05]. Available from: https://mailchi.mp/fc3301ebfc52/nieuwsbrief-inspiratievoor-samenbeslissers-280563? $=\mathrm{e} 7 \mathrm{~d} 36 \mathrm{f} 2044$.

7. Coulter A, Collins A. Making shared decision-making a reality: no decision about me, without me: King's Fund; 2011.

8. Elwyn G, Lloyd A, Joseph-Williams N, Cording E, Thomson R, Durand MA, et al. Option Grids: shared decision making made easier. Patient education and counseling. 2013;90(2):207-12.

9. Mulley AG, Trimble C, Elwyn G. Stop the silent misdiagnosis: patients' preferences matter. BM (Clinical research ed). 2012;345:e6572.

10. Alfandre D. Clinical Recommendations in Medical Practice: A Proposed Framework to Reduce Bias and Improve the Quality of Medical Decisions. The Journal of clinical ethics. 2016;27(1):21-7.

11. Stacey D, Legare F, Lewis K, Barry MJ, Bennett CL, Eden KB, et al. Decision aids for people facing health treatment or screening decisions. The Cochrane database of systematic reviews. 2017:4:Cd001431.

12. Nicholas Z, Butow P, Tesson S, Boyle F. A systematic review of decision aids for patients making decision about treatment for early breast cancer. Breast (Edinburgh, Scotland). 2016;26:31-45.

13. O'Connor AM, Llewellyn-Thomas HA, Flood AB. Modifying unwarranted variations in health care: shared decision making using patient decision aids. Health affairs (Project Hope). 2004;Suppl Variation:Var63-72

14. Shabason JE, Mao JJ, Frankel ES, Vapiwala N. Shared decision-making and patient control in radiation oncology: implications for patient satisfaction. Cancer. 2014;120(12):1863-70.

15. Wong J, D'Alimonte L, Angus J, Paszat L, Metcalfe K, Whelan T, et al. Development of patients' decision aid for older women with stage I breast cancer considering radiotherapy after lumpectomy. International journal of radiation oncology, biology, physics. 2012;84(1):30-8.

16. Woodhouse KD, Tremont K, Vachani A, Schapira MM, Vapiwala N, Simone CB, 2nd, et al. A Review of Shared Decision-Making and Patient Decision Aids in Radiation Oncology. Journal of cancer education : the official journal of the American Association for Cancer Education. 2017;32(2):238-45 
17. Wong J, Szumacher E. Patients' decision-making in radiation oncology. Expert review of pharmacoeconomics \& outcomes research. 2012;12(1):95-104.

18. Whelan T, Levine M, Gafni A, Lukka H, Mohide E, Patel M, et al. Breast irradiation postlumpectomy: development and evaluation of a decision instrument. Journal of Clinical Oncology. 1995;13(4):847-53.

19. Coulter A, Stilwell D, Kryworuchko J, Mullen PD, Ng CJ, van der Weijden T. A systematic development process for patient decision aids. BMC medical informatics and decision making. 2013;13 Suppl 2:S2.

20. Elwyn G, O'Connor AM, Bennett C, Newcombe RG, Politi M, Durand MA, et al. Assessing the quality of decision support technologies using the International Patient Decision Aid Standards instrument (IPDASi). PloS one. 2009;4(3): e4705

21. Elwyn G, O'Connor A, Stacey D, Volk R, Edwards A, Coulter A, et al. Developing a quality criteria framework for patient decision aids: online international Delphi consensus process. BMJ (Clinical research ed). 2006;333(7565):417.

22. Wallberg B, Michelson H, Nystedt M, Bolund C, Degner LF, Wilking N. Information needs and preferences for participation in treatment decisions among Swedish breast cancer patients. Acta oncologica (Stockholm, Sweden). 2000;39(4):467-76.

23. Mercieca-Bebber R, King MT, Boxer MM, Spillane A, Winters ZE, Butow PN, et al. What quality of-life issues do women with ductal carcinoma in situ (DCIS) consider important when making treatment decisions? Breast cancer (Tokyo, Japan). 2017;24(5):720-9.

24. Wang SY, Kelly G, Gross C, Killelea BK, Mougalian S, Presley C, et al. Information Needs of Older Women With Early-Stage Breast Cancer When Making Radiation Therapy Decisions. International journal of radiation oncology, biology, physics. 2017;98(4):733-40.

25. Hendry JA. A qualitative focus group study to explore the information, support and communication needs of women receiving adjuvant radiotherapy for primary breast cancer. Journal of Radiotherapy in Practice. 2011;10(2):103-15.

26. Tong A, Sainsbury P, Craig J. Consolidated criteria for reporting qualitative research (COREQ): a 32-item checklist for interviews and focus groups. International journal for quality in health care : journal of the International Society for Quality in Health Care. 2007;19(6):349-57.

27. Kunkler IH, Canney P, van Tienhoven G, Russell NS. Elucidating the role of chest wall irradiation in 'intermediate-risk' breast cancer: the MRC/EORTC SUPREMO trial. Clinical oncology (Royal College of Radiologists (Great Britain)). 2008;20(1):31-4

28. Kunneman-van Unnik HJA. Shared decision making in adjuvant cancer treatment: Department of Medical Decision Making, Faculty of Medicine, Leiden ...; 2016.

29. Bansback N, Bell M, Spooner L, Pompeo A, Han PKJ, Harrison M. Communicating Uncertainty in Benefits and Harms: A Review of Patient Decision Support Interventions. The patient. 2017;10(3):311-9.

30. Harrison M, Han PKJ, Rabin B, Bell M, Kay H, Spooner L, et al. Communicating uncertainty in cancer prognosis: A review of web-based prognostic tools. Patient education and counseling. 2019;102(5):842-9.

31. Engelhardt EG, Pieterse AH, Han PK, van Duijn-Bakker N, Cluitmans F, Maartense E, et al. Disclosing the Uncertainty Associated with Prognostic Estimates in Breast Cancer. Medical decision making an international journal of the Society for Medical Decision Making. 2017;37(3):179-92.
32. van der Bles AM, van der Linden S, Freeman ALJ, Mitchell J, Galvao AB, Zaval L, et al. Communicating uncertainty about facts, numbers and science. Royal Society open science. 2019;6(5):181870.

33. Klein KA, Watson L, Ash JS, Eden KB. Evaluation of risk communication in a mammography patient decision aid. Patient education and counseling. 2016;99(7):1240-8.

34. Freeman ALJ. How to communicate evidence to patients. Drug and therapeutics bulletin. 2019;57(8):119-24

35. Kunneman M, Marijnen CA, Rozema T, Ceha HM, Grootenboers DA, Neelis KJ, et al. Decision consultations on preoperative radiotherapy for rectal cancer: large variation in benefits and harms that are addressed. British journal of cancer. 2015;112(1):39-43.

36. Schreuder K, Maduro JH, Spronk PER, Bijker N, Poortmans PMP, van Dalen T, et al. Variation in the Use of Boost Irradiation in Breast-Conserving Therapy in the Netherlands: The Effect of a National Guideline and Cofounding Factors. Clinical oncology (Royal College of Radiologists (Great Britain)). 2019;31(4):250-9.

37. Mastaglia B, Kristjanson LJ. Factors influencing women's decisions for choice of surgery for Stage I and Stage II breast cancer in Western Australia. Journal of advanced nursing. 2001;35(6):836-

38. Gillan C, Briggs K, Goytisolo Pazos A, Maurus M, Harnett N, Catton P, et al. Barriers to accessing radiation therapy in Canada: a systematic review. Radiation oncology (London, England). 2012;7:167.

39. Tyldesley S, McGahan C. Utilisation of radiotherapy in rural and urban areas in British Columbia compared with evidence-based estimates of radiotherapy needs for patients with breast, prostate and lung cancer. Clinical oncology (Royal College of Radiologists (Great Britain)). 2010;22(7):526-32

40. Koulis TA, Dang A, Speers C, Olson RA. Factors affecting radiotherapy prescribing patterns in the post-mastectomy setting. Current oncology (Toronto, Ont). 2018;25(2):e146-e51.

41. [Available from: https://richtlijnendatabase.nl/uploaded/docs/Colorectaal_carcinoom/ Kwaliteitsnormen_Radiotherapie_in_Nederland_v2.1.pdf.

42. Donker M, Litiere S, Werutsky G, Julien JP, Fentiman IS, Agresti R, et al. Breast-conservin treatment with or without radiotherapy in ductal carcinoma In Situ: 15 -year recurrence rates and outcome after a recurrence, from the EORTC 10853 randomized phase III trial. Journal of clinical oncology : official journal of the American Society of Clinical Oncology. 2013;31(32):4054-9. 


\section{Appendix}

\section{Informational needs}

Patient: Yes, they were mentioned, but if you would ask me now I don't think I would be able to say with any certainty. What I did take home was the chances of things developing the wrong way increase per year, and because I'm still so young, yes I'm not yet 80... But if you're 50,60 l'll still want to reach an old age... so the percentages... really cannot say any more, but the feeling... of hopefully you've still got some years to go.

Patient: No, I didn't hear anything about them, at any rate I don't remember, that idea of percentages. But those percentages then huh, if you hear that, then you have to think by yourself like: yeah, but what's the point knowing this, as it doesn't actually say anything about me. It's just all or nothing. Either it comes back or it doesn't. Umm yeah, it's a question of wait and see if it goes well or not.

Patient: Then I actually have a choice, like in a while, if it turns out that, if I do the radiation and I've just got $1 \%$ or $2 \%$ yeah, more would help, like now I can consider it, yes I still think it's worth the risk, with possible complications, I think it's still worth doing the radiation. And if it's more percent, like, then yes, then I can say, yes guys, I just have to do it, you know?

Patient: Yeah, the radiation and everything around it, by your ribs maybe or um the tiredness. I was already extremely tired. I hear a lot of women talk about tiredness with radiotherapy. And umm, that your breast gets harder, and gets deformed. I've also got prosthesis in and I just know, radiation and prostheses don't really go together. So umm, and umm, wounds that heals poorly. I don't want to be bothered with all that. To be honest. If it really, uh, if the percentages had been higher, then of course I would have done it, but $5 \%$ ? Then I reckon, you know, leave it at that, it's all right.

Patient: But at the moment I had to make the decision, I found it actually all less important than the idea of: so, all that works.

HP: That we expect some benefit, but because the risk that she gets a recurrence is already very low, and then the benefit is also relatively low and that in any case they are kept in follow-up.

HP: Recently there have been a lot of changes in the values for the rates, hum, that's all very difficult to estimate. So by giving detailed information umm, yes, that's tricky. You can also make mistakes of course. That umm, if you keep it vague, umm then I think that, well that's not much use to anyone.

HP: I always give a rough estimate as there is also uncertainty of course, because you're sitting opposite an individual and you can't really... So you give a general impression, of the statistics, but you can't, I would never say like: you've got, $8 \%$ chance. You can't do that. Or can't manage to do it. You shouldn't do it, because you don't know.

HP: So it should be made visual to be able to introduce it.
Information on treatment burden

Patient: So the consideration of the tiredness and that daily trips to the hospital what I really wasn't looking forward to, like, let that be clear, because I really don't like hospitals, find it all horrible. But I had the feeling of: if it must, it must. So if that helps, then I just do it. So that's no longer a consideration.

\begin{tabular}{l} 
Other attributes \\
Patient: Umm, intimacy. And the feeling of, umm, at any rate my chest is rather public \\
property during that trajectory and really respectful and kind and so on umm, fantastic \\
at the radiotherapy, no bad word about it, but every day with your wherewithal open and \\
naked I had like, I had lost it a bit and it was no longer ours, as it were. \\
\hline Patient: Umm looking back I, umm, would have liked umm more information about what \\
would happen if you don't go for the radiation, in my case then huh, what would be the \\
consequences? \\
\hline Patient: Yeah, that umm, like they did say, at least, that was how I heard it, that if later on \\
something is there, then did they say what would happen? Yes, then we would have to \\
proceed to a mastectomy. \\
Patient: An important argument for me was what if I do the radiation now and I get it again, \\
then I would have to, if I got it again, I would have to have an immediate mastectomy. So \\
that could not be done in the same procedure, while if I don't do the radiation now, the \\
next time I could be treated the same way. That went so quickly and well in my case that \\
was a month of madness, but just one month.
\end{tabular}


Risk communicatio h th a patient decision aid for radiotherapy in breast cancer: how to deal with uncertainty?

Oanielar Raphael Nicola Russell Marcelle ${ }^{2} m i n$ Pavilien Westhoff Ma a k a stenfert kroese sinarcesstam msettevan $N$ aur Desireevah de ${ }^{2}$ ongard Jón nuadure. Marg 1 etsatter Jud vander Weijon Kresbethooersma

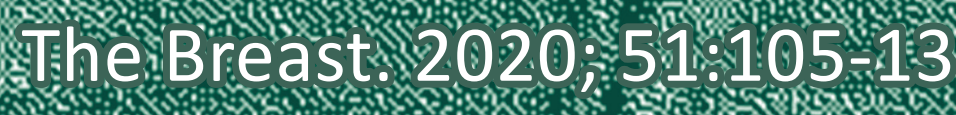




\section{Abstract}

Background and aim: Patient decision aids for oncological treatment options provide information on the effect on recurrence rates and/or survival benefit, and on side effects and/or burden of different treatment options. However, often, uncertainty exists around the probability estimates for recurrence/ survival and side effects which is too relevant to be ignored. Evidence is lacking on the best way to communicate these uncertainties. The aim of this study is to develop a method to incorporate uncertainties in a patient decision aid for breast cancer patients to support their decision on radiotherapy.

Methods: First, qualitative interviews were held with patients and healthcare professionals. Second, in the development phase, thinking aloud sessions were organized with four patients and 12 healthcare professionals, individual and group-wise.

Results: Consensus was reached on a pictograph illustrating the whole range of uncertainty for local recurrence risks, in combination with a textual explanation that a more exact personalized risk would be given by their own physician. The pictograph consisted of 100 female icons in a $10 \times 10$ array. Icons with a stepwise gradient color indicated the uncertainty margin. The prevalence and severity of possible side effects were explained using verbal labels.

Conclusions: We developed a novel way of visualizing uncertainties in recurrence rates in a patient decision aid. The effect of this way of communicating risk uncertainty is currently being tested in the BRASA study (NCT03375801).

\section{Introduction}

In health care, the best treatment for the individual patient is a tradeoff between the medical advantages and disadvantages of different treatment options and the personal values and preferences of the patient. This tradeoff is most relevant in preferencesensitive decisions: treatment decisions where no best treatment exists (1-3).

Some breast cancer patients, e.g. those with an intermediate risk local recurrence risk (LRR), face such a preference-sensitive decision when deciding on adjuvant radiotherapy (RT). The benefits of RT consist of a decrease in the risk of recurrence and sometimes a small survival benefit (4-9). The disadvantages are possible side effects and treatment burden. In many cases however, the exact recurrence risks are unknown. This is amongst other reasons due to literature based on outdated trials; breast cancer clinical trials having a long follow-up, whilst new treatment options develop fast. Another reason is that clinical trials use strictly defined patient categories, and patients do not always fit in the trial population (7). Therefore, estimated recurrence risks are surrounded by an uncertainty margin. Some guidelines reflect this uncertainty, advocating shared decisionmaking with the patient (5)

There are two levels of uncertainty. First-order or aleatory uncertainty is the uncertainty of an event taking place in the future. The risk estimate is known on group level, but it is difficult to predict whether or not it will happen in the individual patient. Second-order or epistemic uncertainty is the uncertainty around the risk estimates (10). There is even uncertainty about the risk estimate on group level. Little is known on the best way to communicate risks and uncertainties to patients $(11,12)$. Risks and aleatory uncertainty are difficult to understand for patients (13). Communicating epistemic uncertainty is even a bigger challenge. Therefore, when clinicians communicate risks to patients, point estimates are commonly used. From ethical and medical-legal considerations, it can be argued that patients should be fully informed on their treatment options, including the uncertainty around these point estimates $(14,15)$.

There is also epistemic uncertainty around the prevalence and severity of the side effects of RT for breast cancer patients. First, the available literature mentioning prevalence and severity of side effects is inconsistent, partly due to the use of different scoring systems to record side effects (16). Consequently, the literature provides a wide range of prevalence and severity estimates $(17,18)$. Second, long-term side effects occur months to many years after irradiation, such that not all side effects may be captured by registries, and that by the time late side-effects occur, new treatments may have become the standard (19). Third, patient and treatment characteristics influence the risk of developing certain side effects, making it harder to translate general risk estimates to specific estimates for individual patients (20).

A patient decision aid (PtDA) may be used to support the decision-making process and communication of risks and uncertainty (21). PtDAs are tools that provide evidence-based information on the advantages and disadvantages of different treatment options, make clear that they can decide between these options, and help patients to clarify which attributes 
are most important to them when making a medical decision (21). However, there is no clear guideline on how uncertainty should be communicated in a PtDA. Therefore, there is significant heterogeneity in how this is done (22). In a review by Bansback et al. (23) only half of the tools described epistemic uncertainty. When epistemic uncertainty was mentioned, it was usually referred to in a qualitative way (large, small, etc.). Although it might seem that these qualitative labels are better understood compared to quantitative risks (24), it is known that patients interpret qualitative labels in very different ways. For example, Freeman describes that the term "common" in an information leaflet is used for a side-effect occurring in 1-10\% of cases, while doctors interpret "common" as something occurring in $25 \%$ of cases and patients in $50 \%$ of cases (15).

Although several PtDAs have been developed for early-stage breast cancer patients who are deciding on different treatment options, to our knowledge there are only two PtDAs for breast cancer patients deciding on RT (25). Both have been developed in Canada for patients deciding on RT after lumpectomy. The PtDAs do not include information on uncertainty around the point estimates or side effects $(26,27)$. Therefore, the primary objective of this study was to assess opinions and attitudes of breast cancer patients and professionals on whether and how to communicate uncertainties in recurrence rates, survival, and side effects. The second objective was to incorporate this knowledge in a PtDA for breast cancer patients to support their decision on radiotherapy.

\section{Methods}

For the content of the PtDA, we followed the guidelines of the International Patien Decision Aid Standards (IPDAS) $(28,29)$. From the start, it was clear that the PtDA had to be made for four different pathways:

1. Patients with low-risk ductal carcinoma in situ (DCIS) after breast-conserving surgery deciding on (partial) breast RT or no RT.

2. Patients with low-risk invasive ductal carcinoma after breast-conserving surgery deciding on (partial) breast RT or no RT.

3. Patients with intermediate-risk breast cancer after mastectomy deciding on thoracic wall RT or no RT.

4. Patients with intermediate-risk breast cancer after breast-conserving surgery deciding on whole breast RT with or without an additional boost dose to the tumor bed.

\section{Phase one: Qualitative interviews}

A qualitative study was conducted to explore patients' and healthcare professionals (HPs) views on important attributes for shared decision-making for breast cancer patients deciding on RT (30). For this paper, we only report the data on the communication of uncertainties. Data on other attributes and preferences are published elsewhere (31).
Phase two: Alpha testing the risk communication part of the PtDA

With information derived from the interviews, the research team developed a draft version of the risk communication part of the PtDA. The PtDA was developed with input from both patients and HPs in different rounds (Figure 1).

Figure 1. Overview of the development of the Patient decision aid.

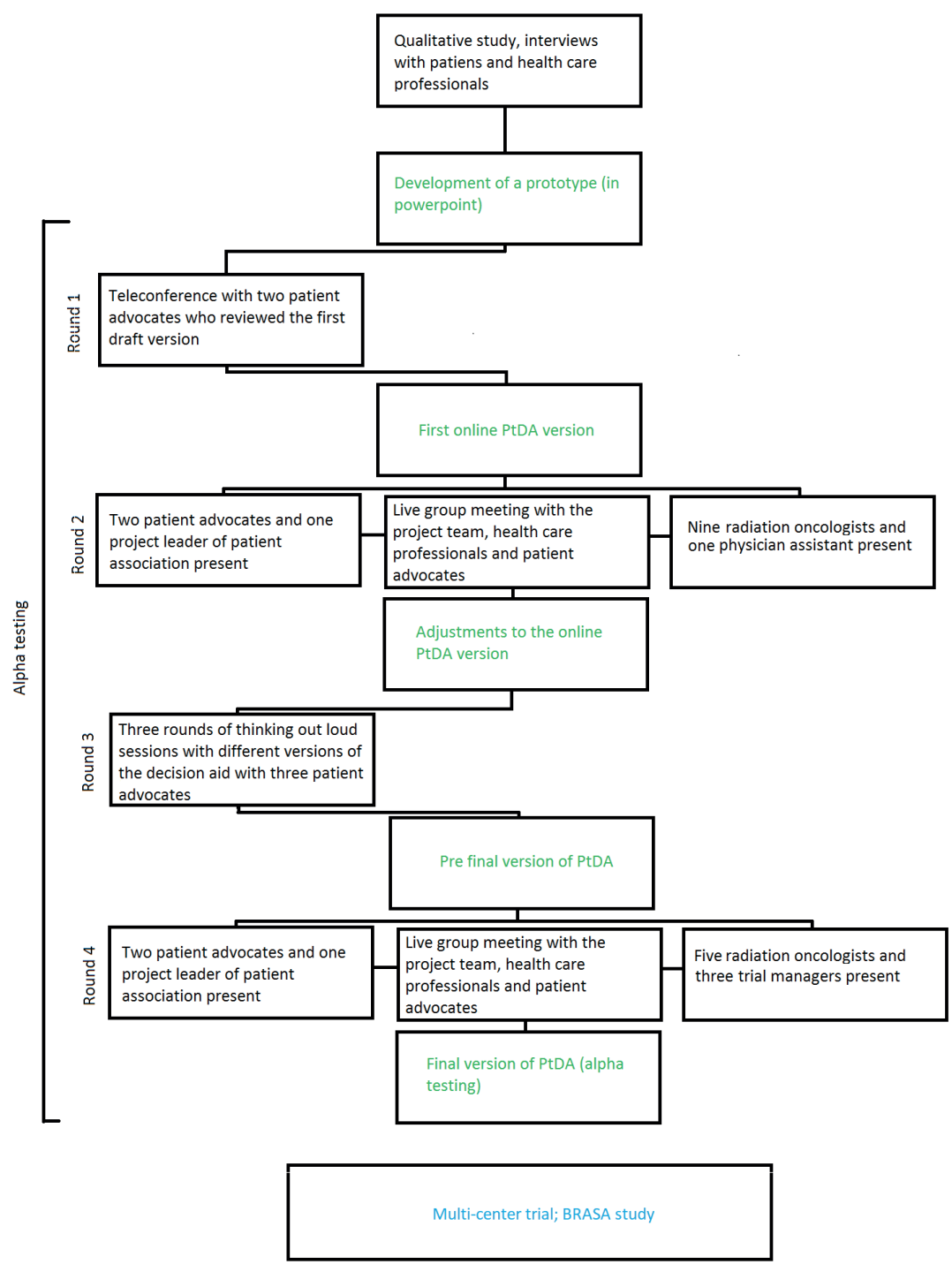


Patient advocates recruitment

Patient advocates were recruited through the national breast cancer association, the patient advisory group of the national breast cancer research group and through the patient advisory board of Maastro, one of the participating hospitals.

Health care professionals' recruitment

Radiation oncologists, surgeons, RT physician assistants and trial managers, all specialized in breast cancer, from 15 RT centers in the Netherlands were invited through personal contacts.

Development rounds

The draft version contained a PowerPoint presentation with a schematic concept of the PtDA, accompanied by a Word document for patient advocates' feedback. In round 1 , the feedback was used to make a first online PtDA version. In round 2, a live group meeting with HPs and patient advocates was organized to discuss this online version. The content and layout of the PtDA was discussed until consensus was reached on the most important topics. In round 3, thinking aloud sessions (32) were organized with new drafts of the PtDA: Patient advocates reviewed the PtDA while speaking out loud what they thought and understood. With this feedback, a pre-final version was developed. Round 4 consisted of a second live group meeting with HPs and patients. Here the pre-final version of the PtDA was discussed until consensus was reached on a version that was created for testing in the field.

\section{Results}

\section{Phase one: Qualitative interviews}

Most patients and HPs agreed that recurrence risks, survival data and side effects in the PtDA should be communicated. While patients were only aware of aleatory uncertainty for recurrence risks, HPs also worried on how to communicate epistemic uncertainty. While patients did not express a specific preference for risk format, HPs agreed on communicating risks in a visual way. The treatment burden was not mentioned as an important attribute to decide on RT. The most relevant side effects to both patients and HPs were extracted from the interviews (31).

Phase two: Alpha testing the risk communication section of the PtDA

LRR and breast cancer specific survival (BCSS) were illustrated by a pictograph, combined with a textual explanation of the LRR/BCSS: " $x$ out of 100 women will have a local recurrence in 10 years" (Figure 2) and "x out of 100 women will die from breast cancer in 10 years". No uncertainty was communicated.

Side effects were divided in short term (red and sensitive skin, edema, tiredness, and pain of the breast) and long-term side effects (fibrosis and change in breast shape, edema, (dark) skin discoloration, pain, rib complications, heart problems, and lung problems). Due to a lack of relevant data, no quantification on probability could be given other than that side effects could occur.
Figure 2. Pictograph in first draft version of the PtDA: Local recurrence risk for low-risk breast cancer after breast-conserving surgery without RT.

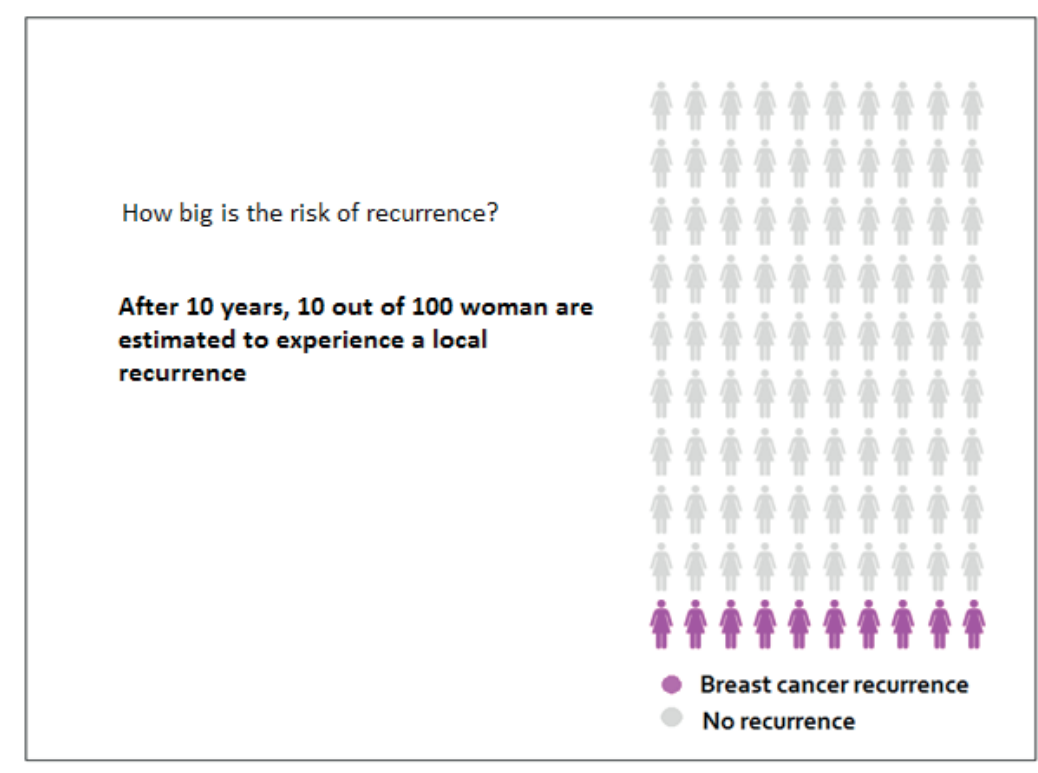

Figure 3. Study-logo adapted pictographs with local recurrence risk with and without radiotherapy, in the first online version: Local recurrence risk for low-risk breast cancer after breast-conserving surgery with and without radiotherapy.

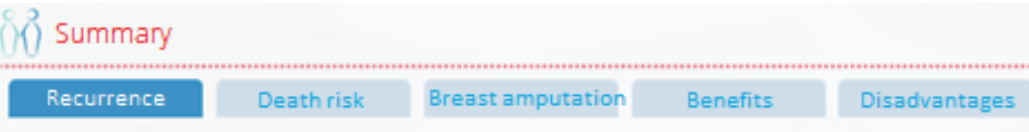

Recurrence risk after 10 years

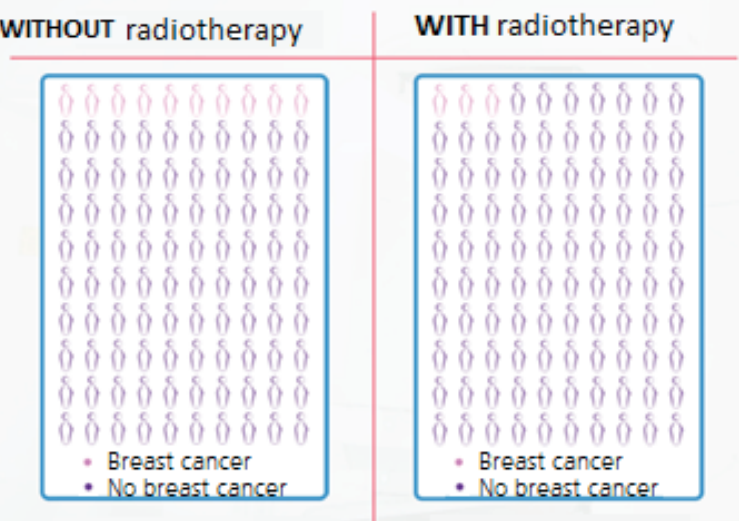

t/ 10 out of 100

+-3 out of 100 woman 
In round 1, patients understood the risks communicated on the pictographs. The data on BCCS were experienced as difficult to hear, although patients thought that it was important to communicate.

The online version of the PtDA was developed together with an e-learning company (EyeSpirations, Amersfoort, The Netherlands) (Figure 3).

During the live group meeting in round 2, with both patients and HPs there was agreement on the 10-year time frame for LRR. For pathway 2, consensus was reached on poin estimates. A debate emerged on the LRR estimates of the other three pathways. It was argued that no estimates could be given, since the LRR depends on the individual patient and on tumor and treatment characteristics, but validated nomograms are lacking. The relative risk reduction is independent of individual characteristics. Therefore, there was consensus on mentioning both the absolute and the relative reduction in recurrence risk in combination with a pictograph. The absolute recurrence risk was mentioned as a range in risk reduction with an explanation that the patient's clinician would personalize the patient's LRR. Two options were suggested for the pictographs. The first option was to use fading colors in the $10 \times 10$ pictograph to indicate a given risk with its uncertainty margin The second option was to show two different pictographs: one with the lowest estimated recurrence risk and another with the highest estimated recurrence risk. Another debate emerged on how to communicate survival risks. It was argued that BCSS is not preferable, because the patient is mainly interested in overall survival expectancy. Overall survival, however, is impossible to generate for the whole group since it also depends on patien characteristics, such as age and co-morbidity. In Pathway 1, 2 and 4 no gain in survival is expected from RT; therefore, it was decided to mention this fact in words without putting an overall quantitative figure on it. For intermediate-risk breast cancer after mastectomy (pathway 3 ), there is assumed to be a small increase in survival benefit (i.e. $<2-3 \%$ ), which was described in this way in the PtDA.

Consensus on the information on the side effects was reached by adding only qualitative labels to indicate an estimate of the prevalence and severity of potential side effects. There was agreement that no estimates on frequency or severity of the expected side effects could be given, since there is a large variation in experienced side effects between patients and no adequate data were available to predict this outcome for any individua patient. For long-term side effects, a distinction was made between common side effects (fibrosis and change in breast shape, edema, and pain) and rare side effects ((dark) skin discoloration, rib complications, heart problems, and lung problems). The severity of the side effects was qualified as varying between patients, between almost no discomfort to very annoying. Smoking was added as an important risk factor for heart problems and secondary lung cancer after breast irradiation. Also, more information was added regarding the consequences of the different side effects.

For the thinking aloud sessions in round 3, new pictorial charts were made. For pathway 2, pictographs with point estimates were made (Figure 4). For the other three pathways, there was a preference for the pictographs with fading colors. Ultimately a choice was made for orange and purple icons. The textual explanation was placed on the virtual "back" of the pictographs. They were visualized when patients clicked on the pictographs (Figure 5a and 5b). It was proposed to add more possible treatment options for the side effects to the PtDA, such as physiotherapy.

Figure 4. Pictograph without uncertainty range before round 3: 10-year local recurrence risk for low-risk breast cancer after breast-conserving surgery with and without radiotherapy, with the BRASA logo pictographs replaced.
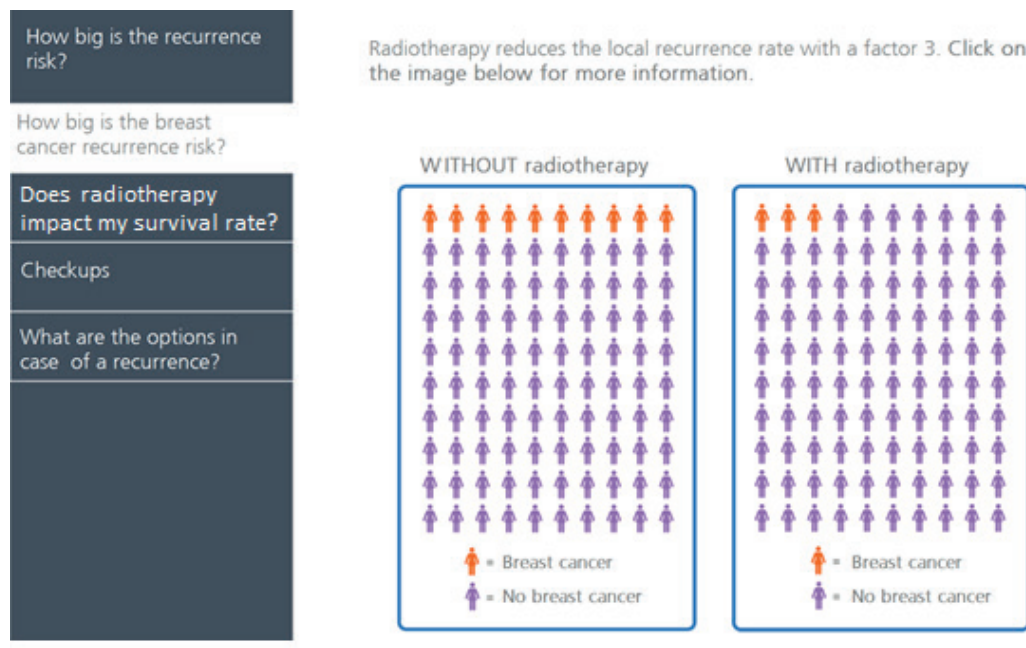

Figure 5a. Turning pictograph with fading colors: 10 -year local recurrence risk for intermediateisk breast cancer after mastectomy with and without radiotherapy.

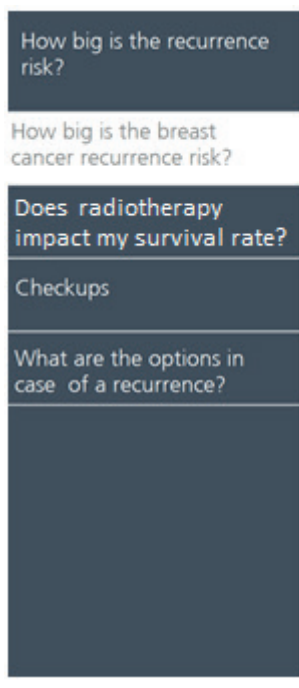

Radiotherapy reduces the local recurrence rate with a factor 3 . Click on
the image below for more information

without radiotherapy

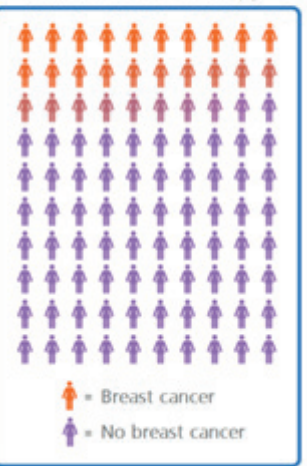

WITH radiotherapy

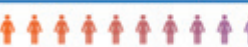

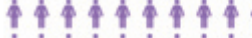

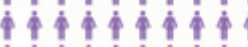

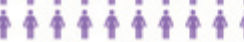

$\$+\uparrow+\uparrow \uparrow \uparrow+\$$

$\$+\$+\$+\$+1+$

14tat

$141+19$

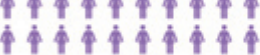

- Breast cancer 
Figure 5b. Reverse side of pictograph with textual explanation: 10-year local recurrence risk for intermediate-risk breast cancer after mastectomy with and without radiotherapy.

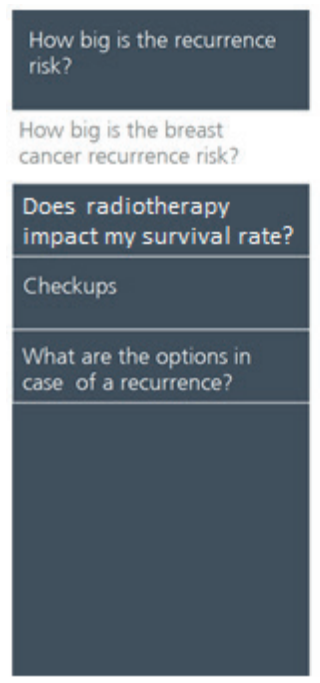

Radiotherapy reduces the local recurrence rate with a factor 3 . Click on

\begin{tabular}{|l|} 
WITHOUT radiotherapy \\
\begin{tabular}{|l|} 
Of the woman treated \\
WHITHOUT radiotherapy \\
$10-30$ out of 100 woman \\
will have a local \\
recurrence after 10 \\
years. In the consultation \\
with your clinician \\
he/she will tell you if \\
your personal chances of \\
a local recurrence is \\
closer to 10 out of 100 \\
or closer to 30 out of \\
100 woman. \\
\hline
\end{tabular} \\
\hline
\end{tabular}

WITH radiotherapy

Of the woman treated

Wut radiotherapy 310

have a local recurrence

after 10 years. In the

consultation with your

clinician he/she will tel

chances of a local

recurrence is closer to 3

out of 100 woman or

closer to 10 out of 100

Figure 6. Pictograph with uncertainty margins, final version of PtDA: 10-year local recurrence risk for intermediate-risk breast cancer after mastectomy with and without radiotherapy.

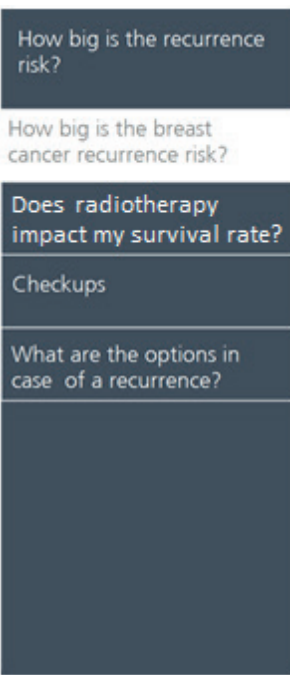

In the second live meeting in round 4, the fading coloring indicating the uncertainty margin of the female icons was found to be unclear since the contrast was lost because of the fading scheme. It was proposed to adjust the fading coloring into changing the color of the icons step by step from orange to purple (Figure 6), leading to the final version of the pictograph for the PtDA.

\section{Discussion}

In the development of a PtDA for breast cancer patients deciding on adjuvant RT, we created a method of communicating epistemic uncertainties when estimating LRR. Consensus was reached between HPs and patients on a pictograph illustrating the whole range of uncertainty, in combination with a textual explanation and the information that their own physician would estimate a more exact risk for the individual patient. The final pictograph consisted of 100 female icons in a $10 \times 10$ array. The female icons indicating the uncertainty margin of the LRR were displayed as step-by-step decoloring icons, from orange to purple (Figure 6). The absent or small gain in survival benefit of RT was communicated verbally without a quantitative indicator. Due to lack of reliable evidence, the prevalence and severity of potential side effects were only expressed using qualitative labels.

We used pictographs, which are known to improve patients understanding in risk communication (15,33-36). Textual risk communication is better understood in combination with visual support (13). The guideline on risk communication for PtDAs, developed by the PDAS collaboration, advises to use natural frequencies and clear denominators over time and to be consistent, using the same denominator in all examples (34). The first online version of the decision aid was therefore consistent with the known literature.

In three of the four pathways, no consensus was reached on an absolute value of a point-estimate for the LRR. Consequently, we had to develop a way of communicating the epistemic uncertainty. Although some effort has been put in researching how to communicate aleatory uncertainty, less research has been done on how to communicate epistemic uncertainty $(22,23,34,37,38)$. Communicating epistemic uncertainty may lead to more cancer worries and may reduce trust, although available literature is inconsistent on this point $(37,39)$. Communicating epistemic uncertainty in a way that will not have a negative impact therefore seems important. We are not aware of other examples of PtDAs communicating epistemic uncertainty in a visual way. In our study, consensus was reached on two-tone icons, showing the whole width of epistemic uncertainty, in combination with a textual explanation, and with the explanation that their own physician would inform them further. Whether this is an effective method of communicating epistemic uncertainty in a PtDA needs further investigation in a clinical setting. At this moment, this way of communicating epistemic uncertainty is being used in a pre-and post-intervention study, the BRASA-study (clinical.trials.gov: NCT03375801). In this study, we ask patients to fill out questionnaires to test their knowledge on their disease, to evaluate the PtDA, and the process of shared decision-making. 
As discussed earlier, qualitative risk labels are well understood by patients but have the disadvantage of being interpreted in different ways (15). No clear data are available on the prevalence and severity of side effects of current RT for breast cancer patients. There is variation in the definition endpoint of side effects, and different studies use different parameters to measure the same outcome. For example, to measure change in shape due to fibrosis as a consequence of radiotherapy, cosmetic outcome has been evaluated in several trials. Some studies use patient-reported outcome measures, whereas others use scoring systems scored by physicians or even computer systems evaluating photographs $(16,40)$. Low agreement has been found between these different methods $(41,42)$. Consequently, we could not include reliable estimates for side effects in the PtDA, not even using uncertainty margins. Although we were aware of the shortcomings of communicating risks through qualitative labels, we felt we had no other option and consensus was reached on using qualitative labels when communicating both the frequency as well as the severity of the possible side effects. Further research is needed to overcome this problem. With modern RT techniques, RT doses to the heart and lungs have been reduced, reducing long-term side effects such as heart disease and lung cancer. For patients who smoke, these risks are substantially higher than for non-smokers (20). Since in this smoker- group the disadvantages might therefore outweigh the advantages, this was mentioned separately.

\section{Strengths and limitations}

We were only able to include four patient advocates in the development team who were mostly highly educated. Patient advocates are trained patients (43) and from literature we know that both patients and HPs involved in the development of a PtDA have a learning curve. Patient advocates are in a different situation than patients looking at the PtDA for the first time when making a decision on their treatment (44). Despite this shortcoming, the patient advocates took an active part in the development team.

\section{Conclusion}

We incorporated pictographs with stepwise gradient color icons indicating the uncertainty margin, in combination with text, to communicate epistemic uncertainty in a PtDA for breast cancer patients deciding on radiotherapy. The prevalence and severity of possible side effects were communicated through qualitative labels. Currently, this PtDA is bein tested in a multi-center pre-and post-implementation study in the Netherlands, the BRASA study.

\section{References:}

1. O'Connor AM, Legare F, Stacey D. Risk communication in practice: the contribution of decision aids. BMJ (Clinical research ed). 2003;327(7417):736-40

2. Coulter A, Collins A. Making shared decision-making a reality: no decision about me, without me: King's Fund; 2011.

3. Mulley AG, Trimble C, Elwyn G. Stop the silent misdiagnosis: patients' preferences matter. BM (Clinical research ed). 2012;345:e6572.

4. Bagenal J, Roche N, Ross G, Kirby A, Dodwell D. Should patients with ductal carcinoma in sit be treated with adjuvant whole breast radiotherapy after breast conservation surgery? BM. (Clinical research ed). 2018:361:k1410.

5. Recht A, Comen EA, Fine RE, Fleming GF, Hardenbergh PH, Ho AY, et al. Postmastectomy Radiotherapy: An American Society of Clinical Oncology, American Society for Radiation Oncology, and Society of Surgical Oncology Focused Guideline Update. Pract Radiat Oncol. 2016;6(6):e219-e34.

6. Darby S, McGale P, Correa C, Taylor C, Arriagada R, Clarke M, et al. Effect of radiotherapy after breast-conserving surgery on 10-year recurrence and 15-year breast cancer death: metaanalysis of individual patient data for 10,801 women in 17 randomised trials. Lancet (London, England). 2011;378(9804):1707-16.

7. Poortmans PMP, Arenas M, Livi L. Over-irradiation. Breast (Edinburgh, Scotland). 2017:31:295302.

8. Speers C, Pierce LJ. Postoperative Radiotherapy After Breast-Conserving Surgery for Early-Stage Breast Cancer: A Review. JAMA oncology. 2016;2(8):1075-82.

9. Bartelink H, Maingon P, Poortmans P, Weltens C, Fourquet A, Jager J, et al. Whole-breast irradiation with or without a boost for patients treated with breast-conserving surgery for early breast cancer: 20-year follow-up of a randomised phase 3 trial. The Lancet Oncology. 2015;16(1):47-56.

10. Han PK, Klein WM, Arora NK. Varieties of uncertainty in health care: a conceptual taxonomy Medical decision making : an international journal of the Society for Medical Decision Making. 2011;31(6):828-38.

11. Harrison M, Rigby D, Vass C, Flynn T, Louviere J, Payne K. Risk as an attribute in discrete choice experiments: a systematic review of the literature. The patient. 2014;7(2):151-70.

12. Engelhardt EG, Pieterse AH, Han PK, van Duijn-Bakker N, Cluitmans F, Maartense E, et al. Disclosing the Uncertainty Associated with Prognostic Estimates in Breast Cancer. Medical decision making : an international journal of the Society for Medical Decision Making. 2017;37(3):179-92.

13. Klein KA, Watson L, Ash JS, Eden KB. Evaluation of risk communication in a mammography patient decision aid. Patient education and counseling. 2016;99(7):1240-8.

14. Lipkus IM, Klein WM, Rimer BK. Communicating breast cancer risks to women using differen formats. Cancer epidemiology, biomarkers \& prevention : a publication of the American Association for Cancer Research, cosponsored by the American Society of Preventive Oncology. 2001;10(8):895-8.

15. Freeman ALJ. How to communicate evidence to patients. Drug and therapeutics bulletin 2019;57(8):119-24 
16. Brouwers PJ, van Werkhoven E, Bartelink H, Fourquet A, Lemanski C, van Loon J, et al. Factors associated with patient-reported cosmetic outcome in the Young Boost Breast Trial. Radiotherapy and oncology : journal of the European Society for Therapeutic Radiology and Oncology. 2016.

17. Meattini I, Guenzi M, Fozza A, Vidali C, Rovea P, Meacci F, et al. Overview on cardiac, pulmonary and cutaneous toxicity in patients treated with adjuvant radiotherapy for breast cancer. Breast cancer (Tokyo, Japan). 2017;24(1):52-62.

18. Jassem J. Post-mastectomy radiation therapy after breast reconstruction: Indications, timing and results. Breast (Edinburgh, Scotland). 2017;34 Suppl 1:S95-s8.

19. Bartelink $\mathrm{H}$. The changing landscape in radiotherapy for breast cancer: Lessons from long term follow-up in some European breast cancer trials. Radiotherapy and oncology : journal of the European Society for Therapeutic Radiology and Oncology. 2016;121(3):348-56.

20. Taylor C, Correa C, Duane FK, Aznar MC, Anderson SJ, Bergh J, et al. Estimating the Risks of Breast Cancer Radiotherapy: Evidence From Modern Radiation Doses to the Lungs and Heart and From Previous Randomized Trials. Journal of clinical oncology : official journal of the American Society of Clinical Oncology. 2017;35(15):1641-9.

21. Stacey D, Legare F, Lewis K, Barry MJ, Bennett CL, Eden KB, et al. Decision aids for people facing health treatment or screening decisions. The Cochrane database of systematic reviews. 2017;4:Cd001431.

22. Harrison M, Han PKJ, Rabin B, Bell M, Kay H, Spooner L, et al. Communicating uncertainty in cancer prognosis: A review of web-based prognostic tools. Patient education and counseling. 2019;102(5):842-9.

23. Bansback N, Bell M, Spooner L, Pompeo A, Han PKJ, Harrison M. Communicating Uncertaint in Benefits and Harms: A Review of Patient Decision Support Interventions. The patient. 2017;10(3):311-9.

24. Bansback N, Harrison M, Marra C. Does Introducing Imprecision around Probabilities for Benefit and Harm Influence the Way People Value Treatments? Medical decision making : an international journal of the Society for Medical Decision Making. 2016;36(4):490-502.

25. Nicholas Z, Butow P, Tesson S, Boyle F. A systematic review of decision aids for patients making a decision about treatment for early breast cancer. Breast (Edinburgh, Scotland). 2016;26:31-45.

26. Wong J, D'Alimonte L, Angus J, Paszat L, Metcalfe K, Whelan T, et al. Development of patients' decision aid for older women with stage I breast cancer considering radiotherapy after lumpectomy. International journal of radiation oncology, biology, physics. 2012;84(1):30-8.

27. Whelan T, Levine M, Gafni A, Lukka H, Mohide E, Patel M, et al. Breast irradiation postlumpectomy: development and evaluation of a decision instrument. Journal of Clinical Oncology. 1995;13(4):847-53.

28. Elwyn G, O'Connor A, Stacey D, Volk R, Edwards A, Coulter A, et al. Developing a quality criteria framework for patient decision aids: online international Delphi consensus process. BMJ (Clinical research ed). 2006;333(7565):417.

29. Joseph-Williams N, Newcombe R, Politi M, Durand MA, Sivell S, Stacey D, et al. Toward Minimum Standards for Certifying Patient Decision Aids: A Modified Delphi Consensus Process. Medical decision making : an international journal of the Society for Medical Decision Making. 2014;34(6):699-710.

30. Coulter A, Stilwell D, Kryworuchko J, Mullen PD, Ng CJ, van der Weijden T. A systematic development process for patient decision aids. BMC medical informatics and decision making. 2013;13 Suppl 2:S2
31. Raphael DB, Ter Stege JA, Russell NS, Boersma LJ, van der Weijden T. What do patients and health care professionals view as important attributes in radiotherapy decisions? Input for a breast cancer patient decision aid. Breast (Edinburgh, Scotland). 2020;49:149-56.

32. Fonteyn ME, Kuipers B, Grobe SJJQhr. A description of think aloud method and protocol analysis. 1993;3(4):430-41.

33. Kasper J, van de Roemer A, Pottgen J, Rahn A, Backhus I, Bay Y, et al. A new graphical format to communicate treatment effects to patients-A web-based randomized controlled trial. Health expectations : an international journal of public participation in health care and health policy. 2017;20(4):797-804.

34. Trevena LJ, Zikmund-Fisher BJ, Edwards A, Gaissmaier W, Galesic M, Han PK, et al. Presenting quantitative information about decision outcomes: a risk communication primer for patient decision aid developers. BMC medical informatics and decision making. 2013;13 Suppl 2:S7.

35. Zikmund-Fisher BJ, Ubel PA, Smith DM, Derry HA, McClure JB, Stark A, et al. Communicatin side effect risks in a tamoxifen prophylaxis decision aid: the debiasing influence of pictographs. Patient education and counseling. 2008;73(2):209-14

36. Franklin L, Plaisant C, Shneiderman B. An information-centric framework for designing patientcentered medical decision aids and risk communication. AMIA Annual Symposium proceedings AMIA Symposium. 2013;2013:456-65.

37. Han PKJ, Babrow A, Hillen MA, Gulbrandsen P, Smets EM, Ofstad EH. Uncertainty in health care: Towards a more systematic program of research. Patient education and counseling. 2019.

38. Fagerlin A, Zikmund-Fisher BJ, Ubel PA. Helping patients decide: ten steps to better risk communication. Journal of the National Cancer Institute. 2011;103(19):1436-43.

39. Han PK, Klein WM, Killam B, Lehman T, Massett H, Freedman AN. Representing randomness in the communication of individualized cancer risk estimates: effects on cancer risk perceptions, worry, and subjective uncertainty about risk. Patient education and counseling. 2012;86(1):10613.

40. Haviland JS, Hopwood P, Mills J, Sydenham M, Bliss JM, Yarnold JR. Do Patient-reported Outcome Measures Agree with Clinical and Photographic Assessments of Normal Tissue Effects after Breast Radiotherapy? The Experience of the Standardisation of Breast Radiotherapy (START) Trials in Early Breast Cancer. Clinical oncology (Royal College of Radiologists (Great Britain)). 2016;28(6):345-53.

41. Elwyn G, Frosch D, Thomson R, Joseph-Williams N, Lloyd A, Kinnersley P, et al. Shared decision making: a model for clinical practice. Journal of general internal medicine. 2012;27(10):1361-7.

42. Brouwers PJ, van Werkhoven E, Bartelink H, Fourquet A, Lemanski C, van Loon J, et al. Factors associated with patient-reported cosmetic outcome in the Young Boost Breast Trial. Radiotherapy and oncology : journal of the European Society for Therapeutic Radiology and Oncology. 2016;120(1):107-13.

43. [05-08-2019]. Available from: https://borstkanker.nl/nl/patient-advocates.

44. Hoddinott P, Pollock A, O'Cathain A, Boyer I, Taylor J, MacDonald C, et al. How to incorporate patient and public perspectives into the design and conduct of research. F1000Research. 2018;7:752. 


\section{Implementing a patient decision aid, a process evaluation of a large- scale pre-and post- inplementation trial}

Danielas Raphael Nicolakn suell Erikvan Werknoven Marcelle $\operatorname{lnmin}$ Paullen Westhoff Marikastenfert kroese Marcelstam Lisette van Maurik Kitty van Gestel Trudy van der Weijden. Hesbeth Boersma

Breast Cancer Research an d Treatment 2020 online a head of pulilication. 


\section{Abstract}

Purpose: Patient decision aids (PtDAs) have been reported to have a positive influence on patients making a health care decision in trials. Nevertheless, post-trial implementation is poor. The aim of this study is to explore patient, clinician, and organizational success factors for implementing a PtDA designed for breast cancer patients who face a decision on their radiation treatment.

Methods: We performed a process evaluation within a multicenter pre- and postimplementation trial. The PtDA was incorporated as much as possible into the logistics of 13 participating centers. Tracking data were collected on PtDA use. Process characteristics were recorded by both clinicians and patients. A logistic regression method was applied to investigate which process characteristics were significantly related to the probability that patients logged in to the PtDA.

Results: 189 patients received the PtDA, of whom 140 (77\%) used the PtDA. When patients received the link via the surgery department, they were more likely to use the PtDA (OR 9.77 (1.28-74.51)) compared to patients that received the link via the radiation oncology department. When the report of the multidisciplinary team stated that radiation treatment "had to be discussed with the patient", patients were more likely to use the PtDA (OR 2.29 (1.12-4.71)). Educational level was not related to the probability of PtDA use.

Conclusions: We accomplished a high level of PtDA use. Patients were more likely to use the PtDA when they received the link via the surgery department and when "to be discussed with the patient" was written in the multidisciplinary team report.

\section{Introduction}

Patient decision aids (PtDA) are known to support the process of shared decisionmaking (SDM) (1-4). In a review of 105 randomized clinical trials, Stacey et al. found that PtDAs improve the quality of the decision-making process, reduce decisional conflict, and improve patient-clinician communication, without causing any harm (5, 6). Despite these positive effects in clinical trials, PtDAs facilitating SDM have not been widely implemented in medical practice $(7,8)$. Stacey et al. found a low uptake of PtDAs after trials, with only $21 \%$ of PtDAs being implemented, and another $7 \%$ being part of implementation studies (9).

While research on SDM and the effectiveness of PtDAs has grown rapidly over the last years (10), research on the implementation of PtDAs in oncology care lags behind (11). A lot of effort has been made to explore patient, clinician, and organization-related factors that determine the level of uptake of PtDAs but no hard conclusions can be drawn yet (7) A frequently mentioned barrier is clinician attitude toward the use of PtDAs and SDM e.g., clinicians are less likely to use the PtDA when they lack confidence in the content of the PtDA or when they believe that the PtDA does not fit their patient population (7, 12). In addition, clinicians often feel that referring to a PtDA and using the PtDA during consultation will be too time consuming $(7,13-15)$. Standardized referral to PtDAs prior to the decision-making consultation has therefore been identified as a facilitator for PtDA use (7). A review by Elwyn et al. on the implementation of PtDAs identified organizational barriers: the PtDA not fitting into the workflow of the clinic and lack of leadership migh hinder implementation $(7,9)$. This was also found in a review by Scholl et al. who reviewed organizational characteristics as barriers for the implementation of shared decisionmaking (8). They pointed out the importance of taking characteristics of healthcare facilities into account to achieve practice changes. A comparative trial in prostate cancer patients also showed large differences in PtDA uptake with different approaches of PtDA dissemination (16).

We developed an online PtDA for breast cancer patients facing a decision in their radiation treatment (RT) (17). RT after surgery lowers local recurrence rate, but in certain groups of patients, this does not clearly translate into an improved survival rate (18-20). The tradeoff between RT accompanied with a lower local recurrence rate versus the possible side effects, RT is therefore a preference-sensitive decision (21).

We performed a multi-center pre- and post-implementation study with a pragmatic approach, adapting the implementation strategy to the logistics of the different centers (BRASA-study). The aim of the current paper is to report on the process evaluation of this study, by describing the level of uptake of the PtDA, and by analyzing whether we can identify patient, clinician, and organizational factors that are related to an increased level of uptake of the PtDA. The effects of the intervention on patient outcomes such as decision conflict will be described separately. 


\section{Methods}

We performed a process evaluation of the introduction of a PtDA within the BRASAstudy (NCT03375801), a multi-center pre- and post-implementation trial, in which the intervention was the use of a PtDA. This trial has a pragmatic design to test the uptake and the effect of a PtDA $(17,21)$ in a setting conformed to normal clinical practice $(22-24)$.

Participants

All 19 radiation oncology centers in the Netherlands were invited to participate in the study. One breast cancer radiation oncologist per center was invited through personal contact by e-mail.

Patients were recruited between October 2018 and July 2019. Eligibility criteria for study participation were female breast cancer patients of 18 years or older, with the ability to comprehend Dutch to understand the content of the PtDA and to give informed consent. The PtDA was developed for four subgroups with a preference-sensitive indication of RT: DCIS group, low-risk breast cancer group, thoracic wall irradiation group and boost/noboost group (table 1). The multidisciplinary team (MDT) of the participating hospitals or the treating clinician determined whether the RT indication had to be discussed with the patient, and thus whether the patient was eligible for participating in the BRASA-study.

Table 1. The four subgroups for whom the PtDA was developed.

Patients with low-risk ductal carcinoma in situ (DCIS) after breast-conserving surgery deciding on whole/partial-breast RT or no RT (DCIS group).

Patients with low-risk invasive ductal carcinoma after breast-conserving surgery deciding on whole/partial-breast RT or no RT (low-risk breast cancer group)

Patients with intermediate-risk breast cancer after mastectomy deciding on thoracic wall RT or no RT (thoracic wall irradiation group).

Patients with intermediate-risk breast cancer after breast-conserving surgery deciding on whole breast RT with or without an extra boost dose to the tumor bed (boost/no-boost group).

\section{Intervention}

Patient decision aid (PtDA)

The PtDA is an online tool, only available in Dutch on www.beslissamen.nl, for decisionmaking on breast cancer RT. The PtDA was developed according to the international criteria for PtDA development (IPDAS criteria (3)), as described earlier (17). The PtDA starts with general information on SDM and an explanation on the PtDA use. The PtDA makes clear that there is a preference-sensitive decision to be made. Subsequently, general information is given on DCIS or breast cancer with links to the website of the national breast cancer association for more information. In addition, general information on the working mechanism and practical aspects of RT is given by written text and by a short animation film. The information of the rest of the PtDA is personalized for the four different sub-groups as mentioned in table 1 , such as information on possible side effects, recurrence rates, and possible survival benefit. We applied textual and graphic risk communication strategies, such as percentages, numeral frequencies, and population diagrams, in combination with clarification of uncertainties in text (17). The PtDA also includes a section where patients are supported in constructing their treatment preferences and involvement in the SDM process. It is possible for patients to print an overview of their preferences to bring to the consultation with their clinician. Patients can use the PtDA at home at their own pace. The PtDA was reviewed by Vromans et al. and scored 83 points out of $100(25)$.

Strategies to implement the PtDA

We developed so-called "recipe cards" to enable the clinician to refer patients to the website with a login code. On these recipe cards, patients could also see which pathway they had to follow, according to their medical situation (Figure 1). The trial logistics and PtDA use was adapted to the specific logistics and organizational preferences of each participating site. Three different moments in the care path could be distinguished to distribute the "recipe cards" in the participating centers (Figure 2).

\section{Via the surgery department}

1. Eligible patients were identified in the postoperative multidisciplinary team meeting (MDT), and eligibility was captured in the MDT report. Patients received the recipe card via the surgery department at the postoperative consultation. They referred the patient to the radiation oncologist to discuss RT and gave information about the PtDA and the trial. Patients could use the PtDA at home, prior to their consultation at the RT department.

Via the radiation oncology department

2. Eligible patients were identified in the postoperative MDT and eligibility was captured in the MDT report. Trial managers from the RT department sent information about the PtDA and the trial to the patient through regular post, together with the recipe card. Patients could use the PtDA at home, prior to their consultation at the RT department.

3. Eligible patients were informed about the study once they visited the RT department. Patients received the recipe card from the clinician in the RT department during the consultation. They could use the PtDA during consultation and/or after the consultation at home. If necessary, a second consultation was planned.

Individual caregivers could freely choose to adapt their trial logistics for individual patients. For example, if participating centers used option 1 or 2 , but patients accidentally did not receive the recipe card prior the consultation with the RT, they could follow option 3 , allowing the radiation oncologist to include eligible patients anyway. In most centers, more than one of the three above-mentioned logistic options were used. Since option 2 was not foreseen when the patient questionnaire was developed, regular post was not 
included in the answer-options on the question "From whom they had received the PtDA link". Consequently, we only analyzed differences between two strategies: link received via the surgical or the RT department.

Figure 1. Front and backside of the recipe card.

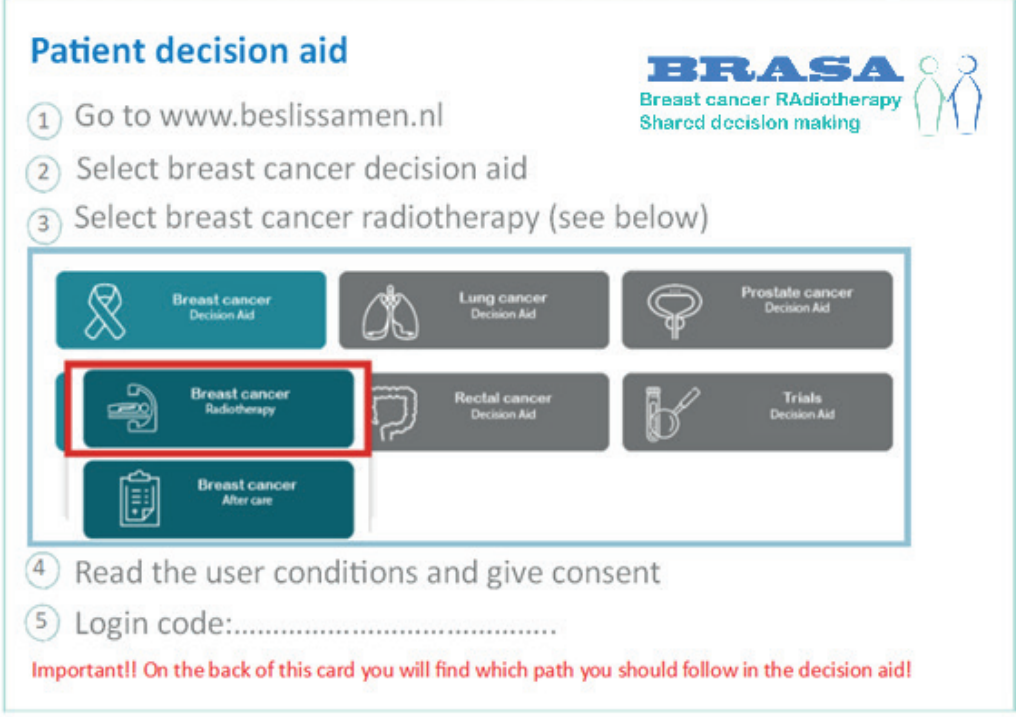

In the decision aid you will be asked to choose 1 out of these 4 paths. Choose the figure that is marked by your clinician.

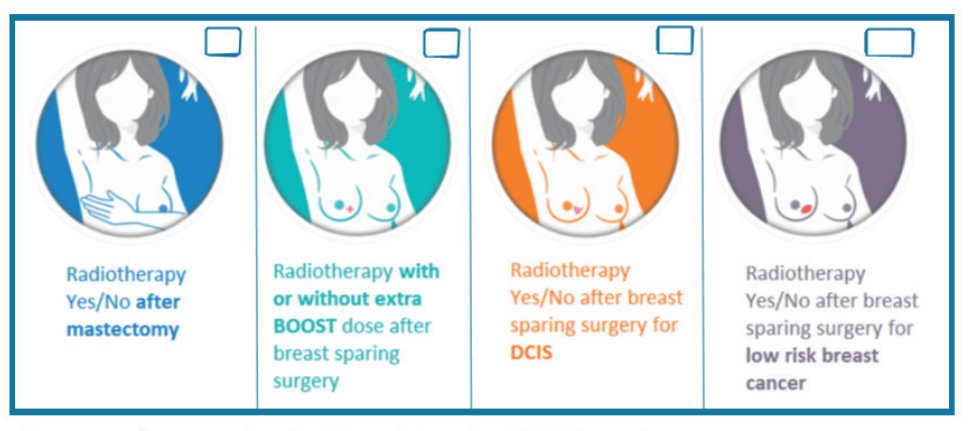

For questions on the decision aid or the BRASA-study:

$\triangle$ brasa@nki.nl C020xxxxxxxx
Figure 2. Possible moments in care path to hand over the recipe card to the patient.

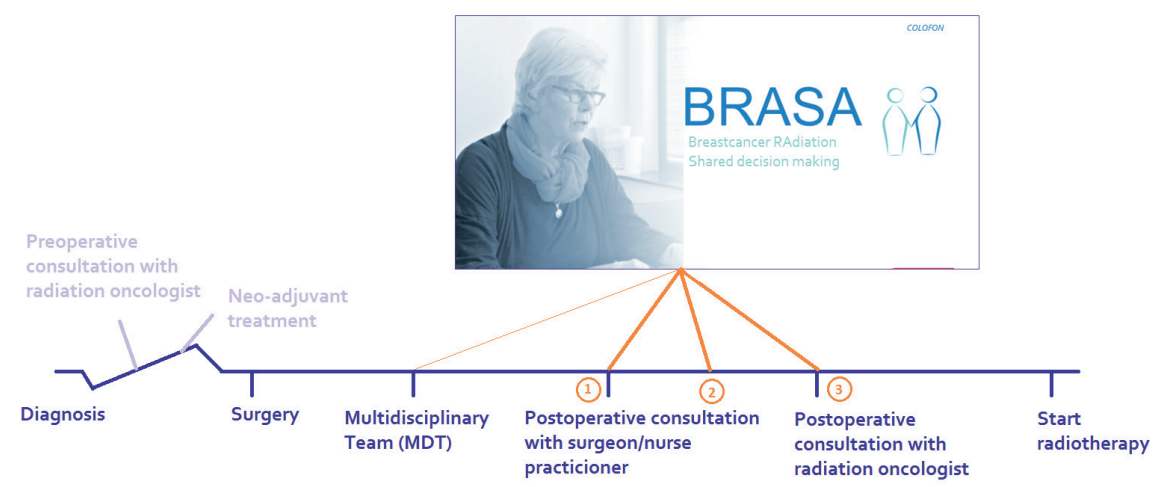

1: Patients received the recipe card via the surgery department at the postoperative consultation; 2: patients received the recipe card via the radiation oncology department via regular post; 3 : patients received the recipe card via the radiation oncology department during the postoperative consultation.

\section{Data collection}

We collected data from three sources (table 2):

1. Tracking data: Clinicians in the participating hospitals recorded the login code of the recipe cards given to the patient on the case report form (CRF). When patients logged in to the website, this was automatically registered.

2. Patient questionnaires: Patients were asked to fill in a questionnaire after the consultation in which the decision was made. In this questionnaire, we asked from whom and when the patient had received the recipe card, if they had used the PtDA, and if they had used the PtDA, if they perceived it as being useful. In addition, we asked some general questions, e.g., on educational level, as defined by the SOI 2016 classification (26).

3. The including clinician filled out a standardized consultation registration form, part of the CRF. The CRF included questions on birth date, disease and treatment characteristics, consultation length, and whether there was a note in the multi-disciplinary team report stating that RT had to be discussed with the patient. 
Table 2. Overview of the different data to be collected.

\begin{tabular}{|c|c|}
\hline 1.Log data & $\begin{array}{l}\text { Log data was automatically tracked when patients logged in to the } \\
\text { PtDA }\end{array}$ \\
\hline \multirow[t]{2}{*}{$\begin{array}{l}\text { 2.Case report form } \\
\text { to be filled in by } \\
\text { radiation oncologist }\end{array}$} & $\begin{array}{l}\text { Did the multidisciplinary board register "to discuss RT with the } \\
\text { patient" in the multi-disciplinary team report? } \\
\text { o No } \\
\text { o Yes } \\
\text { o There is no report of the multidisciplinary team meeting }\end{array}$ \\
\hline & Can you indicate the consultation length? ...... min. \\
\hline \multirow[t]{3}{*}{$\begin{array}{l}\text { 3.Patient } \\
\text { questionnaire }\end{array}$} & $\begin{array}{l}\text { From whom did you receive the link to the decision aid? } \\
\text { o Surgeon } \\
\text { o Nurse/Nurse practitioner at surgery department } \\
\text { o Radiation oncologist } \\
\text { o Nurse/physician assistant at radiation oncology department } \\
\text { o Other, please specify: ... }\end{array}$ \\
\hline & $\begin{array}{l}\text { Did you consider the decision aid to be useful/did it help in the } \\
\text { decision-making process? } \\
\text { o Yes } \\
\text { o Partly } \\
\text { o No }\end{array}$ \\
\hline & $\begin{array}{l}\text { What is your highest education level? } \\
\text { o Primary school } \\
\text { o Lower secondary education } \\
\text { o Preparatory vocational education } \\
\text { o Vocational education } \\
\text { o Senior general secondary education } \\
\text { o Pre-university education } \\
\text { o Higher professional education } \\
\text { o University }\end{array}$ \\
\hline
\end{tabular}

\section{Data analysis}

Tracking data was used as a binary outcome. When patients logged in to the PtDA, this was automatically registered. Patients were coded to have logged in to the PtDA if any login session was registered, independent of the length and the number of times patients logged in. Patients were coded as not having logged-in to the PtDA if the login code was known but no login session was registered by the system. Patients were coded as missing when their login code was unknown.

Descriptive statistics were used to describe patient characteristics and information from the patient questionnaires. The question from whom they had received the link to the PtDA was recoded to three categories: 1) When patients had received the link from the surgeon or the nurse practitioner, this was coded as having received the link from the surgery department; 2) Patients who received the link from the radiation oncologist or the physician assistant were coded as having received the link from the radiation department 3) The third category was the option "other". Educational level was recoded to low, middle and high as defined by the SOI 2016 classification (26).

Descriptive statistics were used to describe the distribution of patients between the four indications for RT and whether it was indicated in the MDT report that RT "had do be discussed with the patient".

Univariable logistic regression was used to compare patients who had and had not logged in to the PtDA. The independent variables tested included: from whom patients received the PtDA link, educational level, whether SDM was indicated in the MDT report, and the indication for RT. We were not able to run a multivariable analysis due to the limited sample size of the categories.

\section{Results}

Fourteen of the nineteen RT centers in the Netherlands agreed to participate in the trial of whom thirteen centers included patients. Patient inclusion started as soon as the trial was approved in each individual center, resulting in a spread in first inclusion per center (Figure 3). There was also a spread for breast cancer patients treated per center, varying between around 1100 new patients per year in the largest center and around 200 patients in the smaller centers. Seventy-eight different clinicians included 189 patients. 185 patients filled in their questionnaire, and of 188 patients a case report form was filled out by their radiation oncologist. For eight patients, the login code was unknown, so that tracking of their PtDA use was not possible. Full data were available for 181 patients.

Number of inclusions per participating centers. Each bar represents one of the participating centers. Participating centers are ordered by starting date of first inclusion.

\section{Patient characteristics}

The mean age was 60.4 years (SD 11.3), 40\% of the patients were highly educated. The low-risk DCIS group was the largest group (33\%), followed by the low-risk invasive breast cancer group (31\%) and the boost/no-boost group (25\%). Fewer patients deciding on thoracic wall RT were included (11\%) (table 3). Patients in the low-risk breast cancer group were the oldest group (mean 67.3, SD 9.1), whereas the boost/no-boost group patients were the youngest (mean 54.7, SD 11.1) 


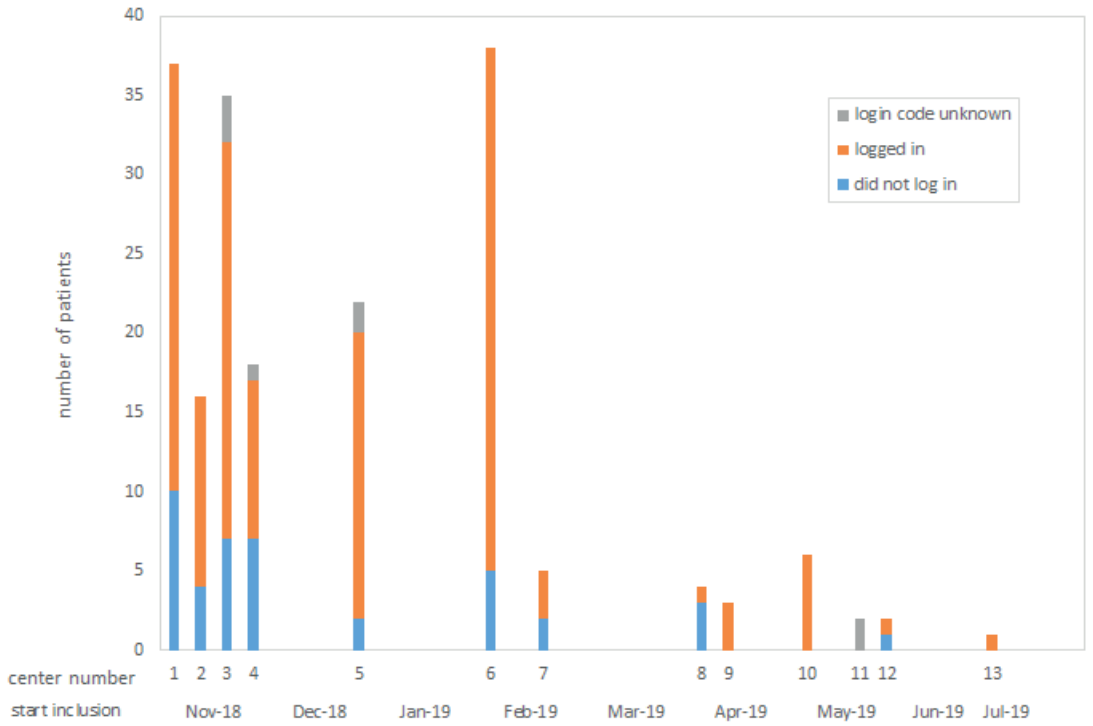

Decision aid use and process characteristics

From the tracking data, we found that 140 (77\%) patients logged in to the PtDA, whereas 41 patients did not login to the PtDA. 158 patients reported to have used the PtDA, of which 136 were traced by the tracking data (table 4). Of the patients who used the PtDA, $88 \%$ perceived the PtDA as being (partly) useful. In 114 patients (65\%), eligibility had been captured in the MDT report (table 5). In the univariable analyses, we found that when the surgery department provided the link to the patient, patients were more likely to log in to the PtDA, OR 9.77 (95\% $\mathrm{Cl} 1.28-74.51)$. In addition, when a remark in the MDT report on the indication for SDM was found, patients were more likely to login to the PtDA, OR 2.29 $(95 \% \mathrm{Cl} 1.12-4.71)$. There was no difference in login frequency between the four different sub-groups/indication for RT. Educational level did not differ between patients who did and did not login to the PtDA. There was no difference in consultation length between patients who logged in to the PtDA and those who did not (mean 41.9 min (SD 13.0) versus $40.5 \mathrm{~min}$ (SD 11.8).
Table 3. Patient characteristics of all 189 included patients.

\begin{tabular}{llc}
\hline & & Mean (SD) \\
\hline Age in years & & $60.4(11.3)$ \\
\hline Consultation length in minutes & $41.7(13.5)$ \\
\hline & & Total N=189 \\
\hline & & $\mathrm{N}(\%)$ \\
\hline Received patient decision & Surgery department & $33(19 \%)$ \\
aid via: & Radiation oncology department & $135(76 \%)$ \\
& Other & $10(6 \%)$ \\
& Missing & 11 \\
\hline Educational level & Low & $50(27 \%)$ \\
& Middle & $59(32 \%)$ \\
& High & $73(40 \%)$ \\
& Missing & 7 \\
\hline SDM indicated in & Yes & $120(66 \%)$ \\
multidisciplinary team report & No & $62(34 \%)$ \\
& Missing & 7 \\
\hline Indication for radiation & DCIS & $62(33 \%)$ \\
treatment & Low-risk breast cancer & $58(31 \%)$ \\
& Boost/no-boost & $47(25 \%)$ \\
& Thoracic wall irradiation & $21(11 \%)$ \\
& Missing & 1 \\
\hline & & $\mathrm{N}=140$ \\
\hline & & $55(40 \%)$ \\
\hline & Yes & $64(47 \%)$ \\
being useful & $17(13 \%)$ \\
& Partly & 4 \\
\hline & No & \\
\hline
\end{tabular}

Table 4. Overview of tracking data and patients answer on the questionnaire on PtDA use.

\begin{tabular}{|c|c|c|c|c|c|}
\hline & \multicolumn{3}{|c|}{ Tracking data } & \multirow[t]{2}{*}{ Tota } \\
\hline & & Logged in & Did not log in & Missing & \\
\hline \multirow{3}{*}{$\begin{array}{l}\text { Patient } \\
\text { questionnaire }\end{array}$} & Used PtDA & 136 & 16 & 6 & 158 \\
\hline & Did not use PtDA & 2 & 22 & 2 & 26 \\
\hline & Missing & 2 & 3 & 0 & 5 \\
\hline Total & & 140 & 41 & 8 & 189 \\
\hline
\end{tabular}


Table 5. Results of the univariable logistic regression analysis in the 181 patients for whom tracking data were available.

\begin{tabular}{|c|c|c|c|c|c|}
\hline & & Did log-in & $\begin{array}{l}\text { Did not } \\
\text { log-in }\end{array}$ & OR $(95 \% \mathrm{Cl})$ & $\begin{array}{l}\text { Diffe- } \\
\text { rence }\end{array}$ \\
\hline $\mathrm{N}(\%)$ & & 140 (77\%) & $41(23 \%)$ & & \\
\hline Mean age in year & $(S D)$ & $59.5(11.0)$ & $63.4(11.9)$ & $0.97(-0.01-7.90)$ & 3.9 \\
\hline $\begin{array}{l}\text { Consultation leng } \\
\text { (SD) }\end{array}$ & th in minutes & $41.9(13.0)$ & $40.5(11.8)$ & $1.00(-5.98-3.18)$ & -1.4 \\
\hline $\begin{array}{l}\text { Received patient } \\
\text { decision aid via: }\end{array}$ & $\begin{array}{l}\text { Radiation } \\
\text { oncology } \\
\text { Surgery } \\
\text { Other } \\
\text { Missings }\end{array}$ & $\begin{array}{c}98(75 \%) \\
29(97 \%) \\
9(90 \%) \\
4 \\
\end{array}$ & $\begin{array}{c}33(25 \%) \\
1(3 \%) \\
1(10 \%) \\
6 \\
\end{array}$ & $\begin{array}{c}1 \\
9.77(1.28-74.51) \\
3.03(0.37-24.83)\end{array}$ & \\
\hline Educational level & $\begin{array}{l}\text { Low } \\
\text { Middle } \\
\text { High } \\
\text { Missings }\end{array}$ & $\begin{array}{c}34(72 \%) \\
45(79 \%) \\
56(80 \%) \\
5\end{array}$ & $\begin{array}{c}13(28 \%) \\
12(21 \%) \\
14(20 \%) \\
2\end{array}$ & $\begin{array}{c}1 \\
1.43(0.58-3.53) \\
1.52(0.64-3.64)\end{array}$ & \\
\hline $\begin{array}{l}\text { Indicated in } \\
\text { multidisciplinary } \\
\text { team report }\end{array}$ & $\begin{array}{l}\text { No } \\
\text { Yes } \\
\text { Missings }\end{array}$ & $\begin{array}{c}41(67 \%) \\
94(82 \%) \\
5\end{array}$ & $\begin{array}{c}20(33 \%) \\
20(18 \%) \\
1\end{array}$ & $\begin{array}{c}1 \\
2.29(1.12-4.71)\end{array}$ & \\
\hline $\begin{array}{l}\text { Indication } \\
\text { for radiation } \\
\text { treatment }\end{array}$ & $\begin{array}{l}\text { Thoracic wall } \\
\text { RT } \\
\text { DCIS } \\
\text { Low-risk breast } \\
\text { cancer } \\
\text { Boost/no-boost } \\
\text { Missings }\end{array}$ & $\begin{array}{l}47(82 \%) \\
43(75 \%)\end{array}$ & $\begin{array}{l}10(18 \%) \\
14(25 \%)\end{array}$ & $\begin{array}{l}0.52(0.10-2.62) \\
0.34(0.07-1.66) \\
0.25(0.05-1.25)\end{array}$ & \\
\hline
\end{tabular}

\section{Discussion}

The main finding in this pragmatic trial was that we reached a high level of PtDA use: 77\% of the patients (140 out of 181) logged in to the PtDA $(15,27)$. In addition, we found that handing out the link via the surgery department, and a remark in the MDT report, RT is to be discussed with the patient, increased the number of patients logging in to the PtDA.

We think that the high uptake level was reached because we tackled several known barriers during trial initiation. As described in our previous paper (17), the PtDA was developed by the research team, including radiation oncologists, in collaboration with clinicians from different radiotherapy centers in the Netherlands. This may have facilitated confidence in the PtDA by clinicians, which is also supported by the fact that 78 different clinicians included patients. This confidence in the intervention, or feeling of ownership is also stated as important in the Consolidated Framework For Implementation Research (CFIR) where it is described as "commitment, involvement and accountability of leader and managers with the implementation" (28). Furthermore, with the pragmatic trial approach, we tackled many other known barriers mentioned in the CFIR, such as logistics and leadership by adapting the implementation of the PtDA to the logistics of the different centers, it interfered as little as possible with the routine in each center. Leadership was accomplished by having dedicated clinicians as principal investigator in each of the participating centers. In the Netherlands, there is a well-functioning national platform for breast cancer radiotherapy, which has been existing for 20 years. This mono-disciplinary platform includes at least one breast cancer radiation oncologist from every RT center, resulting in strong cohesion. A disadvantage is that other breast cancer specialists, such as surgeons and medical oncologists, are not represented. We hypothesize that this was overcome by the dedicated radiation oncologists who informed the surgeons of their referring centers about the trial.

We found in our trial that patients receiving the link to the PtDA via the surgery department were more likely to log in. It is known that if the patient is given a concrete treatment advice by the surgeon, without explaining the treatment to be preference-sensitive, patients might be less open to SDM, because they feel that choosing another treatment than advised by the surgeon goes against his advice $(29,30)$. Therefore, when the link to the PtDA is handled via the surgery department, patients were probably more aware that they have a choice. Patients could use the PtDA prior the consultation with the radiation oncologist to be prepared for the consultation and already contemplate what is important to them (13). In our study, though, we also had a group of patients who received the link to the PtDA via the RT department by regular post, prior the consultation, such that these patients could also use the PtDA for the preparation of the consultation. This might explain the high uptake in the RT group as well. Since we did not register whether the patients received the link via regular post, we cannot draw firm conclusions on which factor is more important: the timing of receiving the link (prior to the consultation with the radiation oncologist), or the department handing out the link (surgery department or RT department).

Capturing eligible patients in the MDT was also found to be an important facilitator Savelberg et al. pointed out that if the MDT report gives advice favoring one of the treatment options, it may be more difficult for clinicians and patients to overrule this advice $(30,31)$. It is not surprising, that if the MDT report did not capture the indication for the PtDA, the patient more often got the link via the radiotherapy department, since the surgeon is less involved in the indication for radiotherapy than the radiation oncologist.

The mean age of our trial population is in line with the age at diagnosis of breast cance patients in the Netherlands (32). Educational level did, however, differ from the genera Dutch population in which, around $33 \%$ is highly educated, as opposed to $40 \%$ in our trial population (33). We found only a slightly better PtDA uptake for younger patients compared to the older patients. This also seems in line with literature, which shows that older patients do want to participate in the shared decision-making process, but they tend to value more the verbal communication with their clinician (34). Vulnerable patients are known to be under-represented in healthcare research, and therefore probably also in this trial (35). Although this might result in less PtDA use in patients with a lower educational 
level, in our study we did not find any difference in PtDA uptake by educational level. This is in line by the results of Pickles et al. who suggest that educational level does not interfere with the effect of a PtDA found in trial setting (36).

A reassuring finding was that we did not find a difference in consultation length betwee patients who did and did not log in to the PtDA. Since perception of time and the fear of onger consultation are known to be important barriers, we hope our results will help implementation of the PtDA in clinical practice $(37,38)$.

A limitation to our study is that we do not know how many patients were eligible for the study but were not offered the PtDA or refused participation. There was a wide variation in the number of patients included by the different centers; this could only partly be explained by different duration of the inclusion periods and the differences in the size of the different centers. Consequently, this may have resulted in overestimation of the actual tDA use and validation in our trial.

Another limitation is that, although we found that $88 \%$ of the patients that used the PtDA perceived it as being (partly) useful, we have no further insight in the patients perspectives on the different logistics of receiving the link to the PtDA. Furthermore, due to technical problems, we do not have more specific tracking data on how long and how often patients logged in to the PtDA. Despite this shortcoming, the fact that we could use log-data to monitor patients using the PtDA is a strength in this study, since the logdata yield objective results. Objective data on uptake appear more accurate than the selfreporting of uptake, because we saw in the results of the patient questionnaires that not all patients who reported to have used the PtDA had actually logged in. Patients may not have understood the question or gave a socially desirable answer when asked about PtDA use. Another strength of this trial is that it interfered as little as possible with routine medical practice. This way we were able to find factors that are related to the level of uptake of the PtDA in regular clinical practice without trial limitations. Our real life study design, with 78 different including clinicians, may facilitate post-trial implementation since Glenn et a. found that a positive personal experience and patient satisfaction motivates clinicians more to use a support tool than scientific evidence (39). In addition no adjustments are needed to continue using the PtDA in the participating centers after the trial. Thus, we achieved a good uptake of the PtDA when it was offered to patients. The PtDA is currently freely available and is incorporated into the website of the patient organization, as proposed by Reumkens et al. (40)

Conclusion

We accomplished a high PtDA uptake. This may be explained by the pragmatic trial design and apparent leadership in the existing network of the involved clinicians. We found that logistics facilitating the PtDA being offered via the surgery department prior to the consultation with the radiation oncologist, as well as with a note in the MDT report that the PtDA should be offered, resulted in high PtDA uptake.

\section{References}

1. Coulter A, Collins A. Making shared decision-making a reality: no decision about me, without me: King's Fund; 2011

2. Elwyn G, Frosch DL, Kobrin S. Implementing shared decision-making: consider all the consequences. Implementation science : IS. 2016;11:114.

3. Elwyn G, O'Connor A, Stacey D, Volk R, Edwards A, Coulter A, et al. Developing a quality criteria framework for patient decision aids: online international Delphi consensus process. Bmj. 2006;333(7565):417

4. Coulter A, Stilwell D, Kryworuchko J, Mullen PD, Ng CJ, van der Weijden T. A systematic development process for patient decision aids. BMC Med Inform Decis Mak. 2013;13 Suppl 2:S2.

5. Stacey D, Legare F, Lewis K, Barry MJ, Bennett CL, Eden KB, et al. Decision aids for people facing health treatment or screening decisions. The Cochrane database of systematic reviews. 2017;4:Cd001431.

6. McAlpine K, Lewis KB, Trevena LJ, Stacey D. What Is the Effectiveness of Patient Decision Aids for Cancer-Related Decisions? A Systematic Review Subanalysis. JCO clinical cancer informatics. 2018;2:1-13

7. Elwyn G, Scholl I, Tietbohl C, Mann M, Edwards AG, Clay C, et al. "Many miles to go ...": a systematic review of the implementation of patient decision support interventions into routine clinical practice. BMC medical informatics and decision making. 2013;13 Suppl 2:S14.

8. Scholl I, LaRussa A, Hahlweg P, Kobrin S, Elwyn G. Organizational- and system-level characteristics that influence implementation of shared decision-making and strategies to address them - a scoping review. Implement Sci. 2018;13(1):40.

9. Stacey D, Suwalska V, Boland L, Lewis KB, Presseau J, Thomson R. Are Patient Decision Aids Used in Clinical Practice after Rigorous Evaluation? A Survey of Trial Authors. Med Decis Making. 2019;39(7):805-15.

10. Lu C, Li X, Yang K. Trends in Shared Decision-Making Studies From 2009 to 2018: A Bibliometric Analysis. Frontiers in public health. 2019;7:384.

11. Herrmann A, Mansfield E, Hall AE, Sanson-Fisher R, Zdenkowski N. Wilfully out of sight? literature review on the effectiveness of cancer-related decision aids and implementation strategies. BMC Med Inform Decis Mak. 2016;16:36.

12. Feibelmann S, Yang TS, Uzogara EE, Sepucha K. What does it take to have sustained use of decision aids? A programme evaluation for the Breast Cancer Initiative. Health expectations : an international journal of public participation in health care and health policy. 2011;14 Suppl $1 \cdot 85-95$

13. Joseph-Williams N, Lloyd A, Edwards A, Stobbart L, Tomson D, Macphail S, et al. Implementing shared decision making in the NHS: lessons from the MAGIC programme. BMJ (Clinical research ed). 2017;357:j1744.

14. Légaré $F$, Thompson-Leduc PJPe, counseling. Twelve myths about shared decision making. 2014;96(3):281-6.

15. Brackett $C D$, Kearing $S$. Use of a web-based survey to facilitate shared decision making for patients eligible for cancer screening. The patient. 2015;8(2):171-7.

16. Stacey D, Taljaard M, Breau RH, Baba N, Blackmore T, Boland L, et al. A Patient Decision Aid for Men With Localized Prostate Cancer: A Comparative Case Study of Natural Implementation Approaches. Cancer nursing. 2018 
17. Raphael DB, Russell NS, Immink JM, Westhoff PG, Stenfert Kroese MC, Stam MR, et al. Risk communication in a patient decision aid for radiotherapy in breast cancer: How to deal with uncertainty? Breast. 2020;51:105-13.

18. Donker $\mathrm{M}$, Litière $\mathrm{S}$, Werutsky $\mathrm{G}$, Julien JP, Fentiman IS, Agresti R, et al. Breast-conserving treatment with or without radiotherapy in ductal carcinoma In Situ: 15-year recurrence rates and outcome after a recurrence, from the EORTC 10853 randomized phase III trial. J Clin Oncol. 2013:31(32):4054-9.

19. Bagenal J, Roche N, Ross G, Kirby A, Dodwell D. Should patients with ductal carcinoma in situ be treated with adjuvant whole breast radiotherapy after breast conservation surgery? BM. (Clinical research ed). 2018;361:k1410.

20. Recht A, Comen EA, Fine RE, Fleming GF, Hardenbergh PH, Ho AY, et al. Postmastectomy Radiotherapy: An American Society of Clinical Oncology, American Society for Radiation Oncology, and Society of Surgical Oncology Focused Guideline Update. Pract Radiat Oncol. 2016;6(6):e219-e34.

21. Raphael DB, Ter Stege JA, Russell NS, Boersma LJ, van der Weijden T. What do patients and health care professionals view as important attributes in radiotherapy decisions? Input for a breast cancer patient decision aid. Breast (Edinburgh, Scotland). 2019;49:149-56.

22. Merali Z, Wilson JR. Explanatory Versus Pragmatic Trials: An Essential Concept in Study Design and Interpretation. Clinical spine surgery. 2017;30(9):404-6.

23. Ford I, Norrie J. Pragmatic Trials. The New England journal of medicine. 2016;375(5):454-63.

24. Thorpe KE, Zwarenstein M, Oxman AD, Treweek S, Furberg CD, Altman DG, et al. A pragmaticexplanatory continuum indicator summary (PRECIS): a tool to help trial designers. CMA. Canadian Medical Association journal $=$ journal de I'Association medicale canadienne. 2009;180(10):E47-57.

25. Vromans R, Tenfelde K, Pauws S, van Eenbergen M, Mares-Engelberts I, Velikova G, et al. Assessing the quality and communicative aspects of patient decision aids for early-stage breast cancer treatment: a systematic review. Breast Cancer Res Treat. 2019;178(1):1-15.

26. [Available from: https://www.cbs.nl/nl-nl/onze-diensten/methoden/classificaties/onderwijsen-beroepen/standaard-onderwijsindeling--soi--/standaard-onderwijsindeling-2016.

27. Belkora JK, Volz S, Teng AE, Moore DH, Loth MK, Sepucha KR. Impact of decision aids in a sustained implementation at a breast care center. Patient education and counseling. 2012;86(2):195-204.

28. Damschroder LJ, Aron DC, Keith RE, Kirsh SR, Alexander JA, Lowery JC. Fostering implementation of health services research findings into practice: a consolidated framework for advancing implementation science. Implementation science : IS. 2009;4:50.

29. Joseph-Williams N, Edwards A, Elwyn G. Power imbalance prevents shared decision making. BMJ (Clinical research ed). 2014;348:g3178.

30. Joseph-Williams N, Elwyn G, Edwards A. Knowledge is not power for patients: a systematic review and thematic synthesis of patient-reported barriers and facilitators to shared decision making. Patient education and counseling. 2014;94(3):291-309.

31. Savelberg W, Boersma LJ, Smidt M, Goossens MFJ, Hermanns R, van der Weijden T. Does lack of deeper understanding of shared decision making explains the suboptimal performance on crucial parts of it? An example from breast cancer care. Eur J Oncol Nurs. 2019;38:92-7.

32. [updated 12-02-201921-01-2020]. Available from: https://www.rivm.nl/bevolkingsonderzoekborstkanker-voor-professionals/feiten-en-cijfers.
33. [Available from: https://www.onderwijsincijfers.nl/kengetallen/internationaal/ opleidingsniveau-bevolking.

34. Burton M, Collins KA, Lifford KJ, Brain K, Wyld L, Caldon L, et al. The information and decision support needs of older women (>75 yrs) facing treatment choices for breast cancer: a qualitative study. Psycho-oncology. 2015;24(8):878-84

35. Dugas M, Trottier ME, Chipenda Dansokho S, Vaisson G, Provencher T, Colquhoun H, et al. Involving members of vulnerable populations in the development of patient decision aids: a mixed methods sequential explanatory study. BMC medical informatics and decision making. 2017;17(1):12.

36. Pickles K, Kazda L, Barratt A, McGeechan K, Hersch J, McCaffery K. Evaluating two decision aids fo Australian men supporting informed decisions about prostate cancer screening: A randomised controlled trial. PloS one. 2020;15(1):e0227304.

37. Silvia KA, Ozanne EM, Sepucha KR. Implementing breast cancer decision aids in community sites: barriers and resources. Health expectations : an international journal of public participation in health care and health policy. 2008;11(1):46-53.

38. Pieterse AH, Stiggelbout AM, Montori VM. Shared Decision Making and the Importance of Time. Jama. 2019;322(1):25-6

39. Glenn A, Urquhart R. Adopting patient-centred tools in cancer care: role of evidence and other factors. Current oncology (Toronto, Ont). 2019;26(1):19-27.

40. Reumkens K, de Die-Smulders CEM, van Osch L. Exploring the preferences of involved health professionals regarding the implementation of an online decision aid to support couples during reproductive decision-making in hereditary cancer: a mixed methods approach. Fam Cancer. 2019;18(2):285-91. 


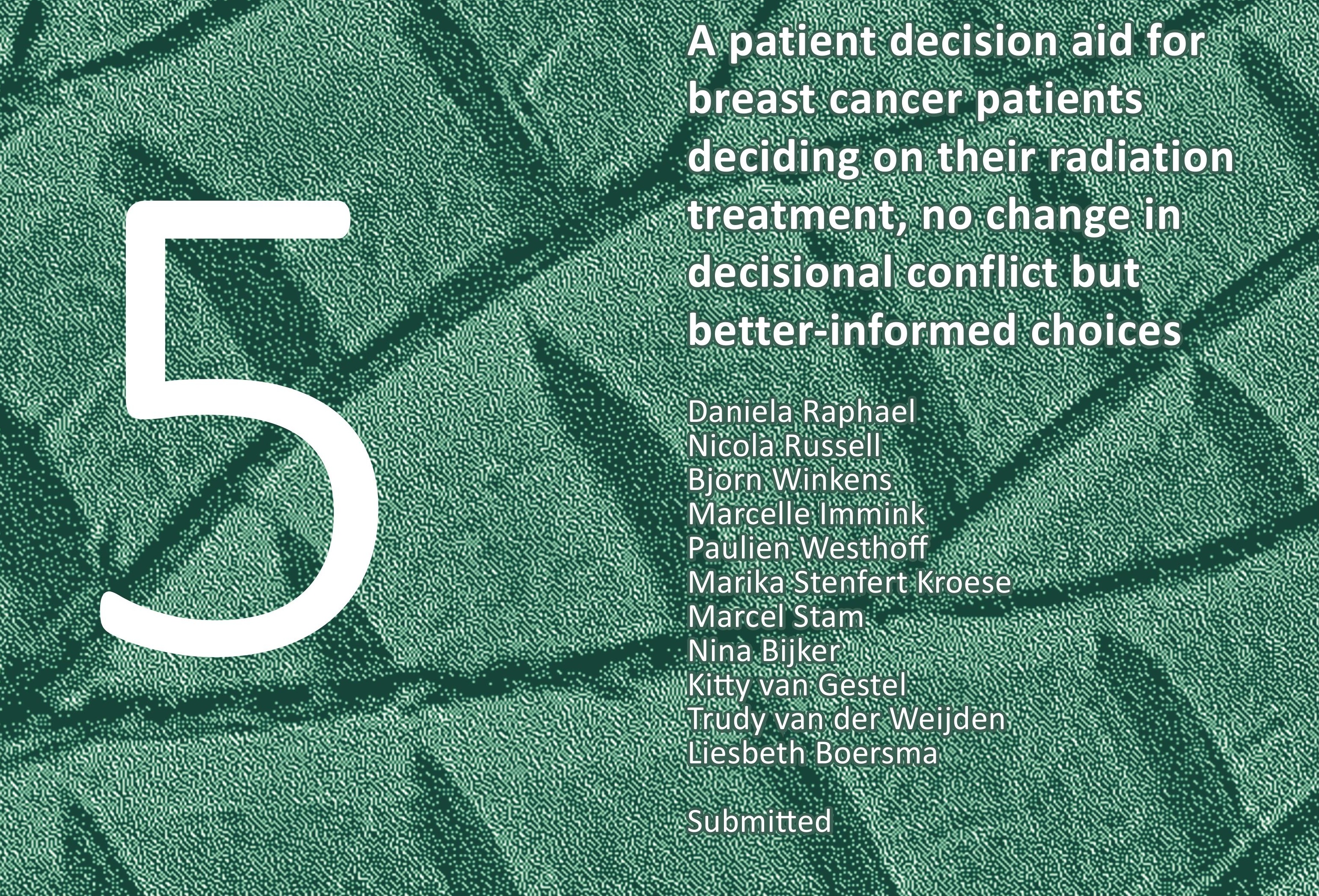




\section{Abstract}

Background and Purpose: In selected breast cancer patients, radiation treatment (RT) lowers the recurrence risk, with minor or no improvement of survival. In these patients, the choice to undergo RT is considered a preference-sensitive decision. To facilitate shared decision-making (SDM) for this choice, a patient decision aid was made by the research team. We aimed to evaluate the effect of the PtDA on decisional conflict.

Material and methods: We performed a multi-center pre- and post-intervention study (BRASA-trial). The first 214 patients made a choice without support of the PtDA; the subsequent 189 patients received a link to the PtDA. Primary endpoint was decisional conflict; secondary endpoints were perceived SDM and knowledge on treatment options. Patients filled out questionnaires immediately after, and three months after their decision. Data were analyzed with multi-level regression analysis.

Results: After correcting for the difference in age and educational level, the mean $( \pm S D)$ decisional conflict for the intervention group $(27.3 \pm 11.4)$ was similar to the contro $(26.8 \pm 11.4$; difference $=0.86,95 \% \mathrm{Cl} 1.67,3.36)$ three months after their decision. This also applied to perceived SDM. Patients exposed to the PtDA pursued additional treatment less often $(45 \%$ vs $56 \%$, odds ratio $0.59,95 \% \mathrm{Cl} 0.37,0.95)$ and scored significantly higher on the knowledge test $(7.4+2.5$ vs $6.1+2.7$, corrected difference $=1.0,95 \% \mathrm{Cl} 0.50,1.49$ ). There was no significant increase in consultation time.

Conclusions: Handing out the PtDA was not associated with improved scores in decisional conflict or perceived SDM, but it was associated with a choice for less (additional) treatment and better knowledge about the treatment options.

\section{Introduction}

In the process of shared decision-making (SDM), patients and clinicians collaborate to select the treatment that fits the patient best $(1,2)$. The patient knows her own personal situation, values, and preferences best, whereas the clinician has the most knowledge about her medical situation. These aspects need to be elicited to achieve optimal sharing of the decision-making process. Patient decision aids (PtDAs) are tools that support the SDM process $(3,4)$. When PtDAs are used, patients are more satisfied with the decision made. In addition, they have more knowledge on their treatment options, are less likely to opt for more intensive treatment, and feel more engaged in SDM (3).

The decision on whether radiotherapy (RT) is offered is usually made according to international and national guidelines. In certain settings, however, administration of postoperative RT can be considered a preference-sensitive decision. In these situations, there is evidence that RT reduces local recurrence risk, with a risk of causing side effects, but with no or uncertain benefit to long-term survival (5-15). In these situations, guidelines may recommend discussing the treatment of choice with the patient (16), or this may be decided by the multidisciplinary team. The latter might happen when guidelines do give a clear recommendation to offer RT, but the latest literature suggests a lower benefit.

There are a number of known preference-sensitive situations when choosing for breast cancer RT, such as patients with a low to intermediate risk on local recurrence after mastectomy, older patients undergoing breast-conserving therapy (BCT) for low-risk invasive breast cancer, the indication for boost irradiation to the tumor bed in case of $\mathrm{BCT}$ or patients with low-risk Ductal Carcinoma In Situ (DCIS) undergoing BCT (9, 17-20). To support SDM in these preference-sensitive treatment decisions, we developed an online PtDA $(13,14)$ according to the international (IPDAS) guidelines $(21-24)$. The PtDA starts with an introduction on SDM, and points out that there is a choice to be made. It explains how RT is performed in text and in an animation film. The PtDA gives information on the possible effect and side effects of RT. Additionally it elicits the patients' preferences. In a review by Vromans et al. this PtDA scored 83 out of 100 points (25). The PtDA is available online in Dutch - with an additional literal translation in English - at www.beslissamen.n. We evaluated the PtDA in a multi-centre pre- and post-intervention study in 13 out of the 19 RT centers in the Netherlands (26). The aim of this study is to investigate whether the PtDA resulted in improved decisional quality, an increased perceived level of SDM, and improved knowledge on the different treatment options. In addition, we investigated the impact of the PtDA on the choice for more or less (additional) radiation treatment, as well as its impact on consultation length.

\section{Materials and methods}

Study design

We performed a multi-center pre- and post-intervention study. In the pre-intervention group, i.e., the control arm, patients were included before introducing the PtDA. In the post-intervention group, i.e., the intervention arm, patients were offered the PtDA. 
Study population

We included patients if they were 18 years or older, had a breast cancer diagnosis, and were able to understand sufficient written Dutch language to use the PtDA. All patients were faced with a preference-sensitive decision on RT, according to the multi-disciplinary team (MDT) of their treating hospital or their treating clinician. Patients had to fit in one of the four pathways the PtDA was developed for: boost/no-boost group, chest wal RT group, low-risk breast cancer group and DCIS group (appendix A). All patients were included in the trial by their radiation oncologist.

\section{Intervention}

Once recruitment of the control arm was complete, clinicians were instructed on how to use the PtDA. We provided an e-learning opportunity, but this training was not obligatory. The logistics for referring patients to the PtDA were adjusted to the existing logistics and referral systems of the participating centers (26). Ideally, patients were identified in the MDT. Patients received the PtDA-link from the surgery department $(n=33)$ or from the RT department $(n=135)$, this could either be during the consultation or previous to the consultation through regular mail. Ten patients received the PtDA link through another route. For ten patients, it was unknown via which route they received the link to the PtDA.

\section{Outcomes}

Patients were requested to complete questionnaires within three days after they had made their decision (T1). After three months (T2), the research team sent the followup questionnaire by mail or e-mail, according to the patient's preference (table 1). We also recorded the final treatment decision concerning the RT. The participating clinicians were asked to fill out a Case Report Form including medical information (tumor type and treatment characteristics) and consultation length immediately after the post-operative consultation.

The primary endpoint was decisional conflict at three months after the decision had been made, measured using the Decisional Conflict Scale (DCS) (Appendix B). The DCS measures how certain patients are about their decision and how they feel about the decision making process. A validated Dutch translation was used $(27,28)$.The DCS consists of 16 questions evaluated on a 5-point Likert scale (scoring $0-4$ ). Higher scores imply more experienced decisional conflict.

The secondary outcomes were perceived level of SDM and patient knowledge on thei treatment options, measured $<3$ days after deciding on RT. Perceived level of SDM was measured with the SDM-Q9 (Appendix C) (29) and the CollaboRATE (Appendix D)(30). The SDM-Q9 consist of nine questions, evaluated on a 6-point Likert scale (scoring 0-5). CollaboRATE consist of three questions evaluated on a 10-point Likert scale $(31,32)$. On both questionnaires, a higher score expresses a higher level of experienced SDM. These are both validated questionnaires of which validated Dutch translations were used, available on the websites of the questionnaires developers $(30,33)$. Patient knowledge was measured by a knowledge test developed by our research team, in the absence of a validated test. This questionnaire consisted of 11 questions aligned to the content of the PtDA ensuring high content validity. Patients scored one point for each correct answer.
One point was deducted for each incorrect answer; no points were given if the patient did not know the answer (appendix E) (34).

To investigate important attributes for the decision-making process, we developed a questionnaire consisting of nine statements on different attributes in the decisionmaking process, as well as one question asking to prioritize which three attributes were the most important for the decision made (appendix F). These statements are similar to the statements asked for in the PtDA, which was developed together with patients (13). All self-developed questionnaires were pilot tested on comprehension and difficulty on breast cancer patients prior to the study.

Table 1. Overview of the time schedule for data acquisition via patient questionnaires and via Case Report Forms (CRFs) filled out by clinicians. T1 is $<3$ days after the decision, T2 is 3 months after the decision.

\begin{tabular}{llll}
\hline & Type of data & T1 & T2 \\
\hline Patients & $\begin{array}{l}\text { Decisional Conflict } \\
\text { Scale }\end{array}$ & $\mathrm{x}$ & $\mathrm{x}$ \\
\hline SDM-Q9 & $\mathrm{x}$ & \\
\hline CollaboRATE & $\mathrm{x}$ & $\mathrm{x}$ \\
\hline Patient knowledge & $\mathrm{x}$ & \\
\hline Clinicians & Patient preferences & $\mathrm{x}$ & \\
\hline Treatment chosen & $\mathrm{x}$ & \\
\hline $\begin{array}{l}\text { CRF with disease } \\
\text { and treatment } \\
\text { characteristics, and } \\
\text { consultation length }\end{array}$ & $\mathrm{x}$ & \\
\hline
\end{tabular}

Sample size calculation

Considering an effect size on the decisional conflict scale of 0.30-0.40 as a meaningfu difference $(28,35)$, we aimed to demonstrate an effect size (if present) of 0.40 , with power of $80 \%(Z=0.84)$ and a two-sided alpha of $0.05(Z=1.96)$. This required 99 patients per group. Because the decision-making process is influenced by input of the clinician, each clinician was considered a different cluster. Assuming each clinician would include 6 patients on average and intra-class correlation equals 0.04 (36), the design effect $(=1+$ $(6-1) * 0.04)$ equals 1.2 . Accounting for an additional $10 \%$ loss in efficiency due to unequal cluster sizes (37), the required sample size per group was calculated to be equal to $99 * 1.2 / 0.9=132$ patients within 22 clinicians. Accounting for $20 \%$ dropout, 28 recruiting clinicians (28 clusters) per group were required, resulting in 168 patients per group. 
Data analyses

Patient and treatment characteristics, as well as patient preferences, were described using the mean value (standard deviation, SD) for numerical variables and number of patients per category (\%) for categorical ones. Differences in these characteristics between control and intervention groups were assessed using Chi-square test or fisher exact tes where appropriate for categorical variables, while independent-samples t-test was used for numerical variables. For the DCS, the SDM-Q9, and the CollaboRATE, we calculated the sum score for the questionnaire according to the manuals of these questionnaires $(31,35,38)$. We used linear mixed models to analyze differences in the scores on the questionnaires between the control and the intervention group. A random intercept on the clinician level accounted for the clustering of patients within a clinician. In addition to the treatment group, we also included characteristics that differed significantly and/ or substantially between the groups in the fixed part of the model to adjust for potential confounding. For the outcome measure of treatment choice, the same variables were included in a generalized linear mixed model with a logit link function to account for the binary data. We did not impute missing outcome, as this was accounted for in the mixed model analysis due to its likelihood-based approach, assuming that outcome data were missing at random (MAR). All analyses were performed using IBM SPSS Statistic for Windows (version 25; Armonk, NY, USA, IBM Corp.), except for mixed model analyses, which were performed using STATA (StataCorp. 2009. Stata Statistical Software: Release 11 College Station, TX: StataCorp LP.). A two-sided $p$-value $\leq 0.05$ was considered statistically significant.

\section{Ethical standards}

The trial was approved by the institutional review board of Maastro and the Netherlands Cancer Institute and was carried out in accordance with the declaration of Helsinki. All participants gave informed consent after reading written trial information. Patients were allocated a study code without personal identifiers.

\section{Results}

As described in a prior publication (26), patients were recruited from 13 out of 19 radiation oncology centers in the Netherlands. Between October 2017 and October 2018, 214 patients were included in the control arm, of which 211 filled in the T1 questionnaire and 209 the T2 questionnaire. Between October 2018 and July 2019, 189 patients were included in the intervention arm, of which 185 filled in the T1 questionnaire, 140 patients used the PtDA (26), and 180 filled in the T2 questionnaire (figure 1). In total 104 different clinicians included patients in the study. Of these 104 clinicians, 65 included patients in the control arm and 76 in the intervention arm.

The mean age was $60.4(S D=11.3)$ years in the intervention arm and $62.8(S D=12.6)$ years in the control arm $(p=0.050)$. In the intervention arm, $28 \%$ of the patients had a low educational level, $32 \%$ had middle education, and $40 \%$ was highly educated; in the control arm, this was $42 \%, 30 \%$, and $28 \%$ respectively $(p<0.007)$. Disease and treatment characteristics were comparable between both groups (table 2).
Figure 1. Flow diagram with an overview of included patients per arm.

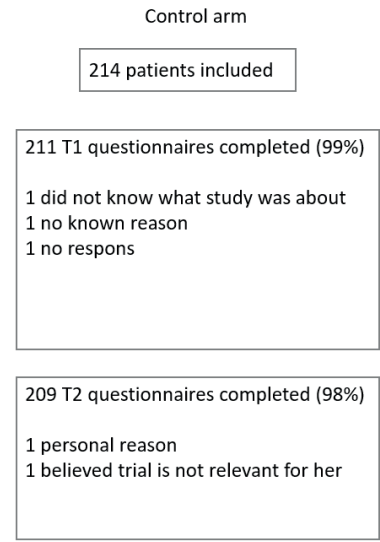

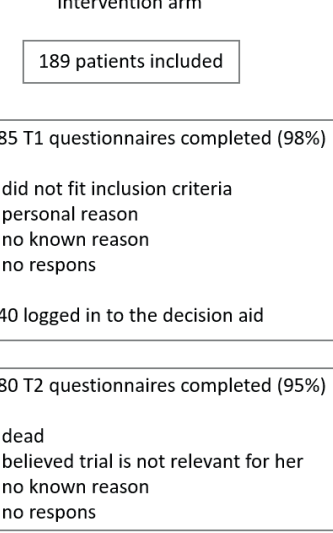

Table 2. Patient characteristics per study-arm.

\begin{tabular}{llccc}
\hline & & $\begin{array}{c}\text { Intervention } \\
(\mathrm{n}=189)\end{array}$ & $\begin{array}{c}\text { Control } \\
(\mathrm{n}=214)\end{array}$ & p-value \\
\hline Mean Age (in years) & $60.4(\mathrm{SD}=11.3)$ & $62.8(\mathrm{SD}=12.6)$ & 0.050 \\
\hline Indication & DCIS & $62(33 \%)$ & $64(30 \%)$ & 0.824 \\
for SDM on & Low-risk invasive & $58(31 \%)$ & $65(30 \%)$ & \\
(additional) RT & Boost & $47(25 \%)$ & $62(29 \%)$ & \\
yes or no: & Chest wall & $21(11 \%)$ & $23(11 \%)$ & \\
& Missing & 1 & 0 & \\
\hline Educational & Low & $50(28 \%)$ & $86(42 \%)$ & 0.007 \\
level & Middle & $59(32 \%)$ & $63(30 \%)$ & \\
& High & $73(40 \%)$ & $58(28 \%)$ & \\
& Missing & 7 & 7 & 0.044 \\
\hline \multirow{2}{*}{ SDM indicated } & No & $62(34 \%)$ & $90(44 \%)$ & \\
in MDT & Yes & $120(66 \%)$ & $114(56 \%)$ & \\
& Missing & 7 & 10 & \\
\hline
\end{tabular}




\begin{tabular}{|c|c|c|c|c|}
\hline \multirow[t]{8}{*}{$\begin{array}{l}\text { Axillary } \\
\text { treatment }\end{array}$} & $\begin{array}{l}\text { Sentinel node procedure } \\
\text { Axillary lymph node } \\
\text { dissection }\end{array}$ & $\begin{array}{c}109(58 \%) \\
5(23 \%)\end{array}$ & $\begin{array}{c}137(65 \%) \\
6(3 \%)\end{array}$ & \multirow[t]{8}{*}{$0.694^{*}$} \\
\hline & MARI & $2(1 \%)$ & $3(1 \%)$ & \\
\hline & $\begin{array}{l}\text { Sentinel node procedure } \\
+ \text { MARI }\end{array}$ & $2(1 \%)$ & $1(0.5 \%)$ & \\
\hline & $\begin{array}{l}\text { Sentinel node procedure } \\
+\mathrm{RT}\end{array}$ & $4(2 \%)$ & $2(1 \%)$ & \\
\hline & $\begin{array}{l}\text { Axillary lymph node } \\
\text { dissection + MARI + RT }\end{array}$ & 0 & $1(0.5 \%)$ & \\
\hline & $\begin{array}{l}\text { Sentinel node procedure } \\
+ \text { Axillary lymph node } \\
\text { dissection + MARI + RT }\end{array}$ & 0 & $1(0.5 \%)$ & \\
\hline & None & 65 (34.8\%) & $61(28.5 \%)$ & \\
\hline & Missing & 2 & 2 & \\
\hline \multirow{3}{*}{$\begin{array}{l}\text { Systemic } \\
\text { therapy }\end{array}$} & Yes & $53(28 \%)$ & $67(31 \%)$ & \multirow[t]{3}{*}{0.458} \\
\hline & No & $134(71 \%)$ & $147(69 \%)$ & \\
\hline & Missing & 2 & 0 & \\
\hline \multirow[t]{8}{*}{ Breast surgery } & Breast-conserving surgery & $167(89 \%)$ & $191(89 \%)$ & \multirow[t]{8}{*}{$0.833^{*}$} \\
\hline & $\begin{array}{l}\text { Amputation with direct } \\
\text { reconstruction }\end{array}$ & $12(6 \%)$ & $9(4 \%)$ & \\
\hline & Amputation with delayed & & & \\
\hline & reconstruction & $2(1 \%)$ & $3(1 \%)$ & \\
\hline & Amputation without & $4(2 \%)$ & $7(3 \%)$ & \\
\hline & Amputation, & & & \\
\hline & $\begin{array}{l}\text { reconstruction unknown } \\
\text { Missing }\end{array}$ & $3(2 \%)$ & $4(2 \%)$ & \\
\hline & & 1 & 0 & \\
\hline \multirow[t]{8}{*}{ CTNM } & TO & $66(35 \%)$ & $75(36 \%)$ & \multirow[t]{5}{*}{$0.601^{*}$} \\
\hline & T1 & 96 (51\%) & $97(46 \%)$ & \\
\hline & $\mathrm{T} 2$ & $23(12 \%)$ & 35 (17\%) & \\
\hline & T3 & $3(2 \%)$ & $3(1 \%)$ & \\
\hline & Missing & 1 & 4 & \\
\hline & NO & $179(95 \%)$ & $197(94 \%)$ & \multirow[t]{3}{*}{0.671} \\
\hline & N1 & $9(5 \%)$ & $12(6 \%)$ & \\
\hline & Missing & 1 & 5 & \\
\hline
\end{tabular}

\begin{tabular}{|c|c|c|c|c|}
\hline pTNM & $\begin{array}{l}\text { T0 } \\
\text { T1 } \\
\text { T2 } \\
\text { T3 } \\
\text { Missing }\end{array}$ & $\begin{array}{c}86(46 \%) \\
92(49 \%) \\
9(5 \%) \\
0 \\
2\end{array}$ & $\begin{array}{c}86(41 \%) \\
103(49 \%) \\
22(10 \%) \\
0\end{array}$ & 0.098 \\
\hline & $\begin{array}{l}\text { N0 } \\
\text { N1 } \\
\text { Missing }\end{array}$ & $\begin{array}{c}172(92 \%) \\
15(8 \%) \\
2 \\
\end{array}$ & $\begin{array}{c}185(89 \%) \\
24(11 \%) \\
5 \\
\end{array}$ & 0.248 \\
\hline Histology & $\begin{array}{l}\text { DCIS } \\
\text { Invasive, no specific type } \\
\text { (NST) } \\
\text { Invasive lobular } \\
\text { carcinoma } \\
\text { Other } \\
\text { Missing }\end{array}$ & $\begin{array}{c}62(33 \%) \\
106(56 \%) \\
11(6 \%) \\
9(5 \%) \\
0\end{array}$ & $\begin{array}{c}68(32 \%) \\
119(56 \%) \\
16(8 \%) \\
9(4 \%) \\
2\end{array}$ & 0.684 \\
\hline $\begin{array}{l}\text { Tumour } \\
\text { grade Bloom } \\
\text { Richardson }\end{array}$ & $\begin{array}{l}1 \\
2 \\
3 \\
\text { Missing } \\
\end{array}$ & $\begin{array}{c}61(34 \%) \\
80(44 \%) \\
41(23 \%) \\
7\end{array}$ & $\begin{array}{c}72(35 \%) \\
86(42 \%) \\
46(23 \%) \\
10\end{array}$ & 0.923 \\
\hline $\begin{array}{l}\text { Receptor } \\
\text { status }\end{array}$ & $\begin{array}{l}\text { ER- } \\
\text { ER + } \\
\text { Missing }\end{array}$ & $\begin{array}{c}83(44 \%) \\
105(56 \%) \\
1\end{array}$ & $\begin{array}{c}87(41 \%) \\
126(59 \%) \\
1\end{array}$ & 0.515 \\
\hline & $\begin{array}{l}\text { PR- } \\
\text { PR + } \\
\text { Missing }\end{array}$ & $\begin{array}{c}98(52 \%) \\
90(48 \%) \\
1\end{array}$ & $\begin{array}{c}109(51 \%) \\
104(49 \%) \\
1\end{array}$ & 0.632 \\
\hline & $\begin{array}{l}\text { HER2- } \\
\text { HER2 + } \\
\text { Missing }\end{array}$ & $\begin{array}{c}182(97 \%) \\
6(3 \%) \\
1\end{array}$ & $\begin{array}{c}199(93 \%) \\
14(7 \%) \\
1\end{array}$ & 0.193 \\
\hline
\end{tabular}

$\mathrm{MDT}=$ multi-disciplinary team, RT = radiotherapy, MARI = MARI method (marking of the axilla with radioactive iodine seeds)

We corrected for baseline characteristics that differed between both groups (age and educational level) in all regression analyses. There was no significant difference between the intervention and control arm in the primary endpoint, i.e. DCS at 3 months after the decision, (27.3 (SD 12.9) vs mean 26.8 (SD 11.4) ( $p=0.510)$ ) (table 3). In addition, no significant difference was found in measures $<3$ days after the decision (T1): DCS (mean 27.3 (SD 12.9) vs 26.2 (SD 12.4) ( $p=0.412)$ ), and perceived SDM level measured with the CollaboRATE (mean 88.6 (SD 14.4) vs 88.9 (SD 15.8) ( $p=0.919)$ ) and the SDM-Q9 (mean 74.0 (SD 19.7) vs 72.2 (SD 22.4) ( $p=0.418)$ ). Patients in the intervention arm scored better on the knowledge test (mean 7.4 (SD 2.5) vs 6.1 (SD 2.7) $(p<0.001)$ ) and chose less often 
for (additional) RT compared to the control group (44.5\% vs $55.7 \%$ (OR 0.59 (95\% Cl 0.37 $0.95)$ ). No significant difference in consultation length ( $41.7 \mathrm{~min}$ vs $40.8 \mathrm{~min}(\mathrm{p}=0.276))$ and number of consultations needed to make the decision ( 2.22 vs $2.01(\mathrm{p}=0.869)$ ) was seen between the intervention and control arm.

Table 3. Results of primary and secondary outcome measures. Raw data are summarized with absolute scores and numbers. The $p$-values represent the results of the linear and logistic mixed model analyses, corrected for age and educational level. $\mathrm{T} 1$ is $<3$ days after the decision, $\mathrm{T} 2$ is 3 months after the decision.

\begin{tabular}{|c|c|c|c|}
\hline Outcome measure & $\begin{array}{c}\text { Intervention } \\
\text { Mean (SD) } \\
N=189\end{array}$ & $\begin{array}{c}\text { Control } \\
\text { Mean (SD) } \\
\mathrm{N}=214\end{array}$ & $\begin{array}{c}\text { Corrected } \\
\text { difference between } \\
\text { intervention and } \\
\text { control }(95 \% \mathrm{Cl})^{*}\end{array}$ \\
\hline T2 DCS (0-100) & 27.3 (12.9) & $26.8(11.4)$ & $0.85(-1.67,3.36)$ \\
\hline Missing & 14 & 7 & \\
\hline T1 DCS (0-100) & $27.3(12.9)$ & $26.2(12.4)$ & $1.10(-1.52,3.72)$ \\
\hline Missing & 8 & 8 & \\
\hline T1 Knowledge (-11-11) & $7.4(2.5)$ & $6.1(2.7)$ & $1.00(0.50,1.49)$ \\
\hline Missing & 10 & 9 & \\
\hline T1 CollaboRATE (0-100) & $88.6(14.4)$ & $88.9(15.8)$ & $-0.16(-3.32,2.99)$ \\
\hline Missing & 4 & 6 & \\
\hline T1 SDMQ9 (0-100) & $74.0(19.7)$ & $72.2(22.4)$ & $1.81(-2.56,6.18)$ \\
\hline Missing & 6 & 8 & \\
\hline Consultation length (min) & $41.7(13.5)$ & $40.8(14.3)$ & $1.52(-1.21,4.25)$ \\
\hline Missing & 19 & 27 & \\
\hline Number of consultations & $2.22(7.2)$ & $2.01(6.78)$ & $0.02(-0.20,0.24)$ \\
\hline \multirow[t]{2}{*}{ Missing } & 4 & 3 & \\
\hline & Intervention & Control & OR $(95 \% \mathrm{Cl})$ \\
\hline $\begin{array}{l}\text { More (additional) treatment chosen } \\
\text { (\%) }\end{array}$ & 44.52 & 55.7 & $0.59(0.37,0.95)$ \\
\hline Missing & 7 & 4 & \\
\hline
\end{tabular}

The important attributes for the decision-making process were similar for the intervention and control arm (appendix F). The most important attributes, both at $\mathrm{T} 1$ and $\mathrm{T} 2$, were the local recurrence risk, the advice of the clinician, and the fact that choosing to pursue RT can give peace of mind. The least frequently chosen attributes were the cosmetic results and the daily trip to the RT center.

\section{Discussion}

We have shown that the patient decision aid (PtDA) was not significantly associated with better score on the decisional conflict scale (DCS), neither immediately after the decision was made nor three months later. We also found no statistically significant difference in the experienced level of shared decision making (SDM) and consultation length. We did find that patients to whom the link to the PtDA had been provided (the intervention group) chose less often for (additional) radiation treatment (RT) and that they had improved scores in the knowledge test.

The findings on DCS and SDM were disappointing, because the aim of a PtDA is to support SDM. SDM in turn aims to ensure that patients chose the treatment that corresponds best with the patients' situation and preferences. Several instruments have been developed to measure decisional quality, but no instrument covers all aspects (39). Since the DCS is frequently used to measure the effect of PtDAs, and Stacey et al. showed that DCS decreased after PtDA use, we chose DCS as our primary outcome $(4,39,40)$. Recently, however, Garvelink et al. (45) showed that it may also matter at what time-point the DCS is applied. They found a significant difference in DCS after PtDA use shortly (1-3 months) after the decision was made, but this difference was not significant immediately (<1 month) after the decision was made or in the long term (41). They found a mean score in DCS for the overall group of $M=26.1$ immediately after the decision was made and $M=26.3$ in the long term; we found scores varying around 26-27 both immediately and three months after the decision. A score on the DCS of $>25$ is considered to be elevated decisional conflict (35), and our scores are only slightly above this cut-off. This raises the question of how much effect we could expect from the PtDA. Others argued that DCS might even rise immediately after PtDA use, because patients might be more aware that there is a difficult decision to be made (42).

We also aimed to measure the process of SDM. For this outcome, several questionnaires are available, but there are no high-quality tools to measure perceived SDM $(43,44)$ and the available tools are all hampered by a strong ceiling effect $(45,46)$. We also found relatively high scores on the SDM-Q9 ( $M=72.2$ and 74.0) compared to the review of Doherr et al. (mean scores 25-75) and CollaboRATE ( $M=88.9$ and 88.6). This might suggest that the SDM process of the participating clinicians was already relatively good, so that there was not enough room for improvement $(31,46)$. However, a high pre-trial level of SDM behavior may be unlikely, as many papers show that there is generally much room for improvement in this area, and we did not provide extensive training on SDM (47).

We found that patients who received the PtDA made different choices, compared to patients who did not receive the PtDA: they chose less often for (additional) RT. This suggests that the PtDA had an added effect on the deliberation of patients deciding on (additional) RT. Although patients indicated that they considered recurrence risk and peace of mind of choosing for RT as important attributes, patients in the intervention arm were more likely to decide to refrain from (additional) RT. We hypothesize they might be more aware of the limited gain of (additional) RT after using the PtDA since we also found improved scores on the knowledge test. (4). 
We found no difference in consultation length and number of consultations for the patients who received the PtDA. This may stimulate implementation, since it is known that clinicians fear that SDM and the use of PtDAs may consume too much time and is a frequently mentioned barrier for implementation of PtDAs $(48,49)$.

A limitation in our study is the lack of randomization. We chose to perform a pre- and post-intervention study, because there is currently a momentum for developing tools to incorporate SDM in clinical practice in the Netherlands (50) and we expected that hospitals would not accept randomization. Clinicians who are instructed how to work with the PtDA might already change their communication style and we therefore only performed an intention to treat analysis. Also many hospitals were represented in the process of developing the PtDA; therefore, randomization at hospital level was not possible. Since 13 different centers included patients, numbers per center were too small to run subgroup analyses on the different centers. The drawback of our approach may be that participating clinicians might have changed their information provision on the different treatment options over time, independently of the PtDA use, particularly because there is a movement towards treatment de-escalation in breast cancer care (5153). Also patients in the intervention arm were slightly younger and were more highly educated than patients in the control arm, suggesting a selection bias. We did correc for these inequalities in our analysis, which improved reliability of our results. A strength of our approach is that we were able to show the effect of the PtDA in a realistic setting resembling daily clinical practice $(54,55)$. We had more referring clinicians than required for our sample, which increases the statistical power of the study.

Although we did not find a significant effect on the perceived level of SDM, the additiona value of the PtDA was evaluated by patients as "good". Of the patients who used the PtDA $88 \%$ considered the PtDA to be useful for the decision-making process (26). Therefore more research is needed on how to improve integration of the PtDA in clinical practice while simultaneously improving the SDM process $(56,57)$.

Conclusion

We found no significant improvement on the DCS or on perceived level of SDM afte handing out the PtDA. However, we did find that patients to whom the PtDA was provided, more often chose to refrain from (additional) RT, and showed better knowledge about the different treatment options, without using additional consultation time.

\section{References}

1. Coulter A, Collins A. Making shared decision-making a reality: no decision about me, without me: King's Fund; 2011

2. Elwyn G, Durand MA, Song J, Aarts J, Barr PJ, Berger Z, et al. A three-talk model for shared decision making: multistage consultation process. Bmj. 2017;359:j4891.

3. Stacey D, Legare F, Col NF, Bennett CL, Barry MJ, Eden KB, et al. Decision aids for people facing health treatment or screening decisions. Cochrane Database Syst Rev. 2014(1):Cd001431.

4. Stacey D, Légaré F, Lewis K, Barry MJ, Bennett CL, Eden KB, et al. Decision aids for people facing health treatment or screening decisions. Cochrane Database Syst Rev. 2017;4(4):Cd001431.

5. Clarke M, Collins R, Darby S, Davies C, Elphinstone P, Evans V, et al. Effects of radiotherapy and of differences in the extent of surgery for early breast cancer on local recurrence and 15-year survival: an overview of the randomised trials. Lancet. 2005;366(9503):2087-106.

6. Favourable and unfavourable effects on long-term survival of radiotherapy for early breast cancer: an overview of the randomised trials. Early Breast Cancer Trialists' Collaborative Group. Lancet. 2000;355(9217):1757-70.

7. Bartelink $\mathrm{H}$. The changing landscape in radiotherapy for breast cancer: Lessons from long term follow-up in some European breast cancer trials. Radiother Oncol. 2016;121(3):348-56.

8. Donker M, Litière $S$, Werutsky G, Julien JP, Fentiman IS, Agresti R, et al. Breast-conserving treatment with or without radiotherapy in ductal carcinoma In Situ: 15-year recurrence rates and outcome after a recurrence, from the EORTC 10853 randomized phase III trial. I Clin Oncol. 2013;31(32):4054-9.

9. Kunkler IH, Williams LJ, Jack WJ, Cameron DA, Dixon JM. Breast-conserving surgery with or without irradiation in women aged 65 years or older with early breast cancer (PRIME II): randomised controlled trial. Lancet Oncol. 2015;16(3):266-73.

10. Kantor $\mathrm{O}$, Pesce $\mathrm{C}$, Singh P, Miller M, Tseng J, Wang $\mathrm{CH}$, et al. Post-mastectomy radiation therapy and overall survival after neoadjuvant chemotherapy. J Surg Oncol. 2017;115(6):668-76.

11. McGale P, Taylor C, Correa C, Cutter D, Duane F, Ewertz M, et al. Effect of radiotherapy after mastectomy and axillary surgery on 10-year recurrence and 20-year breast cancer mortality: meta-analysis of individual patient data for 8135 women in 22 randomised trials. Lancet. 2014;383(9935):2127-35.

12. Sagara Y, Freedman RA, Vaz-Luis I, Mallory MA, Wong SM, Aydogan F, et al. Patient Prognostic Score and Associations With Survival Improvement Offered by Radiotherapy After BreastConserving Surgery for Ductal Carcinoma In Situ: A Population-Based Longitudinal Cohort Study. J Clin Oncol. 2016;34(11):1190-6.

13. Raphael DB, Ter Stege JA, Russell NS, Boersma LJ, van der Weijden T. What do patients and health care professionals view as important attributes in radiotherapy decisions? Input for a breast cancer patient decision aid. Breast. 2020;49:149-56.

14. Raphael DB, Russell NS, Immink JM, Westhoff PG, Stenfert Kroese MC, Stam MR, et al. Risk communication in a patient decision aid for radiotherapy in breast cancer: How to deal with uncertainty? Breast. 2020;51:105-13

15. Taylor C, Correa C, Duane FK, Aznar MC, Anderson SJ, Bergh J, et al. Estimating the Risks of Breast Cancer Radiotherapy: Evidence From Modern Radiation Doses to the Lungs and Heart and From Previous Randomized Trials. J Clin Oncol. 2017;35(15):1641-9. 
16. Recht A, Comen EA, Fine RE, Fleming GF, Hardenbergh PH, Ho AY, et al. Postmastectomy Radiotherapy: An American Society of Clinical Oncology, American Society for Radiation Oncology, and Society of Surgical Oncology Focused Guideline Update. Pract Radiat Oncol. 2016;6(6):e219-e34.

17. Poortmans PMP, Arenas M, Livi L. Over-irradiation. Breast. 2017;31:295-302.

18. Kunkler IH, Canney P, van Tienhoven G, Russell NS. Elucidating the role of chest wall irradiation in 'intermediate-risk' breast cancer: the MRC/EORTC SUPREMO trial. Clin Oncol (R Coll Radiol). 2008;20(1):31-4

19. Solin LJ, Gray R, Hughes LL, Wood WC, Lowen MA, Badve SS, et al. Surgical Excision Without Radiation for Ductal Carcinoma in Situ of the Breast: 12-Year Results From the ECOG-ACRIN E5194 Study. J Clin Oncol. 2015;33(33):3938-44.

20. Bartelink H, Maingon P, Poortmans P, Weltens C, Fourquet A, Jager J, et al. Whole-breast irradiation with or without a boost for patients treated with breast-conserving surgery for early breast cancer: 20-year follow-up of a randomised phase 3 trial. Lancet Oncol. 2015;16(1):47-56.

21. Joseph-Williams N, Newcombe R, Politi M, Durand MA, Sivell S, Stacey D, et al. Toward Minimum Standards for Certifying Patient Decision Aids: A Modified Delphi Consensus Process. Medical decision making : an international journal of the Society for Medical Decision Making. 2014;34(6):699-710.

22. Engels Y, Dautzenberg M, Campbell S, Broge B, Boffin N, Marshall M, et al. Testing a European set of indicators for the evaluation of the management of primary care practices. Family practice. 2006;23(1):137-47.

23. Volk RJ, Llewellyn-Thomas H, Stacey D, Elwyn G. Ten years of the International Patient Decision Aid Standards Collaboration: evolution of the core dimensions for assessing the quality of patient decision aids. BMC medical informatics and decision making. 2013;13 Suppl 2:S1.

24. Elwyn G, O'Connor A, Stacey D, Volk R, Edwards A, Coulter A, et al. Developing a quality criteria framework for patient decision aids: online international Delphi consensus process. Bmj. 2006;333(7565):417.

25. Vromans R, Tenfelde K, Pauws S, van Eenbergen M, Mares-Engelberts I, Velikova G, et al. Assessing the quality and communicative aspects of patient decision aids for early-stage breast cancer treatment: a systematic review. Breast Cancer Res Treat. 2019;178(1):1-15.

26. Raphael Daniela DB, Russell NS, van Werkhoven E, Immink JM, Westhoff DPG, Stenfert Kroese MC, et al. Implementing a patient decision aid, a process evaluation of a large-scale pre- and post-implementation trial. Breast Cancer Research and Treatment. 2020

27. Koedoot N, Molenaar S, Oosterveld P, Bakker P, de Graeff A, Nooy M, et al. The decisional conflict scale: further validation in two samples of Dutch oncology patients. Patient education and counseling. 2001;45(3):187-93.

28. O'Connor AM. Validation of a decisional conflict scale. Med Decis Making. 1995;15(1):25-30

29. Rodenburg-Vandenbussche S, Pieterse AH, Kroonenberg PM, Scholl I, van der Weijden T, Luyten GP, et al. Dutch Translation and Psychometric Testing of the 9-Item Shared Decision Making Questionnaire (SDM-Q-9) and Shared Decision Making Questionnaire-Physician Version (SDMQ-Doc) in Primary and Secondary Care. PLoS One. 2015;10(7):e0132158.

30. [Available from: http://www.glynelwyn.com/collaborate.html.

31. Barr PJ, Thompson R, Walsh T, Grande SW, Ozanne EM, Elwyn G. The psychometric properties of CollaboRATE: a fast and frugal patient-reported measure of the shared decision-making process. J Med Internet Res. 2014;16(1):e2.
32. Barr PJ, Forcino RC, Thompson R, Ozanne EM, Arend R, Castaldo MG, et al. Evaluating CollaboRATE in a clinical setting: analysis of mode effects on scores, response rates and costs of data collection. BMJ open. 2017;7(3):e014681.

33. [28-03-2021]. Available from: http://www.patient-als-partner.de/index.php?article id $=20 \&$ clang $=2 /$.

34. Ickenroth MH, Grispen JE, de Vries NK, Dinant GJ, Ronda G, van der Weijden T. Effects of a webbased decision aid regarding diagnostic self-testing. A single-blind randomized controlled trial. Health education research. 2016;31(3):395-404

35. [Available from: https://decisionaid.ohri.ca/docs/develop/User_Manuals/UM_Decisional_ Conflict.pdf.

36. Eccles M, Grimshaw J, Campbell M, Ramsay C. Research designs for studies evaluating the effectiveness of change and improvement strategies. Qual Saf Health Care. 2003:12(1):47-52.

37. van Breukelen GJ, Candel MJ, Berger MP. Relative efficiency of unequal versus equal cluster sizes in cluster randomized and multicentre trials. Stat Med. 2007;26(13):2589-603.

38. Kriston L, Scholl I, Hölzel L, Simon D, Loh A, Härter M. The 9-item Shared Decision Making Questionnaire (SDM-Q-9). Development and psychometric properties in a primary care sample. Patient Educ Couns. 2010;80(1):94-9.

39. Sepucha KR, Borkhoff CM, Lally J, Levin CA, Matlock DD, Ng CJ, et al. Establishing the effectiveness of patient decision aids: key constructs and measurement instruments. BMC Med Inform Decis Mak. 2013;13 Suppl 2(Suppl 2):S12.

40. Garvelink MM, Boland L, Klein K, Nguyen DV, Menear M, Bekker HL, et al. Decisional Conflict Scale Use over 20 Years: The Anniversary Review. Med Decis Making. 2019;39(4):301-14.

41. Garvelink MM, Boland L, Klein K, Nguyen DV, Menear M, Bekker HL, et al. Decisional Conflict Scale Findings among Patients and Surrogates Making Health Decisions: Part II of an Anniversary Review. Medical decision making : an international journal of the Society for Medical Decision Making. 2019;39(4):315-26.

42. Vickers AJ. Decisional Conflict, Regret, and the Burden of Rational Decision Making. Medical decision making : an international journal of the Society for Medical Decision Making. 2017;37(1):3-5

43. Gärtner FR, Bomhof-Roordink H, Smith IP, Scholl I, Stiggelbout AM, Pieterse AH. The quality of instruments to assess the process of shared decision making: A systematic review. PLoS One. 2018;13(2): :0191747.

44. Hurley EA, Bradley-Ewing A, Bickford C, Lee BR, Myers AL, Newland JG, et al. Measuring shared decision-making in the pediatric outpatient setting: Psychometric performance of the SDM-Q-9 and CollaboRATE among English and Spanish speaking parents in the US Midwest. Patient Educ Couns. 2019;102(4):742-8.

45. McHorney CA, Tarlov AR. Individual-patient monitoring in clinical practice: are available health status surveys adequate? Qual Life Res. 1995;4(4):293-307.

46. Doherr H, Christalle E, Kriston L, Härter M, Scholl I. Use of the 9-item Shared Decision Making Questionnaire (SDM-Q-9 and SDM-Q-Doc) in intervention studies-A systematic review. PLoS One. 2017;12(3):e0173904

47. Couët N, Desroches S, Robitaille H, Vaillancourt H, Leblanc A, Turcotte S, et al. Assessments of the extent to which health-care providers involve patients in decision making: a systematic review of studies using the OPTION instrument. Health Expect. 2015;18(4):542-61.

48. Pieterse AH, Stiggelbout AM, Montori VM. Shared Decision Making and the Importance of Time. Jama. 2019;322(1):25-6. 
49. Silvia KA, Ozanne EM, Sepucha KR. Implementing breast cancer decision aids in community sites: barriers and resources. Health expectations : an international journal of public participation in health care and health policy. 2008;11(1):46-53

50. van der Weijden T, Post H, Brand PLP, van Veenendaal H, Drenthen T, van Mierlo LA, et al. Shared decision making, a buzz-word in the Netherlands, the pace quickens towards nationwide implementation. Zeitschrift fur Evidenz, Fortbildung und Qualitat im Gesundheitswesen. 2017.

51. Boersma LJ, Sonke GS, Verkooijen HM. [Cancer treatment; there are options]. Ned Tijdsch Geneeskd. 2019;163.

52. Franco P, lorio GC, Bartoncini S, Airoldi M, De Sanctis C, Castellano I, et al. De-escalation of breast radiotherapy after conserving surgery in low-risk early breast cancer patients. Med Oncol. 2018;35(5):62

53. Liefers GJ. [Treatment 'to be on the safe side': avoiding every risk in the case of malignancy or pre-malignancy]. Ned Tijdschr Geneeskd. 2015;159:A9517.

54. Merali Z, Wilson JR. Explanatory Versus Pragmatic Trials: An Essential Concept in Study Design and Interpretation. Clinical spine surgery. 2017;30(9):404-6.

55. Ford I, Norrie J. Pragmatic Trials. The New England journal of medicine. 2016;375(5):454-63.

56. Waldron T, Carr T, McMullen L, Westhorp G, Duncan V, Neufeld SM, et al. Development of a program theory for shared decision-making: a realist synthesis. BMC Health Serv Res. 2020;20(1):59.

57. Joseph-Wiliams N AP, Boland L, Bravo P, Brenner A, Brodney S, Coulter A, Giguere A, Hoffman A, Köerner M, Langford A, Légaré F, Matlock D, Moumjid N, Munro S, Dahl Steffensen K, Stirling C, van der Weijden T. . What Works in Implementing Patient Decision Aids in Routine Clinical Settings? A Rapid Realist Review and Update from the International Patient Decision Aid Standards Collaboration. . Med Dec Making in press.

\section{Appendices}

Appendix A. Subgroups for whom the PtDA was developed.

Patients with low-risk ductal carcinoma in situ (DCIS) after breast-conserving surgery deciding on whole/partial breast RT or no RT (DCIS group).

Patients with low-risk invasive ductal carcinoma after breast-conserving surgery deciding on whole/partial breast RT or no RT (low-risk breast cancer group).

Patients with intermediate-risk breast cancer after mastectomy deciding on thoracic wall RT or no RT (chest wall irradiation group).

Patients with intermediate-risk breast cancer after breast-conserving surgery deciding on whole breast RT with or without an extra boost dose to the tumor bed (boost/no-boost group)

\begin{tabular}{|c|c|c|c|c|c|}
\hline & $\begin{array}{l}\text { Strongly } \\
\text { Agree }\end{array}$ & Agree & $\begin{array}{c}\text { Neither } \\
\text { Agree } \\
\text { Nor } \\
\text { Disagree }\end{array}$ & Disagree & $\begin{array}{l}\text { Strongly } \\
\text { Disagree }\end{array}$ \\
\hline $\begin{array}{l}\text { I know which options are available to } \\
\text { me. }\end{array}$ & & & & & \\
\hline I know the benefit of each option. & & & & & \\
\hline $\begin{array}{l}\text { I know the risks and side effects of } \\
\text { each option. }\end{array}$ & & & & & \\
\hline $\begin{array}{l}\text { I am clear about which benefits } \\
\text { matter most to me. }\end{array}$ & & & & & \\
\hline $\begin{array}{l}\text { I am clear about which risks and side } \\
\text { effects matter most to me. }\end{array}$ & & & & & \\
\hline $\begin{array}{l}\text { I am clear about which is more } \\
\text { important to me (the benefits or the } \\
\text { risks and side effects). }\end{array}$ & & & & & \\
\hline $\begin{array}{l}\text { I have enough support from others to } \\
\text { make a choice. }\end{array}$ & & & & & \\
\hline $\begin{array}{l}\text { I am choosing without pressure from } \\
\text { others. }\end{array}$ & & & & & \\
\hline $\begin{array}{l}\text { I have enough advice to make a } \\
\text { choice. }\end{array}$ & & & & & \\
\hline $\begin{array}{l}\text { I am clear about the best choice for } \\
\text { me. }\end{array}$ & & & & & \\
\hline I feel sure about what to choose. & & & & & \\
\hline This decision is easy for me to make. & & & & & \\
\hline I feel I have made an informed choice. & & & & & \\
\hline
\end{tabular}




\begin{tabular}{|l|l|l|l|l|l|}
\hline $\begin{array}{l}\text { My decision shows what is important } \\
\text { to me. }\end{array}$ & & & & & \\
\hline I expect to stick with my decision. & & & & & \\
\hline I expect to stick with my decision & & & & & \\
\hline
\end{tabular}

Appendix D. collaborate

How much effort was made to help you understand your health issue?

\begin{tabular}{c|l|l|l|l|l|l|l|l|c}
\hline $\begin{array}{c}\text { no } \\
\text { effect }\end{array}$ & 1 & 2 & 3 & 4 & 5 & 6 & 7 & 8 & $\begin{array}{c}9 \text { every } \\
\text { effort } \\
\text { was } \\
\text { made }\end{array}$ \\
\hline
\end{tabular}

Appendix C. SDM-Q9

\begin{tabular}{|l|l|l|l|l|l|l|}
\hline & $\begin{array}{c}\text { Com- } \\
\text { pletely } \\
\text { disagree }\end{array}$ & $\begin{array}{c}\text { Strongly } \\
\text { disagree }\end{array}$ & $\begin{array}{c}\text { Some- } \\
\text { what } \\
\text { disagree }\end{array}$ & $\begin{array}{c}\text { Some- } \\
\text { what } \\
\text { agree }\end{array}$ & $\begin{array}{c}\text { Strongly } \\
\text { agree }\end{array}$ & $\begin{array}{c}\text { Com- } \\
\text { pletely } \\
\text { agree }\end{array}$ \\
\hline $\begin{array}{l}\text { My doctor made clear that a } \\
\text { decision needs to be made. }\end{array}$ & & & & & & \\
\hline $\begin{array}{l}\text { My doctor wanted to know } \\
\text { exactly how I want to be } \\
\text { involved in making the } \\
\text { decision. }\end{array}$ & & & & & & \\
\hline $\begin{array}{l}\text { My doctor told me that } \\
\text { there are different options } \\
\text { for treating my medical } \\
\text { condition. }\end{array}$ & & & & & & \\
\hline $\begin{array}{l}\text { My doctor and I thoroughly } \\
\text { weighted the different } \\
\text { treatment options. }\end{array}$ & & & & & & \\
\hline $\begin{array}{l}\text { My doctor helped me } \\
\text { understand all the } \\
\text { information. }\end{array}$ & & & & & & \\
\hline $\begin{array}{l}\text { My doctor precisely } \\
\text { explained the advantages } \\
\text { and disadvantages of the } \\
\text { treatment options. }\end{array}$ & & & & & & \\
\hline $\begin{array}{l}\text { My doctor asked me which } \\
\text { treatment I prefer. }\end{array}$ & & & & & & \\
\hline $\begin{array}{l}\text { My doctor and I selected a } \\
\text { treatment option together. }\end{array}$ & & & & & & \\
\hline $\begin{array}{l}\text { My doctor and I reached } \\
\text { an agreement on how to } \\
\text { proceed. }\end{array}$ & & & & & & \\
\hline
\end{tabular}

How much effort was made to listen to the things that matter most to you about your health issues?

\begin{tabular}{c|c|c|c|c|c|c|c|c|c|}
\hline $\begin{array}{c}0 \\
\text { no } \\
\text { effect }\end{array}$ & 1 & 2 & 3 & 4 & 5 & 6 & 7 & 8 & $\begin{array}{c}9 \text { every } \\
\text { effort } \\
\text { was } \\
\text { made }\end{array}$ \\
\hline
\end{tabular}

How much effort was made to include what matters most to you in choosing what to do next?

\begin{tabular}{|c|l|l|l|l|l|l|l|l|c|}
\hline $\begin{array}{c}0 \\
\text { no } \\
\text { effect }\end{array}$ & 1 & 2 & 3 & 4 & 5 & 6 & 7 & 8 & $\begin{array}{c}9 \text { every } \\
\text { effort } \\
\text { was } \\
\text { made }\end{array}$ \\
\hline
\end{tabular}

Appendix E. Knowledge test.

You received a lot of information about the advantages and disadvantages of choosing for radiotherapy or to leave radiotherapy out of your treatment. Here you see some questions about this subject. Please answer the questions with the knowledge you have, do not look about this subject. Pleas
up the right answers.

\begin{tabular}{|l|l|l|l|}
\hline & True & False & Don't know \\
\hline $\begin{array}{l}\text { The radiation treatment, including the time to get dressed } \\
\text { and undressed, takes } 30 \text { minutes per day. }\end{array}$ & & & \\
\hline $\begin{array}{l}\text { For the radiation treatment I have to go to the hospital on a } \\
\text { daily basis, only on the weekdays. }\end{array}$ & & & \\
\hline I will feel pain during the radiation treatment procedure. & & & \\
\hline $\begin{array}{l}\text { During the radiation treatment I will be radioactive and I will } \\
\text { not be allowed to come close to children. }\end{array}$ & & & \\
\hline $\begin{array}{l}\text { If the surgeon removed the tumor completely, radiation } \\
\text { treatment is not necessary. }\end{array}$ & & & \\
\hline $\begin{array}{l}\text { The shape and the sensitivity of my breast can change even } \\
\text { years after the radiation treatment. }\end{array}$ & & & \\
\hline $\begin{array}{l}\text { It is likely that I will feel nauseous as a consequence of the } \\
\text { radiation treatment. }\end{array}$ & & & \\
\hline $\begin{array}{l}\text { The skin reaction can worsen after the radiation treatment } \\
\text { before it gets better. }\end{array}$ & & & \\
\hline
\end{tabular}




\begin{tabular}{|l|l|l|l|}
\hline $\begin{array}{l}\text { Due to the radiation treatment, my breast might stay painful } \\
\text { in the long term. }\end{array}$ & & \\
\hline $\begin{array}{l}\text { Due to the radiation treatment, I might feel tired for some } \\
\text { weeks. }\end{array}$ & & & \\
\hline For woman who chose (additional) radiation treatment we expect that the tumour will \\
recure in 10 years \\
a. in less than 15 out of 100 woman \\
b. in more than 15 out of 100 woman \\
c. don't know
\end{tabular}

Appendix F. Patient preferences, as indicated in the self-developed questionnaire. These statements are similar to the statements asked for in the PtDA, which was developed together with patients. $\mathrm{T} 1=<3$ days after the decision, $\mathrm{T} 2$ is 3 months after the decision.

These are statements about the decision to undergo radiotherapy or to leave radiotherapy out of your treatment. We would like to ask you to read these statements and to thing about the decision you made. Please indicate whether you agree or disagree with this quote. This way, you indicate which attributes were important to you when making the decision.

\begin{tabular}{|l|c|c|c|c|}
\hline & \multicolumn{2}{|c|}{ T1 } & \multicolumn{2}{|c|}{ T2 } \\
\hline & $\begin{array}{c}\text { Control } \\
(\%)\end{array}$ & $\begin{array}{c}\text { Interven- } \\
\text { tion (\%) }\end{array}$ & $\begin{array}{c}\text { Control } \\
(\%)\end{array}$ & $\begin{array}{c}\text { Interven- } \\
\text { tion (\%) }\end{array}$ \\
\hline 1. I think the idea of radiation is really awful. & & & & \\
Fully agree & $13(6)$ & $17(9)$ & $15(7)$ & $10(6)$ \\
Agree & $72(34)$ & $60(32)$ & $64(31)$ & $57(32)$ \\
Do not agree/disagree & $54(26)$ & $42(23)$ & $51(25)$ & $48(27)$ \\
Disagree & $56(27)$ & $48(26)$ & $54(26)$ & $50(28)$ \\
Fully disagree & $15(7)$ & $16(9)$ & $23(11)$ & $14(8)$ \\
Missing & 0 & 2 & 7 & 10 \\
\hline 2. I'll do whatever it takes to reduce the & & & & \\
chances of tumor recurring & & & & \\
Fully agree & $88(42)$ & $70(39)$ & $82(39)$ & $62(35)$ \\
Agree & $79(38)$ & $61(34)$ & $88(42)$ & $74(41)$ \\
Do not agree/disagree & $21(10)$ & $27(15)$ & $25(12)$ & $26(15)$ \\
Disagree & $18(9)$ & $21(12)$ & $13(6)$ & $16(9)$ \\
Fully disagree & $4(2)$ & $1(.6)$ & $1(.5)$ & $1(.6)$ \\
Missing & 0 & 5 & 5 & 10 \\
\hline 3. I'm put off by the idea of daily radiation & & & & \\
treatment/extra days of radiotherapy (boost) & & & & \\
Fully agree & $7(3)$ & $9(5)$ & $11(5)$ & $5(3)$ \\
Agree & $69(33)$ & $41(23)$ & $68(33)$ & $49(27)$ \\
Do not agree/disagree & $51(24)$ & $44(25)$ & $42(20)$ & $49(27)$ \\
Disagree & $64(31)$ & $64(36)$ & $69(33)$ & $55(31)$ \\
Fully disagree & $18(9)$ & $21(12)$ & $19(9)$ & $21(12)$ \\
Missing & 1 & 6 & 5 & 10 \\
\hline
\end{tabular}

\begin{tabular}{|l|c|c|c|c|}
\hline 4. I'm put off by the radiation side effects & & & & \\
Fully agree & $33(16)$ & $39(22)$ & $32(15)$ & $27(15)$ \\
Agree & $88(42)$ & $80(44)$ & $81(39)$ & $77(43)$ \\
Do not agree/disagree & $40(19)$ & $36(20)$ & $42(20)$ & $38(21)$ \\
Disagree & $41(20)$ & $21(12)$ & $43(21)$ & $31(17)$ \\
Fully disagree & $7(3)$ & $5(3)$ & $11(5)$ & $6(3)$ \\
Missing & 1 & 4 & 5 & 10 \\
\hline 5. The cosmetic result in the long term is & & & & \\
important to me & & & & \\
Fully agree & $14(7)$ & $13(7)$ & $13(6)$ & $7(4)$ \\
Agree & $42(20)$ & $57(32)$ & $45(22)$ & $49(28)$ \\
Do not agree/disagree & $62(30)$ & $51(28)$ & $62(30)$ & $61(34)$ \\
Disagree & $67(32)$ & $47(26)$ & $63(30)$ & $48(27)$ \\
Fully disagree & $25(12)$ & $12(7)$ & $25(12)$ & $13(7)$ \\
Missing & 0 & 5 & 6 & 11 \\
\hline 6. Choosing for $\quad$ radiotherapy/extra & & & & \\
radiotherapy (boost) gives me peace of mind & & & & \\
Fully agree & $31(15)$ & $27(15)$ & $28(13)$ & $23(13)$ \\
Agree & $66(31)$ & $46(25)$ & $72(34)$ & $52(29)$ \\
Do not agree/disagree & $39(19)$ & $36(20)$ & $47(22)$ & $36(20)$ \\
Disagree & $57(27)$ & $54(30)$ & $48(23)$ & $48(27)$ \\
Fully disagree & $17(8)$ & $19(10)$ & $14(7)$ & $20(11)$ \\
Missing & 0 & 3 & 5 & 10 \\
\hline 7. What my health care provider advises is & & & & \\
important to make a decision & & & & \\
Fully agree & $50(24)$ & $31(17)$ & $38(18)$ & $40(22)$ \\
Agree & $126(60)$ & $114(63)$ & $114(55)$ & $94(53)$ \\
Do not agree/disagree & $22(11)$ & $25(14)$ & $32(15)$ & $22(12)$ \\
Disagree & $8(4)$ & $8(4)$ & $18(9)$ & $20(11)$ \\
Fully disagree & $4(2)$ & $2(1)$ & $7(3)$ & $4(2)$ \\
Missing & 0 & 5 & 5 & 10 \\
\hline 8. I feel a responsibility towards those close to & & & & \\
me to choose radiotherapy/extra radiotherapy & & & & \\
(boost) & $18(9)$ & $12(7)$ & $22(11)$ & $12(7)$ \\
Fully agree & $52(25)$ & $26(14)$ & $39(19)$ & $31(17)$ \\
Agree & $45(21)$ & $37(20)$ & $52(25)$ & $35(20)$ \\
Do not agree/disagree & $69(33)$ & $75(41)$ & $69(33)$ & $69(39)$ \\
Disagree & $26(12)$ & $32(18)$ & $27(13)$ & $32(18)$ \\
Fully disagree & 0 & 3 & 5 & 10 \\
Missing & & & & \\
\hline
\end{tabular}




\begin{tabular}{|c|c|c|c|c|}
\hline $\begin{array}{l}\text { 9. Reasons other than those mentioned above } \\
\text { were the most important to me in making my } \\
\text { decision } \\
\text { Fully agree } \\
\text { Agree } \\
\text { Do not agree/disagree } \\
\text { Disagree } \\
\text { Fully disagree } \\
\text { Missing }\end{array}$ & \begin{tabular}{|l} 
\\
\\
$17(8)$ \\
$50(24)$ \\
$59(29)$ \\
$57(27)$ \\
$24(12)$ \\
3
\end{tabular} & $\begin{array}{l}9(5) \\
44(24) \\
60(33) \\
46(26) \\
21(12) \\
5\end{array}$ & \begin{tabular}{|ll}
20 & $(9)$ \\
47 & $(22)$ \\
63 & $(30)$ \\
60 & $(28)$ \\
17 & $(8)$ \\
7
\end{tabular} & $\begin{array}{l}12(7) \\
42(24) \\
56(31) \\
51(29) \\
17(10) \\
11\end{array}$ \\
\hline \multicolumn{5}{|c|}{$\begin{array}{l}\text { Can you identify which } 3 \text { aspects from the } 9 \text { mentioned above were the most important for } \\
\text { you when making the choice to undergo radiotherapy or not? (patients could fill in } 3 \text { boxes } \\
\text { on the form). }\end{array}$} \\
\hline & \multicolumn{4}{|c|}{\begin{tabular}{|l}
$\mathrm{T} 1$ \\
\end{tabular}} \\
\hline Question & $\begin{array}{c}\text { Control } \\
(\%)\end{array}$ & Order* & \begin{tabular}{|c|} 
Interven- \\
tion (\%)
\end{tabular} & Order* \\
\hline 1. I think the idea of radiation is really awful. & $36(6)$ & 7 & $25(5)$ & $7 / 8$ \\
\hline $\begin{array}{l}\text { 2. I'll do whatever it takes to reduce the } \\
\text { chances of tumor recurring }\end{array}$ & $138(23)$ & 1 & $94(19)$ & 2 \\
\hline $\begin{array}{l}\text { 3. I'm put off by the idea of daily radiation } \\
\text { treatment/extra days of radiotherapy (boost) }\end{array}$ & $28(5)$ & 8 & $16(3)$ & 9 \\
\hline 4. I'm put off by the radiation side effects & $71(12)$ & 4 & $74(15)$ & 3 \\
\hline $\begin{array}{l}\text { 5. The cosmetic result in the long term is } \\
\text { important to me }\end{array}$ & $24(4)$ & 9 & $25(5)$ & $7 / 8$ \\
\hline $\begin{array}{l}\text { 6. Choosing for radiotherapy/extra } \\
\text { radiotherapy (boost) gives me peace of mind }\end{array}$ & $81(14)$ & 3 & $69(14)$ & 4 \\
\hline $\begin{array}{l}\text { 7. What my health care provider advises is } \\
\text { important to make a decision }\end{array}$ & $124(21)$ & 2 & $102(21)$ & 1 \\
\hline $\begin{array}{l}8 . \text { I feel a responsibility towards those close to } \\
\text { me to choose radiotherapy/extra radiotherapy } \\
\text { (boost) }\end{array}$ & $45(8)$ & 5 & $34(7)$ & 6 \\
\hline $\begin{array}{l}\text { 9. Reasons other than those mentioned above } \\
\text { were the most important to me in making my } \\
\text { decision }\end{array}$ & $44(7)$ & 6 & $47(10)$ & 5 \\
\hline \multirow[t]{2}{*}{ Total } & 591 & & 486 & \\
\hline & \multicolumn{4}{|c|}{ T2 } \\
\hline
\end{tabular}

\begin{tabular}{|l|c|c|c|c|}
\hline & $\begin{array}{c}\text { Control } \\
(\%)\end{array}$ & Order* & $\begin{array}{c}\text { Interven- } \\
\text { tion (\%) }\end{array}$ & Order* \\
\hline $\begin{array}{l}\text { 1. I think the idea of radiation is really awful } \\
\text { 2. I'll do whatever it takes to reduce the }\end{array}$ & $26(5)$ & 8 & $32(7)$ & 6 \\
chances of tumor recurring & 1 & $100(20)$ & 1 \\
\hline $\begin{array}{l}\text { 3. I'm put off by the idea of daily radiation } \\
\text { treatment/extra days of radiotherapy (boost) }\end{array}$ & $30(5)$ & 7 & $20(4)$ & 8 \\
\hline $\begin{array}{l}\text { 4. I'm put off by the radiation side effects } \\
\text { 5. The cosmetic result in the long term is }\end{array}$ & $58(10)$ & 4 & $72(15)$ & 3 \\
\hline $\begin{array}{l}\text { important to me } \\
\begin{array}{l}\text { 6. Choosing for radiotherapy/extra } \\
\text { radiotherapy (boost) gives me peace of mind }\end{array}\end{array}$ & $92(16)$ & 3 & $19(4)$ & 9 \\
\hline $\begin{array}{l}\text { 7. What my health care provider advises is } \\
\text { important to make a decision }\end{array}$ & $117(21)$ & 2 & $97(20)$ & 2 \\
\hline $\begin{array}{l}\text { 8. I feel a responsibility towards those close to } \\
\text { me to choose radiotherapy/extra radiotherapy } \\
\text { (boost) }\end{array}$ & $45(8)$ & 6 & $31(6)$ & 7 \\
\hline $\begin{array}{l}\text { 9. Reasons other than those mentioned above } \\
\text { were the most important to me in making my } \\
\text { decision }\end{array}$ & $47(8)$ & 5 & $50(10)$ & 5 \\
\hline Total & 561 & & 492 & \\
\hline
\end{tabular}




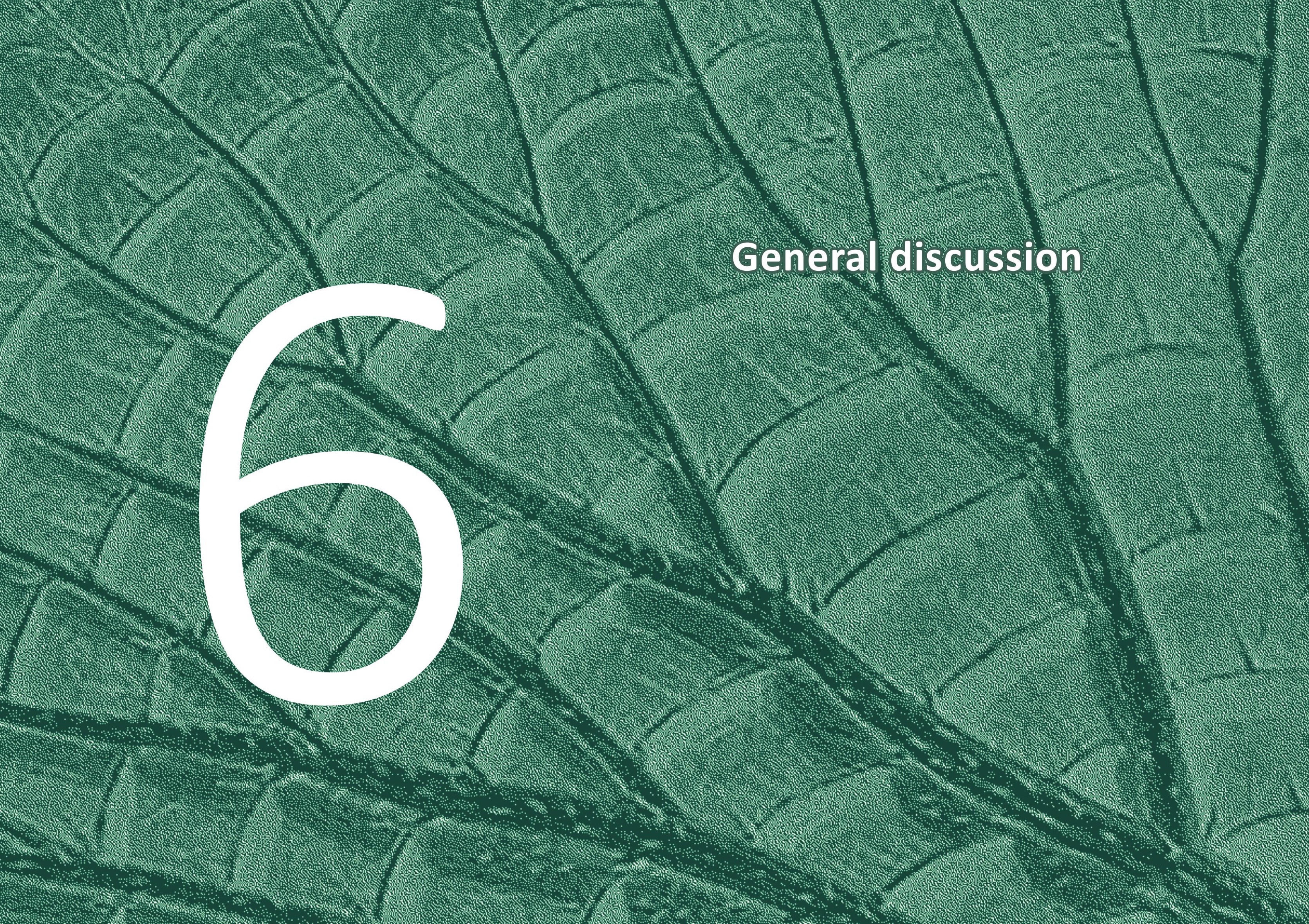


This chapter starts with an overview of the research questions and a summary of the main results of this thesis. Subsequently, insight is given on the added value of these results and provide a critical appraisal of the strengths and limitations of the full thesis. Lastly, we finish with a conclusion and recommendations for practice and for future research.

\section{Research questions}

In some situations, the policy to advise the administration of post-operative radiotherapy (RT) in breast cancer patients is not clear-cut based on clinical trial results and scientific evidence. In these patient groups, post-operative RT lowers the (local) recurrence risk but can cause side effects, without a clear survival benefit. Therefore, the indication for (additional) RT can be considered a "gray area" or, in other words, a preference-sensitive decision. Patients and clinicians in these cases should work together to find the treatment for the patient that best fits her personal situation and preferences. This process is called shared decision making (SDM). To support clinicians and patient in the process of SDM, patient decision aids (PtDAs) can be used.

We developed a PtDA for breast cancer patients deciding on their RT treatment. The PtDA was developed for: 1) patients with Ductal Carcinoma In Situ (DCIS) deciding on (whole) breast RT or no RT after breast-conserving surgery, 2) patients with a very lowrisk invasive breast cancer deciding on (whole) breast RT or no RT after breast-conserving surgery, 3) patients with an intermediate-risk breast cancer deciding on chest wall RT after mastectomy, and 4) patients with an intermediate-risk breast cancer deciding on RT with or without an extra boost dose to the tumor bed after breast-conserving surgery. In this thesis we aimed to evaluate the development of the PtDA, analyze the effect of the PtDA in daily clinical practice, and investigate barriers and facilitators for implementation of the PtDA. The four research questions we investigated were:

1. What are patients' and health care professionals' experiences, decisional attributes, and needs as input for the development of a patient decision aid for breast cance patients, deciding on radiation treatment, to facilitate SDM?

2. How can we incorporate uncertainties in a patient decision aid for breast cancer patients to support their decision on radiation treatment?

3. What are important patient, clinician, and organizational success factors for implementing a patient decision aid, designed for breast cancer patients, facing a decision on their radiation treatment?

4. What is the effect of a patient decision aid for breast cancer patients deciding on radiation treatment, on decisional conflict, perceived SDM and knowledge on treatment options? 


\section{Summary of the main results}

What are patients' and health care professionals' experiences, decisional attributes and needs as input for the development of a patient decision aid for breast cancer patients, deciding on radiation treatment, to facilitate SDM? We performed a qualitative study interviewing 15 breast cancer patients that had faced a decision on RT in the past, as well as 15 breast cancer clinicians. We found that patients and clinicians agreed on the importance of communicating local recurrence risks and survival benefit. They did differ on their perspectives on communicating the uncertainty around the numbers. Although some patients did remember the exact numbers mentioned to them in consultation, others only remembered a sense of the risk of a recurrence being low or high. No patient mentioned or remembered the clinician mentioning an uncertainty margin. Clinicians, on the other hand, were aware of the uncertainty margins around risk estimates and they indicated that it is important to mention them in consultations and to incorporate them in the PtDA to be developed. Most patients only remembered a few possible side effects mentioned by their clinician. Between clinicians, there was wide variation in the number of side effects that they believed were important to mention to patients. We also found a difference in framing of the side effects. While patients often mentioned skin burn and deformation of the breast as possible side effects, these side effects were framed as skin reaction and fibrosis by the clinicians. The most important short-term side effects mentioned were red and sensitive skin, edema, tiredness, and pain of the breast. The most important long-term side effects mentioned were fibrosis and change in breast shape, edema, (dark) skin discoloration, pain, rib complications, heart problems, and lung problems. The treatment burden-a daily visit to a radiation clinic for 3-4 weeks-was no mentioned as an important attribute when choosing for RT or not, neither by patients or clinicians.

How can we incorporate uncertainties in a patient decision aid for breast cancer patients to support their decision on radiation treatment? With the results of the interviews, the research team made a first draft version of the PtDA. This draft version was used for further development of the decision aid in collaboration with four patient advocates and 12 clinicians. The final version of the PtDA was developed in four different rounds of individual Think Aloud sessions with patient advocates and group meetings with patien advocates, the research team, and clinicians. During the development of the PtDA, most debate emerged on the risk communication of the local recurrence risks, potentia survival benefit, and side effects. Consensus was reached on communicating the local recurrence risk with an uncertainty range. This was done with a pictogram illustrating 100 female icons in a 10x10 array. The female figures indicating the uncertainty margins were displayed as icons with a step-by-step color gradient. On the back of the pictograms, there was a textual explanation on the possible recurrence risk and uncertainty margin. There was agreement on mentioning the absence of, or only small effect on, survival benefit in words only. The prognosis on expected side effects and severity of the potential side effects was framed with qualitative labels, due to lack more of precise evidence-based numbers. The patient decision aid was evaluated by Vromans et al. (1), and scored 83 out of 100 points.
What are important patient, clinician, and organizational success factors for implementing patient decision aid, designed for breast cancer patients, facing a decision on their radiation treatment? A process evaluation was performed on the intervention arm of the pre- and post-intervention study (BRASA-study). The intervention consisted of providing the PtDA to the four groups of breast cancer patients with a preference-sensitive indication for RT as mentioned above. In total, 189 patients from 13 different RT centers in the Netherlands were included. The logistics of the trial and implementation of the PtDA were adjusted as much as possible to the existing logistics of the participating centers. Ideally, patients were identified as being eligible for the study during the multidisciplinary team meeting. They received a link to the online PtDA via the surgery department during the post-operative consultation, or via the RT department. Patients who received the link via the RT department, received the link either via mail prior the consultation, or during the post-operative consultation at the RT department. We found a very high PtDA uptake (77\% of patients logged in to the PtDA). When patients received the PtDA from the surgery department, prior the consultation with their radiation oncologist, they were more likely to use the PtDA than patient who received the link from their radiation oncologist (OR $9.77,95 \% \mathrm{Cl} 1.28,74.51$ ). Patients were more likely to use the PtDA if there was a note in their report of the multidisciplinary team meeting that "RT should be discussed with the patient" (OR 2.29, 95\% Cl 1.12,4.71).

What is the effect of a patient decision aid for breast cancer patients deciding on radiation treatment, on decisional conflict, perceived SDM and knowledge on treatment options? To answer this question, we evaluated the data of the pre- and post-intervention study. In the pre-intervention arm, the control arm, 214 patients were included. These patients received standard care when deciding on their RT. In the post-intervention arm, the intervention arm, 189 patients were included. These patients received a link to the PtDA to support them and their clinicians in the decision-making process deciding on their RT In total, 104 different clinicians included patients. Our primary outcome was decisional conflict 3 months after the decision was made. The secondary outcomes were decisional conflict, perceived SDM, and knowledge about the different treatment options, measured $<3$ days after the decision was made. We performed multi-level regression analysis, where we corrected for age and educational level. No difference was found between the contro and the intervention arm in our primary outcome, decisional conflict three months after the decision was made ( 26.8 vs 27.3 , corrected mean difference $0.86,95 \% \mathrm{Cl}-1.67,3.36$ ). In addition, no difference was found on our secondary outcomes: decisional conflict $<3$ days after the decision was made and perceived level of SDM. Patients who received the link to the PtDA did score higher on the knowledge test (6.1 versus 7.4 , corrected difference 1.0 , $95 \% \mathrm{Cl} 0.50,1.49)$, and chose less often for a more intensive radiation treatment $(55.7 \%$ versus $44.5 \%$, OR $0.59,95 \% \mathrm{Cl} 0.37,0.95$ ).

\section{Added value of this thesis}

Development of a patient decision aid for breast cancer patients deciding on RT We developed the PtDA according to the International Patient Decision Aids Standard (IPDAS-criteria, 2). According to these criteria, a PtDA should describe the positive 
and negative features of the different treatment options. However, which positive and negative features should be mentioned in case of breast cancer patients deciding on RT was not known at the start of the project. We were able to clarify a number of issues, as described in this thesis.

Risk communication in a PtDA

We found agreement on the importance of communicating the risk of a local recurrence when deciding on RT. While patients did not mention the uncertainty around these numbers, clinicians felt it was important to communicate the range of uncertainty around the estimated local recurrence risk. In the literature, a distinction is made between aleatory or first-order uncertainty (the chance of an event taking place or not), and epistemic or second-order uncertainty (the uncertainty around a risk estimate). In our study, clinicians believed it was important to mention the range around the risks estimates (epistemic uncertainty) in the PtDA, from literature it is known that epistemic uncertainty is not frequently mentioned in consultation. It is also known that communicating uncertainty in a comprehensive way is challenging and patients find it hard to understand. Engelhardt et al. audiotaped 197 consultations of breast cancer patients with their clinician (3). n only 23 of these 197 consultations, epistemic uncertainty was mentioned by the clinician. Th research team interviewed the patients after consultation, but most of these patients did not recall this epistemic uncertainty (3). Thus, the patients in the qualitative study did not mention that epistemic uncertainty was communicated to them. However, in our group meetings with health professionals and patients in the development phase of the final PtDA, the patients did understand why clinicians found it important to mention the uncertainty range. They agreed on the importance of communicating the epistemic uncertainty. Harrison et al. found in a review on web-based prognosis tools that only in $14 \%$ of the tools, epistemic uncertainty was described (4). Bansback et al. reviewed 460 patient decision support interventions. They found that if epistemic uncertainty was mentioned in patient decision support interventions, this was usually done in a qualitative way (5). A possible explanation why uncertainty is not frequently mentioned in decision support tools is that little is known about the best way to do this. Garcia-Retamero et al. showed in a review that visual aids improve risk communication, especially in vulnerable patients (6). It is known that when risks are communicated in a qualitative way only, these risks are overestimated. Therefore, it is recommended to use verbal risk estimation in combination with numerical estimates (7). In our trial, consensus was reached on communicating the uncertainty margin in a pictogram in combination with a textual explanation. Icon arrays were chosen for the pictograph since they are frequently used in PtDAs and are considered comprehensive for patients $(8,9)$. Our novel way of indicating uncertainty margins for the local recurrence risk in an online PtDA might therefore be a starting point for more research.

\section{Communication of side effects in a PtDA}

According to our qualitative study, the negative aspect when choosing for RT are the possible side effects. We found that patients and clinicians agreed on the most important side effects that should be mentioned in a PtDA for breast cancer patients deciding on RT We did find a difference in framing of the possible side effects. Although clinicians described the normal tissue effect as fibrosis, scar tissue, or change in shape, patients framed this reaction of the normal tissue as misshaping or deformation. Skin toxicity was framed as skin reaction or dermatitis by clinicians, whereas this was framed as skin burn by the patients. Apart from the framing, from literature it is known that there is a discrepancy in experienced severity of the side effects between patient-reported and clinician-reported outcomes. For example, fibrosis of the breast after RT is known to result in worse cosmetic outcome. Therefore, cosmetic outcome is frequently used as an outcome measure for fibrosis. Different trials use either patient-reported cosmetic outcome, physician-reported cosmetic outcome or objective measurements with photographs of the breast. In the Young Boost Trial (NCT00212121), young ( $\leq 50$ years of age) breast cancer patients were randomized to receive an extra boost dose to the tumor bed of 16 Gy or $26 \mathrm{~Gy}$. Cosmetic outcome was measured using all three types of different measurements. They found only a moderate agreement on cosmetic outcome between patient-reported and physicianreported outcomes (10). Similarly, in the IMPORT LOW trial which investigated different radiation volumes, patient-reported outcomes, clinician-reported outcomes, and photographs were used to measure the normal tissue effect. They found poor concordance between patient-reported and clinician-reported outcomes. Patients reported more often more severe side effects than clinicians (11). Brouwers et al. also found a concordance of only $58 \%$ between patient-reported outcomes and clinician-reported outcomes for breast cancer patients after RT (12). More agreement was seen between patient-reported and clinician-reported outcomes in a review by Lam et al. on skin toxicity (13). Which and how the risk and severity of side effects should be communicated in a PtDA is therefore up for debate. Reliable data on the prevalence and severity of possible side effects are lacking. One of the reasons for this lack of data is that side effects after RT develop months to years after RT. Clinical and trial follow-up of patients is in general only 5-10 years; therefore, the incidence and severity of very late side effects after breast RT is not well documented. In the last decade, initiatives such as Utrecht Cohort for Multiple Breast Cancer Intervention Studies and Long-term Evaluation, The UMBRELLA (NCT02839863), a prospective cohort trial, measuring quality of life in breast cancer patients eligible for RT have been set up to acquire more patient reported outcome data (14). Our qualitative study gave insigh that there is not only an experienced discrepancy in the incidence and severity of the side effects, but that the reason for this might be the difference in framing of the side effects as well. Considering the results of our qualitative study, we argue that patient-reported outcomes and framing the side effects in accordance with patients' perspectives should be taken into account when communicating side effects in a PtDA.

mplementation of a patient decision aid for breast cancer patients deciding on RT In the last decades, there has been a strong movement towards SDM. PtDAs have proven to be helpful in supporting the SDM process in clinical trials (15). Although many PtDAs have been developed (16), implementation in daily clinical practice lags behind (17). The clinical trial described in this thesis demonstrated how it is possible to incorporate the use of a PtDA into routine clinical practice.

Although much effort has been put into researching the facilitators and barriers of implementing PtDAs and SDM in clinical practice, no clear answers have been found yet (18). Waldron et al. recently developed a "program theory for SDM" (19). They conclude that the process of SDM is very complex and can vary across different situations and 
contexts. In our study population, there was a high perceived level of SDM reported in the groups with and without the opportunity to use the PtDA. During the clinical trial, we observed a very high uptake of the PtDA as $77 \%$ of patients who received the link to the PtDA logged in to the PtDA. We hypothesize that one of the reasons why we reached such a high uptake, is that the PtDA was developed by the research team in collaboration with patient advocates and clinicians from the field. The project was initiated by radiation oncologists from the field, who perceived an unmet need for a PtDA for breast cancer patients deciding on post-operative RT in the clinic. Therefore, the development and testing of the PtDA was a bottom-up initiative. In total, 12 clinicians from 11 different RT clinics were present at the group meetings during the development of the PtDA, two other clinicians from two more RT centers gave input on the PtDA by e-mail. During the pre-and post-intervention study, 14 RT centers agreed to participate in the trial. Since there are 19 RT centers in the Netherlands, we feel that this is a substantial proportion

Facilitators for PtDA implementation

Analyzing the facilitators of better PtDA uptake in our trial, we found that if there was a note in the multidisciplinary team report that "RT had to be discussed with the patient", patients were more likely to use the PtDA. This has also been found by Savelberg et al. to be an important facilitator for PtDA implementation (20). They found that when a decision for one of the treatment options is already made by the multidisciplinary team, this creates an "uneven balance between the patient and the clinician". The important role for the multidisciplinary team was also confirmed in a qualitative study by Scholl at al., who interviewed cancer care stakeholders on important barriers and facilitators of implementing SDM in clinical practice (21).

We also found that if the link to the PtDA was handed over to the patient by the surgeon prior the consultation with the radiation oncologist, more patients logged in to the PtDA than when patients received the link to the PtDA from the radiation oncologist. A possible explanation is that in most cases, the surgeon is the principal treating clinician for the patients. When they receive the link to the PtDA from their surgeon, patients are already primed that choosing for RT in their case is a preference-sensitive decision, and that their surgeon agrees that the treatment is preference-sensitive. When they are referred to the radiation oncologist by their surgeon to receive radiation treatment, not explaining that it is a preference-sensitive decision, this may cause a conflict for patients. They might get the feeling that choosing against RT conflicts with the treatment advice of their treating surgeon. Another possible explanation might be the timing of receiving the link to the PtDA. Patients who received the link to the PtDA from the surgery department, received the link prior to the consultation with the radiation oncologist. A number of the patients who received the link to the PtDA from the radiation oncology department in our trial, also received the link to the PtDA prior the consultation with the radiation oncologist via regular mail. Unfortunately, this was not foreseen when we developed the questionnaire, such that we have no data on the exact timing that patients received the PtDA link.

We found that there was no difference in consultation time between patients who received the PtDA link, compared to patients who did not receive the PtDA link. In the intervention arm, we also found no difference in consultation time between patient who had used the PtDA and those who had not used it. Since an expected increase in consultation time is described as an important barrier by Waldron et al., we hope that the finding that there was no increase in consultation time will facilitate PtDA implementation in the future $(19,22)$

In a recent review by Joseph-Williams et al. aiming to create a theory program on PtDA implementation, some of the strategies we applied for implementation, are described (23). First, they describe the importance of co-production of the tool and implementation with the end-user. They address the importance of the trust in the tool and the tool fitting into the care setting. As mentioned above, our PtDA was developed in collaboration with patient advocates and clinicians. Furthermore, we incorporated the implementation of the PtDA and the trial logistics as much as possible to the logistics of the different participating centers. Secondly, they mention "preparing and prompting" the patient for the PtDA. Patients should be prepared for the decision to be made. They describe that patients should be explained the purpose of the PtDA prior to the consultation, to preven them from being overwhelmed by the decision to be made during consultation. This is also in line with our results: we saw better PtDA uptake in patients who received the link via the surgery department prior to the consultation with the radiation oncologist. A third point addressed by the review is the importance of leadership in PtDA implementation in the clinic. In our study, we had dedicated principal investigators in all participating centers. Almost all of the principal investigators of the participating centers also took part in the development of the PtDA. In short, we think that the results of our real life trial are confirmed by the theoretical model and that these facilitators for implementation can be taken into account in further research and implementation of PtDAs.

Barriers for PtDA implementation

We did not, however, tackle all the implementation strategies mentioned by Joseph William et al. since we did not provide extensive training to the participating clinicians. We did offer a free online training on SDM, but this was only a limited online course which was also not obligatory to follow. Appropriate training is also pointed out as an important facilitator in the program theory by Waldron et al. (19)

\section{Strengths and limitations of this thesis}

Limitations

In our study, we found no effect of the PtDA on decisional conflict and experienced level of SDM. One of the possible explanations why we did not find an effect on the experienced evel of SDM is that we did not provide extensive training as mentioned above. Anothe explanation might be the lack of a good tool to measure the level of SDM. Recently Bomhof Roordink et al. published a new tool to measure SDM, the I-SHARE questionnaire (24). They argue that the existing tools, such as the collaboRATE and the SDM-Q9, which we used in our trial, do not fully cover the "underlying construct" of the SDM process and focus on one consultation only. The I-SHARE questionnaire, however, was not yet available durin our clinical trial. However, we also did not find any difference in decisional conflict scores between the intervention and control arms in our study, neither immediately after the 
decision was made nor three months later. We hypothesize two possible explanations. First, in a review, Garvelink et al. found a significant difference only in a short time frame after the decision was made, with lower decisional conflict reported by patients who received the PtDA ), suggesting that a long-term effect of a PtDA on DCS might be hard to measure (25). Second, we found relatively low decisional conflict in both the intervention arm as well as the control arm (26-27 out of 100), possibly not leaving enough room for improvement. We did find a positive effect of the PtDA on patient knowledge and patients choosing for less intensive treatments, without causing longer consultations.

We performed a pre- and post-intervention study, as opposed to a randomized clinical trial, which is considered the golden standard to produce an evidence base for medical policy. However, we expected that a randomized clinical trial would induce bias, because there might be a learning curve from clinicians in SDM when they treat patients who do receive the link to the PtDA and patients who do not. Therefore, the only option would have been to randomize RT centers, meaning that half of the RT centers would offer the PtDA to patients and the other half would not. Because clinicians from almost all participating centers wanted to participate in the development of the PtDA we felt that performing a randomized clinical trial, randomizing RT centers would not be feasible. We first included breast cancer patients in our trial who had a preference-sensitive treatment decision in their radiation treatment in one of the four gray areas identified in our study. These patients received standard care and did not receive support from the PtDA. At this time, the PtDA was still in development and therefore not available to the clinics. The intervention arm was started in the trial after recruitment to the control arm was completed and as soon as the PtDA was ready for use. Patients in the control arm did thus not receive a link to the PtDA. A disadvantage of this study design is that we cannot rule out the effect of time in our study results. For example, later patients may have chosen less intensive treatments, not because of the effect of the PtDA but because there is a movement towards treatment de-escalation and clinicians may have changed the way they inform their patients (26-28). We also found that patients in the intervention arm were slightly younger and more highly educated than patients in the control arm. From literature it is known that there is relationship between SDM and health literacy. More highly educated patients are associated with a higher health literacy, and patients with a higher health literacy are more involved in $\operatorname{SDM}(29,30)$. Molina et al. investigated the "preferred approach" in the decision-making process of women deciding on prenatal genetic testing (31). They found that women with a lower health numeracy more often had a preference for a more paternalistic approach in the decisionmaking process, i.e., they wanted the clinician to make the healthcare decision. More highly educated women more often preferred a more autonomous or participatory approach. However, we asked participating clinicians to include all patients who were offered the PtDA in the intervention arm, also if the patient did not want to use the PtDA. In the intervention arm, we saw no difference in age or educational level between patients who did or did not use the PtDA. Therefore, we hypothesize that the difference in patient characteristics between the intervention and the control arm is mainly due to selection bias. Clinicians may have only included patients in the study who said that they wanted to use the PtDA, or they may have offered study participation more often to younger and higher educated patients. This is also suggested by Ousseine et al. who found that patients with a lower health literacy experienced a lower level of effort from the clinicians to involve them in SDM (30).
A shortcoming of our trial is that we did not perform an economic evaluation of the implementation of our tool. A recent review by Scalia et al. investigated whether PtDAs result in lower health care costs (32). They found 22 heterogeneous studies, of which 12 reported cost savings and 10 did not. Therefore, they could not draw firm conclusions. Policymakers, however, do not only look at the costs but more at cost-effectiveness/ qualityadjusted life years. The costs of introducing a PtDA mostly lie in the development and maintenance of the tool. Since PtDAs are mostly used for preference-sensitive decisions, with comparable medical outcomes, such as our PtDA, no gained life years saved are expected. We did find that patients who received the PtDA chose less often for more intensive treatments, which reduces treatment costs. In other studies it has been shown that SDM results in improvements in patient-reported health outcomes (33). This can also be accounted as gain in quality -adjusted life years. Not many studies investigating the effect of PtDAs have looked at the cost-effectiveness of PtDAs (34). However, some literature has investigated the cost-effectiveness of PtDAs and found that PtDAs can be cost-effective, e.g. the BRECONDA trial (evaluating the cost-effectiveness of a PtDA for breast cancer patients choosing for different types of breast reconstructions in Australia) and a trial by Cantor et al. on screening for colon cancer $(35,36)$. These trial results, however, are hard to compare with our trial because of the large differences between clinical decisions under study. On the other hand, we could argue whether the lack of an economic evaluation is really a limitation of our study, since SDM is considered to be a right for patients, such that it does not matter whether the implementation of SDM is cost effective or not.

Strengths

It has been argued that splitting of effectiveness trials and implementation trials result in less knowledge on implementation in the clinic (37). Therefore Curran et al. proposed a hybrid study design in which the effect and implementation of a new tool can be tested simultaneously, facilitating post-trial implementation (37). Our pre- and post-intervention design, testing the effect of the PtDA while simultaneously implementing the tool, can be viewed as such a hybrid study design (37-39). Explanatory trials are mostly designed to prove the effectiveness of an intervention. Therefore, trial logistics are mostly protocolled, to prevent introduction of bias. This can result in trial logistics not fitting into the logistics of all clinical centers, hindering post-trial implementation. Our pragmatic study design adjusted the trial and logistics to offer the link of the PtDA to the logistics of the different participating centers.

As stated before, we believe that an important strength of our study is that it is a bottom up initiative. The project was initiated and performed by radiation oncologists who faced problems with preference-sensitive decisions from the field.

\section{Conclusion}

We conclude that both patients and clinicians agree that the local recurrence risks and the side effects following RT should be communicated in a PtDA. Clinicians find it importan to also communicate the uncertainty around these risks, acknowledging the difficulties in communicating this uncertainty to patients. In addition, there is a discrepancy in the framing of the side effects between patient and clinicians: clinicians frame side effects by their biological etiology, but patients frame them by their effect on their quality of life. From 
our pre- and post-intervention study, we conclude that a note in the multi-disciplinary team report that the post-operative RT treatment has to be discussed with the patient facilitates the use of the PtDA. The same holds true for handing the link to the PtDA is handed to the patient by the surgery department, prior the consultation with the radiation oncologist. In addition, use of the PtDA was associated with an increased knowledge, and with a choice for less intensive RT, but it had no statistically significant effect on decisional conflict and experienced level of SDM. Based on this finding in combination with the literature, we conclude that handing out the PtDA is not sufficient, and we probably we should have paid more attention on training aspects.

\section{Future perspectives}

The development and implementation of PtDAs and SDM is a hybrid process in which clinical practice and research overlap and strengthen each other. Therefore, the future perspectives in this section are ordered by theme, rather than divided into recommendations for practice and research.

\section{Implementation of SDM in clinical practice}

As known from literature and found in our study, the implementation of a PtDA alone is not sufficient for implementation of SDM. Therefore, the question remains on how PtDAs can contribute to the implementation of SDM and what more is needed for widespread implementation of PtDAs and SDM in daily clinical practice. As stated before, training of clinicians has been described as one of the most important attributes for implementation of PtDAs and SDM. In addition, training and awareness among patients have been described as important attributes. The "ask three questions campaign" started in Australia and England, and it has been shown to improve patents involvement in the consultation (40). This campaign aims to create awareness among patients to participate in the decision-making process regarding their treatment. The three questions patients should ask themselves and their clinicians are: 1 . What are my options? 2.What are the possible benefits and risks of those options? 3. What help do I need to make my decision? Therefore, this initiative was endorsed by the Dutch Federation of Medical Specialists and the Dutch Patient Federation in 2016 (41). These federations launched a campaign together to create more awareness on SDM among both patients and clinicians. A new campaign is planned for launch in 202 (42). This campaign is a collaboration of not only health care professionals and patients, but also the Dutch Ministry of Health and health insurance companies.

In addition, more and more attention is given to training medical students, post-graduates and medical specialists in how to conduct the SDM process. Yen et al. performed a crosssectional study on attitudes and knowledge on SDM among medical students in fou countries (the Netherlands, the United States, the United Kingdom and Canada, 43). They found high awareness of SDM: $75 \%$ of the medical students had received prior training on SDM. In the group of post-graduates, training in SDM still seems to be limited, but there is a movement towards more SDM training among this group $(44,45)$. The Dutch Federation of Medical Specialists has stated that SDM should be implemented in daily clinical practice by 2025 (46). They emphasize the importance of SDM training for post-graduate students. SDM has been integrated in the project education 2025 for post-graduate students, as one of the new themes that post-graduate students can choose to focus on (47). Despite this intent, there are still no widespread training facilities, such that there is still a lot of room for improvement in training clinicians in SDM on a national level.

\section{Sustainable implementation and updating of the PtDA}

We were aware that training is an important factor in implementation of SDM and PtDAs. However, in this thesis we focused on the development of the PtDA in collaboration with patients and clinicians from different centers, as a result of the bottom-up initiative from clinicians in the field, who were in need of a PtDA for breast cancer patients deciding on RT. Although we accomplished a high level of leadership and a high uptake of the PtDA during our clinical trial, the question remains whether the PtDA will be incorporated in daily clinical practice after the completion of the trial. New implementation problems may arise in the future. This PtDA was developed by the research team with funding of the Dutch cancer society. A full-time PhD student was responsible for the development of the tool and for the dissemination of the tool during the clinical trial. However, who will pay for further maintenance of the online PtDA and who is taking the time and responsibility of keeping the PtDA up to date. Stacey et al. found low post-trial implementation of PtDAs (17). They describe the lack of having a plan to keep the PtDA up-to-date, according to the newest literature and insights from experts, as being a barrier for post-trial implementation. Also, a lack of funding for implementation and dissemination is described as an important barrier for implementation.

As a possible solution, Stacey et al. point out that PtDAs should be disseminated by professional organizations. It has therefore been argued that dissemination could be don through patient advocate organizations (48). For example, the BRECONDA patient decision aid, a patient decision aid for breast cancer patients deciding on breast reconstruction, is being implemented in collaboration with the breast cancer network Australia (36). Although our PtDA is also available through the website of the national breast cancer association, the breast cancer association does not take an active role in the dissemination of the PtDA. In the Netherlands, the breast cancer association also does not have the expertise or resources to keep the PtDA up to date.

Another option to keep the PtDA up to date is to give a greater role to the developers of clinical guidelines in dissemination and updating of the PtDA, as proposed by van der Weijden et al. (49). It has also been argued that guidelines can play a role in implementing PtDAs by emphasizing that certain treatments are preference-sensitive decisions. Guidelines should advise SDM and when available, the PtDAs for preference-sensitive decisions to choose the best treatment for the individual patient (49). This way, clinicians are more aware of the preference-sensitive decisions and the option to use the PtDA. We do see a trend that SDM is increasingly advised in guidelines, but this is still an exception. For example, the American Society of Clinical Oncology advises SDM for post-mastectomy RT in certain patient groups (50). So far, we have no agreement with the clinical guideline developers on how the dissemination and updating of our PtDA should be organized and who should pay for this. Agoritsas et al. describe a new model to develop guidelines, in which tools to facilitate SDM are integrated (51). Unfortunately, this new model is not yet integrated into the Dutch healthcare system. Therefore, it is important for researchers developing PtDAs in the future to have a plan in forehand and to make agreements on post- 
trial implementation, maintenance, and updating of the tool. In the Netherlands, there are also some commercial companies who develop, maintain, and disseminate PtDAs. An ethical question arises however, since commercial companies charge clinical centers who want to use the PtDA. Not all clinical centers are willing to pay for this service, and therefore existing PtDAs are not freely available for all eligible patients. Policy is needed governance of existing PtDAs and reimbursement of the dissemination and maintenance costs of PtDAs on national level.

\section{Feasibility of PtDA development}

A broader question arises on the feasibility of the development of PtDAs. We developed our patient decision aid according to the IPDAS criteria, including qualitative research on important attributes for both patients and clinicians to decide on post-operative RT for breast cancer patients. We subsequently developed the PtDA in several rounds, in collaboration with patient advocates and clinicians from the field. Lastly, we tested the too in a clinical trial. This process took us almost four years and consequently costed a lot of resources (time and money) from all involved participants. Van der Weijden et al. recently published the results of a consensus study on practical guidelines to develop patient decision aids. They state that the minimal requirements are forming a team, defining the scope of the PtDA, identifying the needs, producing the content, testing the PtDA, finalizing the PtDA, disseminating the tool, and defining ownership (52). Although this is in line with our research, the question arises whether it was necessary to run such a big clinical trial. In the minimal requirements, no clinical trial is indicated by van der Weijden et al. To move towards development of more affordable PtDAs, we therefore argue that PtDA developers should meet these minimal requirements and be more critical whether extensive testing of each PtDA is absolutely necessary.

\section{Further development of the PtDA for breast cancer patients deciding on RT}

As stated before, the potential side effects of RT are only mentioned by qualitative labels in the PtDA developed for this thesis. This is due to lack of data on the incidence and severity of the side effects. In addition, we found a difference in framing of the side effects between clinicians and patients. We acknowledged a lack of knowledge on the most important side effects to be mentioned for the patients and knowledge on the best way to communicate the incidence and severity of these side effects in the PtDA. Therefore, with a grant from the Netherlands Organization for Health Research and Development (ZonMw 427003002) a two-day workshop was organized with clinicians, researchers, and patients, to discuss further development and implementation of the PtDA for breast cancer patients deciding on RT. During these two days, we found that there is an urgent need for more contex on the consequences of the possible side effects for quality of life, rather than detailed information on the incidence. We also found a need for more complete and integrated information of all the possible treatment options breast cancer patients, including surgical and systemic treatment options. The results of this workshop are now being used for a grant application with more focus on quality of life, and integration of (existing) PtDAs, and on implementation of SDM to enhance SDM for breast cancer patients.

\section{References}

1. Vromans R, Tenfelde K, Pauws S, van Eenbergen M, Mares-Engelberts I, Velikova G, et al. Assessing the quality and communicative aspects of patient decision aids for early-stage breast cancer treatment: a systematic review. Breast Cancer Res Treat. 2019;178(1):1-15.

2. Elwyn G, O'Connor A, Stacey D, Volk R, Edwards A, Coulter A, et al. Developing a quality criteri framework for patient decision aids: online international Delphi consensus process. Bmi. 2006;333(7565):417.

3. Engelhardt EG, Pieterse AH, Han PK, van Duijn-Bakker N, Cluitmans F, Maartense E, et al. Disclosing the Uncertainty Associated with Prognostic Estimates in Breast Cancer. Med Decis Making. 2017;37(3):179-92.

4. Harrison M, Han PKJ, Rabin B, Bell M, Kay H, Spooner L, et al. Communicating uncertainty in cancer prognosis: A review of web-based prognostic tools. Patient Educ Couns. 2019;102(5):842-9.

5. Bansback N, Bell M, Spooner L, Pompeo A, Han PKJ, Harrison M. Communicating Uncertainty in Benefits and Harms: A Review of Patient Decision Support Interventions. Patient. 2017:10(3):311-9.

6. Garcia-Retamero R, Cokely ET. Designing Visual Aids That Promote Risk Literacy: A Systematic Review of Health Research and Evidence-Based Design Heuristics. Hum Factors. 2017;59(4):582-627.

7. Vromans RD, Pauws SC, Bol N, van de Poll-Franse LV, Krahmer EJ. Communicating tailored risk information of cancer treatment side effects: Only words or also numbers? BMC Med Inform Decis Mak. 2020;20(1):277.

8. Kasper J, van de Roemer A, Pöttgen J, Rahn A, Backhus I, Bay Y, et al. A new graphical format to communicate treatment effects to patients-A web-based randomized controlled trial. Health Expect. 2017;20(4):797-804.

9. Poirier MW, Decker C, Spertus JA, McDowd JM. What eye-tracking methods can reveal about the role of information format in decision-aid processing: an exploratory study. Patient Educ Couns. 2019;102(11):1977-84.

10. Brouwers PJ, van Werkhoven E, Bartelink H, Fourquet A, Lemanski C, van Loon J, et al. Factors associated with patient-reported cosmetic outcome in the Young Boost Breast Trial. Radiother Oncol. 2016.

11. Bhattacharya IS, Haviland JS, Hopwood P, Coles CE, Yarnold JR, Bliss JM, et al. Can patientreported outcomes be used instead of clinician-reported outcomes and photographs as primary endpoints of late normal tissue effects in breast radiotherapy trials? Results from the IMPORT LOW trial. Radiother Oncol. 2019;134:220-30.

12. Brouwers P, van Loon J, Houben RMA, Paulissen J, Engelen SME, Heuts M, et al. Are PROMs sufficient to record late outcome of breast cancer patients treated with radiotherapy? A comparison between patient and clinician reported outcome through an outpatient clinic afte 10years of follow up. Radiother Oncol. 2018;126(1):163-9.

13. Lam E, Yee $\mathrm{C}$, Wong $\mathrm{G}$, Popovic M, Drost L, Pon $\mathrm{K}$, et al. A systematic review and meta-analysis of clinician-reported versus patient-reported outcomes of radiation dermatitis. Breast. 2020;50:125-34.

14. Young-Afat DA, van Gils $\mathrm{CH}$, van den Bongard $\mathrm{H}$, Verkooijen $\mathrm{HM}$. The Utrecht cohort for Multiple BREast cancer intervention studies and Long-term evaLuAtion (UMBRELLA): objectives, design, and baseline results. Breast Cancer Res Treat. 2017;164(2):445-50.

15. Stacey D, Hill S, McCaffery K, Boland L, Lewis KB, Horvat L. Shared Decision Making Interventions: Theoretical and Empirical Evidence with Implications for Health Literacy. Stud Health Technol Inform. 2017;240:263-83. 
16. Dreesens D, Kremer L, van der Weijden T. The Dutch chaos case: A scoping review of knowledge and decision support tools available to clinicians in the Netherlands. Health Policy. 2019;123(12):1288-97.

17. Stacey D, Suwalska V, Boland L, Lewis KB, Presseau J, Thomson R. Are Patient Decision Aids Used in Clinical Practice after Rigorous Evaluation? A Survey of Trial Authors. Med Decis Making. 2019;39(7):805-15.

18. Elwyn G, Scholl I, Tietbohl C, Mann M, Edwards AG, Clay C, et al. "Many miles to go ...": systematic review of the implementation of patient decision support interventions into routine clinical practice. BMC Med Inform Decis Mak. 2013;13 Suppl 2(Suppl 2):S14.

19. Groot G, Waldron T, Carr T, McMullen L, Bandura LA, Neufeld SM, et al. Development of a program theory for shared decision-making: a realist review protocol. Syst Rev. 2017;6(1):114.

20. Savelberg W, Boersma LJ, Smidt M, Goossens MFJ, Hermanns R, van der Weijden T. Does lack of deeper understanding of shared decision making explains the suboptimal performance on crucial parts of it? An example from breast cancer care. Eur J Oncol Nurs. 2019;38:92-7.

21. Scholl I, Kobrin S, Elwyn G. "All about the money?" A qualitative interview study examining organizational- and system-level characteristics that promote or hinder shared decision-making in cancer care in the United States. Implement Sci. 2020;15(1):81.

22. Alsulamy N, Lee A, Thokala P, Alessa T. What Influences the Implementation of Shared Decision Making: An Umbrella Review. Patient Educ Couns. 2020.

23. Joseph-Wiliams N AP, Boland L, Bravo P, Brenner A, Brodney S, Coulter A, Giguere A, Hoffman A, Köerner M, Langford A, Légaré F, Matlock D, Moumjid N, Munro S, Dahl Steffensen K, Stirling C, van der Weijden T. . What Works in Implementing Patient Decision Aids in Routine Clinical Settings? A Rapid Realist Review and Update from the International Patient Decision Aid Standards Collaboration. . Med Dec Making in press.

24. Bomhof-Roordink H, Gärtner FR, van Duijn-Bakker N, van der Weijden T, Stiggelbout AM, Pieterse AH. Measuring shared decision making in oncology: Development and first testing of the iSHAREpatient and iSHAREphysician questionnaires. Health Expect. 2020;23(2):496-508.

25. Garvelink MM, Boland L, Klein K, Nguyen DV, Menear M, Bekker HL, et al. Decisional Conflict Scale Use over 20 Years: The Anniversary Review. Med Decis Making. 2019;39(4):301-14.

26. Franco P, Iorio GC, Bartoncini S, Airoldi M, De Sanctis C, Castellano I, et al. De-escalation of breast radiotherapy after conserving surgery in low-risk early breast cancer patients. Med Oncol. 2018;35(5):62.

27. Boersma LJ, Sonke GS, Verkooijen HM. [Cancer treatment; there are options]. Ned Tijdschr Geneeskd. 2019;163.

28. Liefers GJ. [Treatment 'to be on the safe side': avoiding every risk in the case of malignancy or pre-malignancy]. Ned Tijdschr Geneeskd. 2015;159:A9517.

29. Chang HL, Li FS, Lin CF. Factors Influencing Implementation Of Shared Medical Decision Making In Patients With Cancer. Patient Prefer Adherence. 2019;13:1995-2005.

30. Ousseine YM, Durand MA, Bouhnik AD, Smith A, Mancini J. Multiple health literacy dimensions are associated with physicians' efforts to achieve shared decision-making. Patient Educ Couns. 2019;102(11):1949-56.

31. Molina F, Dehlendorf C, Gregorich SE, Kuppermann M. Women's preferences for and experiences with prenatal genetic testing decision making: Sociodemographic disparities in preferenceconcordant decision making. Patient Educ Couns. 2019;102(3):595-601.

32. Scalia P, Barr PJ, O'Neill C, Crealey GE, Bagley PJ, Blunt HB, et al. Does the use of patient decision aids lead to cost savings? a systematic review. BMJ Open. 2020;10(11):e036834.
33. Shay LA, Lafata JE. Where is the evidence? A systematic review of shared decision making and patient outcomes. Med Decis Making. 2015;35(1):114-31.

34. Trenaman L, Bryan S, Bansback N. The cost-effectiveness of patient decision aids: A systematic review. Healthc (Amst). 2014;2(4):251-7.

35. Cantor SB, Rajan T, Linder SK, Volk RJ. A framework for evaluating the cost-effectiveness of patient decision aids: A case study using colorectal cancer screening. Prev Med. 2015;77:16873.

36. Parkinson B, Sherman KA, Brown P, Shaw LE, Boyages J, Cameron LD, et al. Cost-effectiveness of the BRECONDA decision aid for women with breast cancer: Results from a randomized controlled trial. Psychooncology. 2018;27(6):1589-96.

37. Curran GM, Bauer M, Mittman B, Pyne JM, Stetler C. Effectiveness-implementation hybrid designs: combining elements of clinical effectiveness and implementation research to enhance public health impact. Med Care. 2012;50(3):217-26.

38. Landes SJ, McBain SA, Curran GM. An introduction to effectiveness-implementation hybrid designs. Psychiatry Res. 2019;280:112513.

39. Thorpe KE, Zwarenstein M, Oxman AD, Treweek S, Furberg CD, Altman DG, et al. A pragmaticexplanatory continuum indicator summary (PRECIS): a tool to help trial designers. I Clin Epidemiol. 2009;62(5):464-75

40. Shepherd HL, Barratt A, Trevena LJ, McGeechan K, Carey K, Epstein RM, et al. Three questions that patients can ask to improve the quality of information physicians give about treatment options: a cross-over trial. Patient Educ Couns. 2011;84(3):379-85.

41. [Available from: https://3goedevragen.nl/de-3-goede-vragen/over-3-goede-vragen/.

42. [Available from: https://begineengoedgesprek.nl/professionals/over-de-campagne/.

43. Yen RW, Barr PJ, Cochran N, Aarts JW, Légaré F, Reed M, et al. Medical Students' Knowledge and Attitudes Toward Shared Decision Making: Results From a Multinational, Cross-Sectional Survey. MDM Policy Pract. 2019;4(2):2381468319885871.

44. Rusiecki J, Schell J, Rothenberger S, Merriam S, McNeil M, Spagnoletti C. An Innovative Shared Decision-Making Curriculum for Internal Medicine Residents: Findings From the University of Pittsburgh Medical Center. Acad Med. 2018;93(6):937-42.

45. Baghus A, Giroldi E, Muris J, Stiggelbout A, van de Pol M, Timmerman A, et al. Identifying Entrustable Professional Activities for Shared Decision Making in Postgraduate Medical Education: A National Delphi Study. Acad Med. 2020.

46. [Available from: https://www.demedischspecialist.nl/sites/default/files/FMS_VisiedocSamenBeslissen\%282019\%29 v03.pdf.

47. [Available from: https://dejongespecialist.nl/2020/opleidingsduur-wordt-niet-verder-verkort/.

48. Reumkens K, de Die-Smulders CEM, van Osch L. Exploring the preferences of involved health professionals regarding the implementation of an online decision aid to support couples during reproductive decision-making in hereditary cancer: a mixed methods approach. Fam Cancer. 2019;18(2):285-91.

49. van der Weijden T, Post H, Brand PLP, van Veenendaal H, Drenthen T, van Mierlo LA, et al. Shared decision making, a buzz-word in the Netherlands, the pace quickens towards nationwide implementation.... Z Evid Fortbild Qual Gesundhwes. 2017;123-124:69-74.

50. Recht A, Comen EA, Fine RE, Fleming GF, Hardenbergh PH, Ho AY, et al. Postmastectomy Radiotherapy: An American Society of Clinical Oncology, American Society for Radiation Oncology, and Society of Surgical Oncology Focused Guideline Update. Pract Radiat Oncol. 2016;6(6):e219-e34. 
51. Agoritsas T, Darbellay Farhoumand P, Siemieniuk R, Heen AF, Lytvyn L, MacDonald H, et al. [The BMJ Rapid Recommendations: towards a new model for the production of clinical practice guidelines]. Rev Med Suisse. 2019;15( $N^{\circ}$ 632-633):149-55.

52. van der Weijden T, Dreesens D, Faber MJ, Bos N, Drenthen T, Maas I, et al. Developing quality criteria for patient-directed knowledge tools related to clinical practice guidelines. A development and consensus study. Health Expect. 2019;22(2):201-8. 


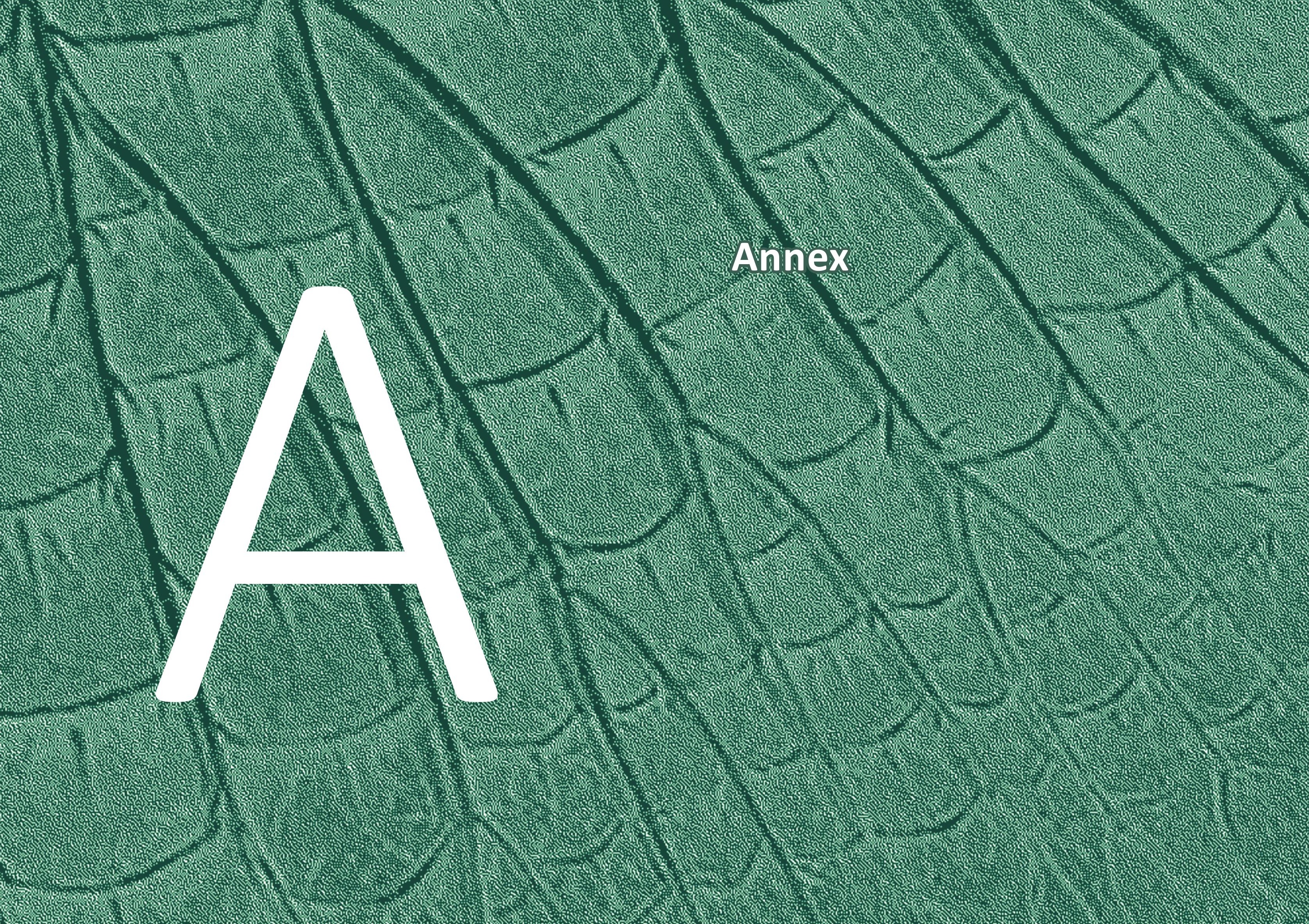




\section{Summary}

Breast cancer is the most frequently diagnosed cancer in women worldwide. Breast cancer is considered a heterogeneous disease. The specific tumor and patient characteristics differ per case. Therefore, different patients are treated with different treatment modalities. The best treatment for each patient depends on both patient and tumor characteristics but can also depend on the specific wishes and preferences of the patient. One of the possible treatment modalities is radiation treatment (RT). RT is a local treatment that reduces the chances of developing a local recurrence after treatment with a factor of 3-4. The absolute effect size is dependent on the absolute risk for a local recurrence prior the RT. Patients with a high local recurrence risk without RT have a large absolute benefit of RT. These patients normally also have a survival benefit from RT. Patients with a smal local recurrence risk have also a small absolute benefit of RT. There is, however, a group in between. These patients have a moderate effect on their local recurrence risk, but these patients have no or only little benefit in survival from RT. However, RT can cause side effects in these patients. Choosing for RT or to leave RT out of their treatment is therefore a preference-sensitive decision for these patients. We identified four patient categories who face a preference-sensitive treatment decision when choosing for (more) RT or not.

1. Patients with low risk Ductal Carcinoma In Situ (DCIS) treated with breast conserving surgery choosing for whole breast or partial breast RT.

2. Patients with very low risk invasive ductal carcinoma treated with breast conserving surgery choosing for whole breast or partial breast RT.

3. Patients with intermediate risk breast cancer treated with a mastectomy choosing for chest wall RT.

4. Patients with an intermediate risk breast cancer treated with breast conserving surgery choosing for whole breast RT with or without an extra boost dose to the tumor bed.

Shared decision-making (SDM) is the process in which patients and clinicians work together to decide on the best treatment option for the patient. SDM is required for these preference-sensitive decisions, because there is no best (medical) treatment option. However, the process of SDM is difficult and not well implemented in daily clinical practice. Patient decision aids (PtDAs) are tools that are proven to support the process of SDM to help both patients and clinicians in deciding together on the best treatment.

Little is known about the important attributes for breast cancer patients and their clinicians when making a decision on RT. The advantage of choosing for RT is a reduction in local recurrence risk. How this should be communicated in a PtDA and how to communicate the uncertainty around these risks is also unknown. In addition, PtDAs so far have not yet been implemented in daily clinical practice. 
Therefore, we concentrated this thesis around four research questions:

1. What are patients' and health care professionals' experiences, decisional attributes and needs as input for the development of a patient decision aid for breast cancer patients, deciding on radiation treatment, to facilitate shared decision making? (chapter 2)

2. How can we incorporate uncertainties in a patient decision aid for breast cancer patients to support their decision on radiation treatment? (chapter 3)

3. What are important patient, clinician, and organizational success factors for implementing a patient decision aid, designed for breast cancer patients, facing a decision on their radiation treatment? (chapter 4)

4. What is the effect of a patient decision aid for breast cancer patients deciding on radiation treatment, on decisional conflict, perceived shared decision making and knowledge on treatment options? (chapter 5 )

In Chapter 2, we focused on research question 1, and described the results of a qualitative study. We interviewed 15 breast cancer patients who had faced a preferencesensitive decision on their RT prior to the interview. We also interviewed 15 clinicians who treat breast cancer patients. We interviewed them both on the most important attributes when deciding on RT. We found that both patients and clinicians agreed on the importance of communicating the possible local recurrence risk for both treatment options. However, there was no consensus on whether the uncertainty around these recurrence risks should be communicated. Patients did not recall any uncertainty being communicated to them, but clinicians believed that it is important to communicate the uncertainty around the risk numbers. We also found a spread in the number of side effects mentioned by the different clinicians (range 1-14) and the number of side effects patients remembered to be told to them. There was consensus on the most important side effects to be mentioned prior to making a decision on RT. Clinicians made a distinction between short- and long-term side effects, but this distinction was not mentioned by the patients. The most frequently mentioned short-term side effects were red and sensitive skin, edema, tiredness, and pain of the breast. The most frequently mentioned long-term side effects were fibrosis and change in breast shape, edema, (dark) skin discoloration, pain, rib complications, heart problems, and lung problems. There was a discrepancy in the framing of the side effects between patients and clinicians. Patients framed the side effects by the effect on their daily life (e.g., deformation of the breast), but clinicians were more likely to frame the side effects by their biological etiology (e.g., scarring of the healthy tissue). We also found that the treatment burden (i.e., patients having to trave to the RT clinic on a daily basis for 3-4 weeks) was not an important attribute for most patients and clinicians when deciding on RT.

A draft version of the PtDA was made with the knowledge gained from the qualitative study.
In chapter 3 we described the steps conducted in the development of the PtDA, and especially addressed research question 2 . The first round consisted of a teleconference with patient advocates and the researcher on the comprehension and content of the draft version of PtDA. Thereafter a group meeting with patient advocates, clinicians, and the research team was organized, Think Aloud sessions with patient advocates and another group meeting with all involved participants. During the group meeting, a debate emerged on the communication of the recurrence risks, survival risks, and risks of developing side effects. Due to lack of data, we decided to describe the risk of developing side effects in a qualitative way, since no reliable estimates could be given. More debate emerged the communication of survival and local recurrence risk. It was argued that a 10-yea overall survival number would not be realistic for all patients, because overall survival is partially dependent on patient characteristics (e.g., co-morbidity and age). On the other hand, breast cancer specific survival does not cover potential mortality as consequence of the breast cancer treatment. Since patients who face a preference-sensitive treatment decision on RT have little to no survival benefit from RT, this was also framed in this way in words only in the PtDA. Clinicians believed it is important to communicate the uncertainty around the local recurrence risk. Therefore, a novel way had to be developed to communicate this in the PtDA. We reached consensus on female icons in a 10x10 array. The uncertainty range was presented by a stepwise color gradient in the figures.

The PtDA was tested in a multicenter pre- and post-intervention trial. Between Octobe 2017 and October 2018, 214 patients were included in the pre-intervention arm, i.e., the control group. These patients all faced a preference-sensitive decision in one of the four patient categories identified for the study. They received standard care when making the decision on RT. Between October 2018 and July 2019, 189 patients were included in the post-intervention arm, i.e., the intervention group. These patients all faced a preferencesensitive decision in one of the four patient categories identified for the study. They received a link to the online PtDA to support the decision-making process with their clinician. The logistics of the trial and the distribution of the link to the PtDA were adjusted to the logistics of the participating centers. Patients were included in 13 out of the 19 RT centers in the Netherlands. All patients were asked to fill out questionnaires within three days after the decision was made (T1) and three months later (T2). Clinicians filled out a case report form on the patient, disease characteristics, and treatment characteristics.

We found a high uptake of the PtDA: of the 189 patients who received the link to the PtDA, 141 (77\%), logged in to the PtDA. In chapter 4 we described the patient, clinician, and organizational factors related to a higher uptake of the PtDA, as addressed in research question 3 . In this chapter, we only analyzed the data of the patient who received a link to the PtDA, the intervention group. Ideally, patients were identified as facing a preferencesensitive treatment decision for RT by the multi-disciplinary team, and a note was made in the multi-disciplinary team report that RT had to be discussed with the patient. Since the logistics of the dissemination of the PtDA were adjusted to the logistics of the differen centers, patients could either 1) receive the link to the PtDA from the surgery department at the post-operative consult or 2) from the RT department, 2A) either through regular mail prior the consultation or $2 \mathrm{~B}$ ) through the radiation oncologist during the postoperative consultation. We found that patients who received the PtDA link via the surgery 
department were more likely to login to the PtDA than patients who received the link via the RT department. We also found that patients for whom the multi-disciplinary team report included a note that "RT had to be discussed with the patient" were more likely to login to the PtDA than patients who did not have this note in their multi-disciplinary team report.

In chapter 5 we focused on research question 4 and described the effect of the PtDA as measured in the pre-and post-intervention trial. We found that patients who were offered the PtDA were slightly younger and more highly educated than patients in the control group. Data were analyzed with multi-level regression analysis. We found no statistically significant difference in decisional conflict both three months after making the decision (primary outcome) or immediately after making the decision between the intervention and the control arm. We also found no statistically significant difference in experienced level of SDM between the two groups. We did find a correlation between knowledge and the availability of the PtDA: patients who had been offered the PtDA scored higher on the knowledge test. These results still hold after correcting for age and educational level. We also found that patients who were offered the PtDA chose less often for the more intensive RT option. We found that there was no additional time needed in consultation for patients to whom the PtDA was offered compared to those to whom the PtDA was not offered.

Although we found a high uptake of the PtDA in our study, there was no effect of the PtDA on decisional conflict and on experienced level of SDM. In chapter 6, we outlined the limitations and strengths of our study and provided suggestions for further research and implementation of PtDAs and SDM. A limitation of our study is that we performed a pre-and post-implementation trial. Therefore, we cannot rule out the effect of time of on our results. Clinicians may have changed the way they inform patients over time, independently of the introduction of the PTDA. On the other hand, our hybrid design, testing the tool while simultaneously implementing it in daily clinical practice, which should be considered a strength. Another important strength of our study is that it was a bottomup project initiated and executed by clinicians from the field, in collaboration with patient advocates. We probably reached such a high uptake, thanks to leadership and trust in the tool, since clinicians from most RT centers had collaborated in the development of the tool. However, there are still some challenges for the future. From clinical trials it is known that post-trial implementation of PtDAs is very poor. Important barriers include the lack of finance for maintenance of the tool and a solid plan to keep the tool updated according to the fast development and changes in clinical treatments. Furthermore, implementing a PtDA is not sufficient for implementation of shared decision-making. More awareness and training are needed for clinicians. Finally, the PtDA developed in this trial needs further improvements. Side effects were only mentioned in a quantitative way, due to lack of data on incidence and severity. Currently, a new research proposal is being written at this moment to improve the representation of side effects through input from bigdata and with more background in the consequences of the possible side effect for patients' quality of life. 


\section{Nederlandse samenvatting}

Borstkanker is de meest voorkomende kankersoort bij vrouwen in de wereld. Borstkanker wordt gezien als een heterogene ziekte. Dat wil zeggen dat borstkanker bij iedere patiënt anders is. De beste behandeling voor de individuele patiënt hangt dan ook af van de specifieke kenmerken van zowel de tumor als de patiënt. Daarnaast spelen ook de wensen en de persoonlijke situatie van de patiënt mee in de keuze voor de beste behandeling voor de individuele patiënt.

Naast operatief verwijderen van de kanker en systemische therapie is bestraling een van de mogelijke behandelingen voor borstkankerpatiënten. Bestraling is een lokale behandeling die de kans dat de tumor terugkeert na de behandeling drie tot vier keer verkleint. Hoe groter de absolute kans dat de tumor terugkomt vóór de bestraling, des te groter is dan ook het effect van de bestraling. Oftewel, patiënten met een hoge kans dat de tumo terugkomt na de operatie hebben veel absolute winst van bestraling. Bij deze patiënten zorgt bestraling er ook voor dat de kans om aan de borstkanker te overlijden kleiner wordt. Patiënten die na de operatie al een kleine kans hebben dat de tumor terugkomt zullen ook weinig winst hebben van bestraling. Er zijn echter ook patiënten die ertussenin zitten. Deze patiënten hebben wel winst van de bestraling wat betreft hun kans op terugkeer van de borstkanker, maar ze hebben geen of weinig verschil in kans om aan de borstkanker te overlijden als ze wel of geen bestraling krijgen. Aan de andere kant kan bestraling wel zorgen voor vervelende bijwerkingen. Kiezen voor wel of geen bestraling wordt dan ook gezien als een voorkeursgevoelige beslissing voor deze patiënten. Voor dit proefschrift hebben we 4 groepen borstkanker patiënten geïdentificeerd met een voorkeursgevoelige beslissing voor (extra) bestraling.

1. Patiënten met laagrisico Ductaal Carcinoom In Situ (DCIS) die behandeld zijn middels een borstsparende operatie en een keuze hebben voor wel of geen (partiële) borstbestraling.

2. Patiënten met zeer laagrisico borstkanker die behandeld zijn middels een borstsparende operatie en een keuze hebben voor wel of geen (partiële) borstbestraling.

3. Patiënten met intermediate-risico borstkanker die behandeld zijn middels een borstamputatie en een keuze hebben voor wel of geen bestraling van de borstkas.

4. Patiënten intermediate-risico borstkanker die behandeld zijn middels een borstsparende operatie en een keuze hebben voor wel of geen extra bestralingsdosis (boost) op de plek waar de tumor heeft gezeten.

Samen beslissen is het proces waarin arts en patiënt samenwerken om de beste behandeling te kiezen voor de individuele patiënt. De arts is de medisch expert; de patiënt is de expert ten aanzien van haar eigen voorkeuren en wensen. Samen beslissen is met name belangrijk bij deze voorkeurgevoelige beslissingen, waarbij er dus medisch gezien geen "beste" behandeling is. Samen beslissen is echter een complex proces. Een keuzehulp is een hulpmiddel om zowel artsen als patiënten te ondersteunen in het proces van samen beslissen. 
Er is nog weinig bekend over wat de belangrijke "attributen" zijn voor zowel artsen als borstkankerpatiënten bij het maken van een keuze ten opzichte van hun bestralingsbehandeling. Het voordeel van kiezen voor (meer) bestraling is een afname van de kans op terugkeer van de tumor. Hoe deze kansen gecommuniceerd moeten worden en hoe de onzekerheid rondom deze kansen gecommuniceerd moet worden in een keuzehulp is echter niet bekend. Daarnaast zijn keuzehulpen nog niet goed geïmplementeerd in de klinische praktijk en in de spreekkamer. Daarom hebben we voor dit proefschrift deze vie onderzoeksvragen opgesteld:

1. Wat zijn de ervaringen, belangrijke attributen en behoeften van patiënten en artsen die relevant zijn voor de ontwikkeling van een keuzehulp voor borstkanker patiënten die een beslissing moeten maken over hun bestralingsbehandeling? (hoofdstuk 2)

2. Hoe kunnen we de onzekerheid in kansen op terugkeer van de tumor weergeven in een keuzehulp voor borstkankerpatiënten die een keuze moeten maken over hun bestralingsbehandeling? (hoofdstuk 3)

3. Wat zijn belangrijke patiëntgebonden, artsgebonden en organisatorische factoren die bijdragen aan het succesvol implementeren van een keuzehulpvoor borstkankerpatiënten die een keuze moeten maken over hun bestralingsbehandeling? (hoofdstuk 4)

4. Wat is het effect van een keuzehulp voor borstkankerpatiënten die een keuze moeten maken over hun bestralingsbehandeling op keuzestress, ervaren proces van samen beslissen en kennis over de verschillende behandelopties? (hoofdstuk 5)

In hoofdstuk 2 gaan we in op de 1 e onderzoeksvraag en beschrijven we de resultaten van een kwalitatieve studie. We hebben interviews gehouden met 15 borstkankerpatiënten die een voorkeursgevoelige beslissing moesten maken ten aanzien van hun bestralingsbehandeling. Daarnaast hebben we 15 borstkankerclinici geïnterviewd. De interviews gingen over de belangrijke attributen bij het maken van een keuze over de bestralingsbehandeling. We ontdekten dat patiënten en artsen het met elkaar eens waren dat het belangrijk is om de kans op terugkeer van de tumor weer te geven in de keuzehulp. Er was echter een discrepantie in het belang van het communiceren van de onzekerheid rondom de kansen. Patiënten waren zich niet bewust van de onzekerheid in getallen en wisten zich niet te herinneren dat dit naar hen gecommuniceerd zou zijn. Clinici gaven echter aan dat zij het heel belangrijk vonden dat de onzekerheid van de risico's gecommuniceerd zouden worden in de keuzehulp. Daarnaast vonden we veel variatie in het aantal bijwerkingen dat genoemd werd door clinici (spreiding 1-14). Patiënten konden zich vaak maar enkele bijwerkingen herinneren die hen verteld waren. Er was wel consensus wat betreft de belangrijkste bijwerkingen die genoemd zouden moeten worden in een keuzehulp. Clinici maakten daarbij ook onderscheid tussen bijwerkingen op de korte en lange termijn. De meest genoemde bijwerkingen op korte termijn waren: rode en gevoelige huid, oedeem, vermoeidheid en pijnlijke borst. De meest genoemde bijwerkingen op lange termijn waren: fibrose en vormverandering van de borst, oedeem, (donkere) verkleuring van de huid, pijn, complicaties van de ribben en bijwerkingen aan hart en longen. Wel was er een discrepantie in hoe de bijwerkingen beschreven worden. Clinici benoemen de mogelijke bijwerkingen aan de hand van hun biologische ontstaanswijze (bijvoorbeeld het ontstaan van littekenweefsel) terwijl patiënten vooral benoemen wat het effect is van de bijwerkingen op hun kwaliteit van leven (bijvoorbeeld de vormverandering van de borst). Daarnaast hebben we gevonden dat de behandellast (patiënten moeten voor de bestraling gedurende 3-4 weken dagelijks naar het ziekenhuis komen) geen belangrijk attribuut was bij het maken van de keuze voor de bestralingsbehandeling.

Met de resultaten van de interviews werd een eerste versie van de keuzehulp gemaakt. In hoofdstuk 3 wordt de 2e onderzoeksvraag beantwoord en beschrijven we alle stappen die genomen zijn om tot de uiteindelijke versie van de keuzehulp te komen. De eerste ronde was een telefonisch overleg tussen de onderzoeker en patiëntvertegenwoordigers. In dit overleg werd met name feedback gegeven door de patiëntvertegenwoordigers over de inhoud van de keuzehulp en of de opzet van de keuzehulp begrijpelijk was. Over de daaruit doorontwikkelde keuzehulp vroeg het onderzoeksteam feedback van zowe patiëntvertegenwoordigers en clinici tijdens een groepsbijeenkomst. De volgende rondes bestonden uit "Think Aloud"-sessies tussen de onderzoeker en patiëntvertegenwoordigers. Tijdens deze "Think Aloud"-sessies bekeken de patiëntvertegenwoordigers de keuzehulp in aanwezigheid van de onderzoeker en gaven meteen aan wat ze wel of niet duidelijk of wel of niet goed vonden aan de keuzehulp. Afsluitend werd er nog een groepsbijeenkoms georganiseerd met alle betrokken om de laatste details en verbeteringen te bespreken voor de uiteindelijke versie van de keuzehulp. Er was tijdens de eerste groepsbijeenkomst veel discussie over het communiceren van de kansen en de onzekerheid van de kansen op terugkeer van de tumor, het ontstaan van bijwerkingen en overleving. Omdat er weinig bekend is over de kans op het ontstaan van bijwerkingen, konden er ook gee kansen gecommuniceerd worden in de keuzehulp. Er werd dan ook besloten om de kans op bijwerkingen alleen te duiden op een kwalitatieve manier (vaak voorkomend/ zelden voorkomend). Er was meer discussie rondom de overlevingskansen en de kan op terugkeer van de tumor. Cijfers over 10-jaarsoverleving zijn namelijk afhankelijk van patiëntkarakteristieken (leeftijd en co-morbiditeit) en geven dus niet voor iedereen een realistisch beeld. Aan de andere kant geven kansen op borstkanker-specifieke overleving geen realistisch beeld van de sterfte als gevold van de bijwerkingen van de behandeling. Aangezien er bij de voorkeursgevoelige beslissingen waar de keuzehulp over gaat geen of slechts weinig winst is wat betreft overleving werd besloten dit feit in woorden weer te geven in de keuzehulp. Aangezien het voor de clinici belangrijk was dat de onzekerheid in getallen weergegeven zou worden in de keuzehulp moest hiervoor een manier ontwikkeld worden om dit zo duidelijk mogelijk weer te geven. We hebben daarvoor een poppetjesdiagram met 100 poppetjes ontwikkeld, waarbij de onzekerheidsmarge wordt weergegeven door poppetjes in een aflopende kleur.

We hebben de keuzehulp getest in een multicenter pre- en post-interventiestudie. Tussen oktober 2017 en oktober 2018 hebben we 214 patiënten geïncludeerd in de pre-interventie arm, oftewel de controle arm. Al deze patiënten hadden een voorkeursgevoelige bestralingsbehandeling in een van de vier groepen die hierboven genoemd zijn. Zij maakten een beslissing ten aanzien van hun bestralingsbehandeling zonder ondersteuning van de keuzehulp. Tussen oktober 2018 en juli 2019 hebben 189 patiënten geïncludeerd in de post-interventie arm, oftewel de interventie arm. Ook al deze patiënten hadden 
een voorkeursgevoelige bestralingsbehandeling in een van de vier groepen die hierboven genoemd zijn. Zij kregen de link naar de keuzehulp van hun clinicus ter ondersteuning bij het maken van de beslissing. De logistiek van de studie en van het uitreiken van de link naar de keuzehulp werd aangepast aan de logistiek van de verschillende deelnemende centra. Patiënten werden geïncludeerd in 13 van de 19 bestralingscentra in Nederland. Alle patiënten werd gevraagd een vragenlijst in te vullen binnen drie dagen na het maken van de keuze (T1) en drie maanden later (T2). Clinici werd gevraagd een vragenlijst in te vullen over de specifieke patiënt-, tumor- en behandelkarakteristieken.

Een groot deel van de patiënten die een link naar de keuzehulp kreeg uitgedeeld, heeft ingelogd in de keuzehulp (141 van de 189 patiënten, 77\%). In hoofdstuk 4 gaan we in op de $3 e$ onderzoeksvraag en beschrijven we de patiëntgebonden, artsgebonden en organisatorische factoren die bijdragen aan de kans dat patiënten inloggen om de keuzehulp te bekijken. In dit hoofdstuk hebben we alleen gekeken naar de patiënten die de keuzehulplink wel hebben gekregen, de interventie arm. Idealiter werden patiënten die in aanmerking kwamen voor de keuzehulp geïdentificeerd bij het multidisciplinair overleg. Er werd dan een aantekening gemaakt in het verslag van multidisciplinair overleg dat de patiënt een voorkeursgevoelige beslissing moest nemen ten aanzien van de bestralingsbehandeling. Aangezien de logistiek van het uitreiken van de keuzehulplin was aangepast aan de logistiek van de verschillende centra was het mogelijk dat patiënten de link kregen via: 1 . De chirurgieafdeling tijdens het postoperatieve consult, 2. de bestralingsafdeling, $2 \mathrm{a}$. per post voorafgaand aan het consult of $2 \mathrm{~b}$. tijdens het consult met de bestralingsarts. We zagen dat patiënten die de keuzehulp link via de chirurgieafdeling kregen vaker inlogden om de keuzehulp te bekijken dan patiënten die de link via de bestralingsafdeling kregen uitgereikt. Daarnaast zagen we dat patiënten ook vaker gebruik maakten van de keuzehulp als het verslag van het multidisciplinair overles vermelde dat de patiënt een voorkeursgevoelige beslissing moest nemen ten aanzien van haar bestralingsbehandeling.

In hoofdstuk 5 beantwoorden we de 4e onderzoeksvraag en beschrijven we de resultaten van de pre- en post-interventie studie. We zagen dat de patiënten in de interventie arm jonger waren en hoger opgeleid dan de patiënten in de controle arm. De data werden geanalyseerd middels multilevel-regressieanalyse, waarbij we gecorrigeerd hebben voor leeftijd en opleidingsniveau. We vonden geen statistisch significant verschil in keuzestress tussen de interventie arm en de controle arm, zowel na drie maanden (primaire uitkomstmaat) als binnen drie dagen na het maken van de beslissing. Ook hebben we geen statistisch significant verschil gevonden tussen beide groepen in ervaren proces van samen beslissen. Wel vonden we een verband tussen het beschikbaar hebben van de keuzehulp en kennis over de verschillende behandelopties. Patiënten die de keuzehulplink kregen uitgereikt, scoorden hoger op een kennistoets over de verschillende behandelopties. Ook zagen we dat patiënten die de keuzehulplink kregen uitgereikt minder vaak kozen voor de meer intensieve behandeloptie. Er was geen verschil in consultduur tussen patiënten die de keuzehulp link wel of niet kregen uitgereikt.
Hoewel veel patienten die de keuzehulplink uitgereikt kregen hier gebruik van hebben gemaakt, zagen we geen effect van de keuzehulp op keuzestress en op ervaren proces van samen beslissen. In hoofdstuk 6 gaan we in op de zwakke en sterke punten van onze studie en geven we suggesties voor verder onderzoek en implementatie van keuzehulpen en samen beslissen. Een zwakte van onze studie is dat we hebben gekozen voor een preen post-implementatiestudie, in plaats van een gerandomiseerde trial. Hierdoor kunnen we niet uitsluiten dat de factor tijd mogelijk een rol heeft gespeeld bij de uitkomsten van onze studie. Gedurende de looptijd van de studie veranderden clinici mogelijk de manier waarop zij patiënten informeren over de verschillende behandelopties, onafhankelijk van de introductie van de keuzehulp. Daarentegen kan deze hybride studieopzet juist ook als een sterk punt gezien kunnen worden, omdat we de keuzehulp simultaan geïmplementeerd en getest hebben in de dagelijkse praktijk. Een ander sterk punt van onze studie is dat dit project echt een "bottom-up" initiatief is. Het onderzoek is geïnitieerd en uitgevoerd door clinici uit het veld in samenwerking met patiëntvertegenwoordigers. We denken dat veel patiënten hebben ingelogd in de keuzehulp dankzij sterk leiderschap en vertrouwen in de keuzehulp, aangezien clinici van de meeste deelnemende centra ook hadden meegeholpen bij de ontwikkeling van de keuzehulp. Wel liggen er nog enkele uitdagingen voor de toekomst. Uit eerder onderzoek blijkt dat de implementatie van keuzehulpen na het afronden van de wetenschappelijke studie erg slecht is. Belangrijke barrières hiervoor zijn het gebrek aan geld voor het onderhoud van de keuzehulp en een gedegen plan om de keuzehulp actueel te houden ten aanzien van de snel veranderende medische behandelingen. Daarnaast is enkel het implementeren van een keuzehulp onvoldoende om samen beslissen te implementeren. Er is hiervoor meer kennis en training nodig onder artsen. Tot slot moet ook de keuzehulp die we ontwikkeld hebben voor deze studie nog doorontwikkeld worden. De bijwerkingen worden in de keuzehulp alleen op een kwalitatieve manier genoemd, omdat er onvoldoende data beschikbaar is. Op dit moment wordt er een subsidieaanvraag geschreven om de weergaven van de bijwerkingen te verbeteren en meer achtergrondinformatie te geven over het effect van de mogelijke bijwerkingen op de kwaliteit van leven. 


\section{Impact section}

In this thesis we describe the process of the development, implementation, and testing of a patient decision aid for breast cancer patients who face a preference-sensitive treatment decision for their post-operative radiation treatment (RT). In some patient groups, postoperative RT lowers the local recurrence risk, with no or only little benefit in survival. However, RT can cause side effects. For these patients, deciding on post-operative RT is therefore a preference-sensitive treatment decision. Because there is no best (medical) treatment option for these patients, different patients receive different advice on the bes treatment from different clinicians. The aim of the patient decision aid is to support both clinicians and patients to decide together on the best treatment for the individual patient. In this chapter, we describe the impact of this thesis for science and the impact of the work described on a patient decision aid for patients and clinicians.

\section{Scientific impact}

Communication of uncertainty in risks in a patient decision aid

The patient decision aid is a computerized, web-based product that describes the advantages and disadvantages of the different treatment options. The advantage of choosing for (more) RT is a decrease in local recurrence risk of the tumor. The patient decision aid gives information on the risk of suffering from a local recurrence, when choosing for the additional radiation treatment and the risk of suffering from a local recurrence when choosing to retrain the additional radiation treatment. That means that the local recurrence risk for patients who choose not to have post-operative RT is displayed next to the possible local recurrence risk for patients who choose to undergo post-operative RT. The same accounts for patients choosing to receive an extra radiation (boost) dose to the place where the tumor was removed by the surgeon. In the development phase of the patient decision aid, we found that clinicians in particular believed that not only the recurrence risk should be communicated in the patient decision aid, but also the uncertainty around these risk estimates. However, not much research has been done on the best way to communicate such uncertainties to patients. We developed a novel method using population diagrams with a stepwise color gradient indicating the uncertainty margin, in combination with numbers and a textual explanation of the numbers and the uncertainty around these numbers (figure $1 \mathrm{a}$ and $1 \mathrm{~b}$ ). We presented these population diagrams in an international scientific conference and in a scientific journal. Whether this is an appropriate and comprehensive way of communicating uncertainty to patients in a patient decision aid is still under investigation. 
Figure 1a. Population diagram with uncertainty margins for the 10-year local recurrence risk for intermediate-risk breast cancer after mastectomy with and without radiotherapy. The stepwise color gradient indicates the uncertainty margin.

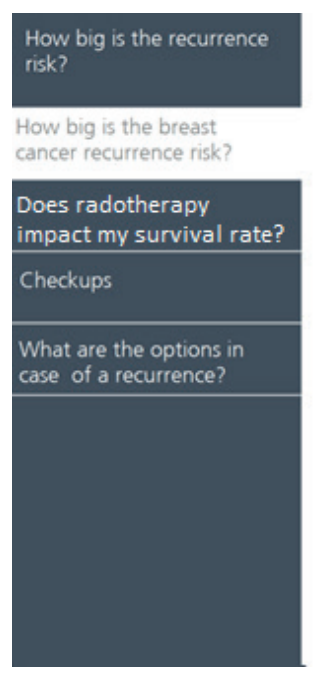

Radionterapy reduces the local recurrence rate with a factor 3 . Click on

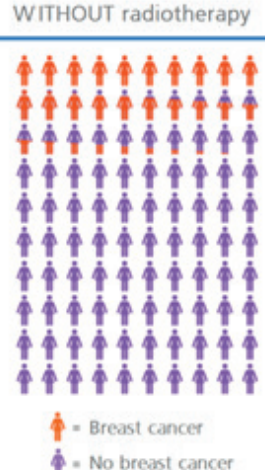

WITH radiotherapy

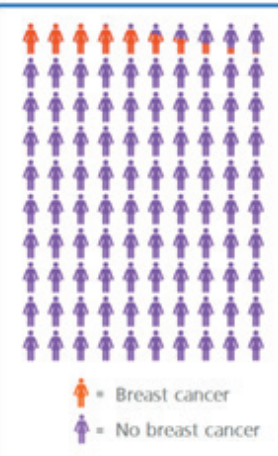

Figure $1 \mathrm{~b}$. The population diagram flips when tapped, showing the numbers and the textual explanation of the numbers and the uncertainty around these numbers.

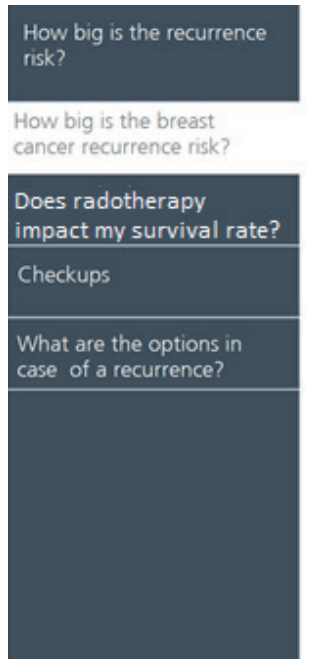

WITH radiotherapy

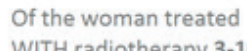
WITH radiotherapy 3-10 out of 100 woman will have a local recurrence
after 10 years. In the aiter lo years. In the clinician he/she will tell you if your personal chances of a local recurrence is closer to 3
out of 100 woman or closer to 10 out of 100 woman.
Communication of side effects in a patient decision aid

During the development of the patient decision aid, we also found that patients and clinicians have a different perspective towards the potential side effects. In scientific research and in clinician-patient communication, the side effects are mostly framed by their biological cause. Patients, on the other hand, frame the potential side effects around the possible consequences for their daily life. For example, breast irradiation can cause side effects on the healthy breast tissue. Clinicians frame this effect as scarring of the tissue, but the same side effect is framed as hardening of the breast or deformation of the breast by the patients. In a follow-up to our study, a two-day workshop was organized by members of the research team, in collaboration with other researchers and the National Breast Cancer Association to gather more insight into the patients' perspectives on side effects. This two-day workshop was financed by the Netherlands Organization for Health Research and Development (ZonMw 427003002). The participating ex-patients indicated that they had missed information on the effects of side effects on their daily life, such as not being able to play tennis or not being able to clean the windows. Since until recent, however, most research data are collected from the perspective of the clinician; as a result, not much is known on the incidence and impact of the potential side effect from the patients' perspectives. At this moment, a research proposal is being written for a grant application to tackle this problem.

\section{Implementation of a patient decision aid}

In the last decades, many patient decision aids have been developed for various patient categories. There is increasing evidence that patient decision aids have a positive effect on patients and clinicians making a decision together on the best treatment option for the individual patient. Patient decision aids and shared decision-making however, are not widely implemented in daily clinical practice. The probable reason for this implementation problem is that shared decision-making is a complex process with different barriers and facilitators on different levels of the health care system. Much research is being done on this topic. In our study, we found several facilitators for implementation of the decision aid. First, we found that patients were more likely to use the decision aid if the medical team, with different medical specialists, agreed that the radiation treatment was a preference-sensitive decision. Second, we found that patients who were informed about the decision aid by their treating surgeon, prior their visit to the radiation clinic, were also more likely to use the decision aid. These results are in line with earlier research and therefore confirm the importance of these findings. We presented our results in an international scientific conference and published them in a scientific journal.

Effect of the patient decision aid

In the clinical study, we investigated whether offering the decision aid to patients would result in a decrease in decisional conflict. Decisional conflict is a measurement on "how satisfied" patients are with the decision they have made. The scale measures whether patients feel that they understood what they were deciding on and what the different options were, as well as how sure they felt about their choice. We found that offering the patient decision aid did not result in significant improvements on decisional conflict. We also measured whether the decision aid improved the perceived level of shared decision-making to patients. We did this with two different questionnaires. On both 
questionnaires, we found no difference in perceived level of shared decision-making between patients who received the decision aid and those who did not receive the decision aid. Patients who were offered the patient decision aid had more knowledge on the different treatment options and chose less often for a more intensive treatment then patients who were not offered the patient decision aid. These results were published in or submitted to international peer-reviewed journals. They were also presented at an international scientific conference. At this moment, a lot of research is being performed on how patient decision aids in combination with other approaches such as specific training can contribute to improved shared decision-making as well.

\section{Societal impact}

Patients

In our study we saw that $77 \%$ of the patients who were offered the patient decision aid logged in to the patient decision aid. This is an extremely high percentage compared to papers reported in literature. However, we need to be humble about this number since we have to admit that this number could be an overestimation, because patients who were not interested in using the patient decision aid may also have refused to be included in the trial. Of the patients who logged in to the patient decision aid, $88 \%$ declared that they found the patient decision aid to be useful or partly useful for the decision-making process. In addition, we saw that patients who received a link to the patient decision aid had more knowledge on the different treatment options than patients who did not receive a link to the patient decision aid. The patient decision aid remains available online at no cost, and no login is required. The patient decision aid is available through www. beslissamen.nl. Patients can also find a link to the patient decision aid on the website of the national breast cancer association at https://online-ondersteuning.borstkanker.nl/ Thus, the patient decision aid is also available for future breast cancer patients with a preference-sensitive decision on their radiation treatment.

Clinicians

This project was initiated by radiation oncologists who felt that there was a need for a patient decision aid for breast cancer patients deciding on radiation treatment. As mentioned before, in patients with a preference-sensitive decision on their radiation treatment, different advice is given by different clinicians. Shared decision-making is a complex process and is therefore not always performed in case of these preferencesensitive cases. Therefore, these clinicians believed a decision aid could be a usefu tool for them. In the development phase of the patient decision aid, there was great willingness from clinicians from different radiation oncology centers to contribute to the development of the tool. We also saw that inclusion of patients in our trial went very fast, especially when clinicians could offer the link to the patient decision aid. This indicates that the patient decision aid was offered to many patients in a short time period. At the moment, the patient decision aid is still being used in several radiation clinics. We have received positive feedback from clinicians on the use of the patient decision aid, as well as on their awareness of the importance, and on their skills of performing shared decisionmaking. 


\section{Curriculum Vitae}

Daniela Raphael is geboren op 28 oktober 1986 in Santiago, Chili. Ze behaalde haar VWO diploma in 2006 op het Jan van Egmond college in Purmerend. In 2007 is zij gestart met de opleiding geneeskunde aan de Vrije Universiteit in Amsterdam. Tijdens de masterfase van haar studie liep zij stage in de primaire gezondheidszorg in CESFAM Zavala, Viña de

Mar, Chili, onder leiding van Dr. Guerra. Haar masterscriptie, getiteld Electrophysiological Evidence of Cognate Word Processing in Trilinguals, heeft zij geschreven in het Basque Centre on Cognition, Brain and Language, San Sebastian, Spanje, onder leiding van Jon Andoni Duñabeitia. In 2012 ronde ze haar geneeskundestudie af. In het jaar erna werkte ze als ANIOS op de spoedeisende hulp in het Antonius ziekenhuis in Sneek. In 2013 vertrok zij naar Suriname om daar een jaar als ANIOS chirurgie te werken in het academisch ziekenhuis van Paramaribo. Hierna werkte ze een jaar in het Medisch Centrum Haaglanden als ANIOS chirurgie. In juni 2016 startte zij met haar promotieonderzoek bij Maastricht University, Maastro en het NKI/AVL onder leiding van Prof. dr. L.J Boersma, Prof. dr. T. van der Weijden en Dr. N.S. Russell. Tijdens haar promotieonderzoek ontwikkelde zij een keuzehulp voor borstkankerpatiënten die een keuze moeten maken over hun bestralingsbehandeling. Daarnaast zette zij een studie op om de keuzehulp te testen in de klinische praktijk. Zij heeft de resultaten van haar studie beschreven in dit proefschrift

en gepresenteerd op meerdere internationale congressen. Ze was als project-adviseur betrokken bij de verkregen ZONMW- 427003002 beurs, Big Data-gedreven keuzehulp voor borstkankerpatiënten. Zij zal in 2021 starten met de opleiding tot radiotherapeutoncoloog in Maastro. 


\section{Dankwoord}

Een proefschrift schrijven doe je zeker niet alleen, ik wil hierbij dan ook iedereen bedanken die een bijdrage heeft geleverd aan dit mooie proefschrift. Een aantal mensen wil ik daarbij in het bijzonder noemen.

\section{Ten eerste mijn promotieteam:}

Prof. Dr. L.J.Boersma, beste Liesbeth, ik kon me echt geen fijnere promotor wensen. Je maakte altijd tijd om naar mijn stukken te kijken en kon me inhoudelijk op weg helpen. Maar boven alles stond je altijd open voor mijn mening en kon ik altijd op jouw steun rekenen zowel professioneel als persoonlijk. Je motiveerde me als ik even vastliep en je was wat strenger wanneer ik me aanstelde.

Prof. Dr. T. Van der Weijden, beste Trudy, jij hebt de meeste kennis van samen beslissen en (implementatie) van keuzehulpen. Jouw input op het project en voor dit proefschrift waren dan ook onmisbaar. Je was kritisch waar nodig en wist me daarbij uit te dagen om anders en dieper over onderwerpen na te denken.

Dr. N.S. Russell, beste Nicola, jij was het dichtste bij en ik kon dan ook altijd bij je binnen lopen met grote of kleine problemen. Al heb je het enorm druk, ik voelde me nooit te veel. Je stond altijd open voor overleg, uitleg en steun.

\section{Daarnaast wil ik danken:}

Prof. Dr. E. Bleiker, beste Eveline jij hebt me opgevangen op de PSOE. Ookal had ik geen eigen onderzoeksgroep, doordat je me in de Bleiker groep hebt geadopteerd was dat geen enkel probleem. Dankzij jou voelde ik me thuis op de PSOE en had ik een groep om mee te sparren.

Nicole en Silvie, bedankt voor jullie hulp bij de uitvoering van de BRASA-studie, jullie brachten orde in mijn chaos en zorgden ervoor dat de studie soepel verliep.

Alle PIs en trial-managers van MAASTRO, AVL-NKI, Radboud UMC, UMCU, Amsterdam UMC, RdGg/LUMC, HMC, ZRTI, UMCG, HAGA, CZE, Erasmus MC en RIF, bedankt voor het meewerken en vooral meedenken om de BRASA-studie een succes te maken. Ook mijn dank aan alle patiënten die bereid waren deel te nemen aan de BRASA-studie en aan de artsen die patiente geincludeerd hebben.

DaniellE, wat een geluk om met jou ons kantoor te mogen delen. Bedankt dat je altijd tijd had voor overleg, koffie, roddels, klagen, lachen, (statistiek) uitleg, hulp en gezelschap! En uiteraard bedankt dat je ervoor zorgde dat ik dagelijks wat, maar niet te veel chocolade kon eten. 
Jacqueline, Lara, Suzanne, Kete, Barbara, Melanie en Emmie, bedankt voor alle intermezzo's tussen het werken door. Jullie verhalen, koffie en lunch momenten waren altijd een welkome afleiding van de dagen achter de computer. Maar ook bedankt dat ik met jullie alles kon bespreken en ik niet het wiel altijd opnieuw hoefde uit te vinden.

Eveline, Cecile en Anouk, dankzij jullie waren de dagen dat ik uren in de trein zat voor werk extra leuk en gezellig!

Paul Alders, beste Paul, bedankt voor je eindeloze geduld met alle aanpassingen en veranderingen aan de keuzehulp, mede dankzij jouw inzet hebben we een prachtige too ontwikkeld.

Daarnaast wil ik ook een aantal mensen bedanken die buiten het onderzoek, me zeer dierbaar zijn geweest in de afgelopen jaren.

Suzy, Arie, Annamiek en Hester, mijn vriendinnetjes, met jullie ben ik nooit alleen. Suzy, bedankt voor het ontwerpen van deze prachtige kaft! Samen op naar nieuwe avonturen in het zuiden. Arie, bedankt voor de ellelange (telefoon)gesprekken, jij weet inmiddels ook bijna alles wat in dit proefschrift staat. Annamiek, bedankt voor de gezellige etentjes en goede gesprekken. Hester, ver weg maar toch dichtbij.

Jeroen, Bas, George en Niels, bedankt voor al het plezier tussen de onderzoeksdagen door: dansen, lachen, wijntjes, bier, hangen in het park, samen eten en bootje varen.

Karla, Matthijs en Boaz, bij jullie kunnen we altijd aan komen waaien en voelen wij ons thuis. De liefste zus en de mooiste oom en tante voor de kleine meisjes. Daarnaast hebben jullie mij het leukste neefje gegeven. Bedankt voor jullie steun en voor het oppassen zodat ik dit proefschrift kon afronden.

Mirte, Tom, Sallie en Moos, een goede buur is beter dan een verre vriend. Zonder jullie was dit proefschrift echt nog lang niet af geweest. Bedankt voor al jullie hulp en steun, zeker in dit laatste gekke jaar.

Lieve Marion, jij bent de beste oma die mijn meisjes zich konden wensen. Bedankt dat je er altijd voor ons bent.

Mijn ouders: Papi, gracias por apoyarme siempre. Mami, aunque estas lejos yo se que siempre puedo contar contigo. Los amo.

Andy bedankt voor de mooie momenten, de liefste meisjes en het heerlijke eten.

Lieve Zoë en Aïda, hoe klein jullie ook zijn, jullie liefde geeft me energie. Jullie zijn de allermooisten en de allerliefsten. 